\title{
High Capacity Demonstration of Honeycomb Panel Heat Pipes
}

\author{
Final Technical Report
}

\section{H. J. Tanzer}

Hughes Aircraft Company - Electron Dynamics Division

Torrance, California 90509
(MASA-CE-181776) BIGE CAFACIIY
IEAONSTBATICA CP ECAEYCCAB EAIEL EEAT PIEES
N89-21191
Final technical sefort (Hugbes dircraft
(c.) $73 \mathrm{~F}$
CSCL 2OD
Denclas
G3/34 0191956

February 1989

Prepared for

National Aeronautics and Space Administration

Langley Research Center

Hampton, VA 23665

Contract NAS1-17674

W-30851

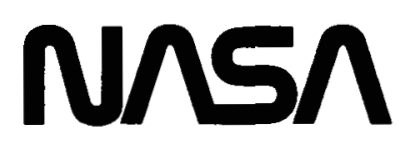

National Aeronautics and

Space Administration

Langley Research Center

Hampton, Virginia 23665-5225 


\section{FOREWORD}

This report was prepared by the Hughes Aircraft Company, Electron Dynamics Division, for the NASA Langley Research Center.

The purpose of this program was to determine the feasibility of enhancing the performance of honeycomb sandwich panel heatpipes for future high power space radiators. The effort is defined as exploratory development. The scope of the program includes prediction modeling, design, fabrication, and ground testing of representative segments of space radiators.

The program was conducted in accordance with the requirements and instructions of NASA Contract NAS1-17674, with revisions mutually agreed upon by NASA and Hughes. Mr. H.J. Tanzer was the Hughes Electron Dynamics Division Project Manager, while Mr. A. Basiulis served as both administrative and technical adviser at Hughes. Technical direction was provided by Mr. J.B. Hall, Jr., Technical Representative, NASA Langley Research Center. 


\section{TABLE OF CONTENTS}

Section

Page

$1.0 \quad$ SUMMARY

$2.0 \quad$ INTRODUCTION

3.0 ANALYSIS MODEL DEVELOPMENT

3.1 Sideflow Operation 5

3.2 Variable Conductance Operation 8

3.3 Prediction Model Development 8

3.3.1 Analytical Model $\quad 9$

3.3.2 Computer Modeling $\quad 11$

$3.4 \quad$ Typical Analytical Results 11

3.5 Panel Scaling Investigation 13

3.6 Performance Test Plan 18

4.0 FABRICATION OF RADIATOR SEGMENTS 19

$\begin{array}{llr}4.1 & \text { Fabrication Methods } & 19\end{array}$

4.2 Fabrication Methods 20

5.0 PERFORMANCE TESTS $\quad 25$

5.1. Test Description 25

5.2 Test Results 26

6.0 UPGRADE ANALYSIS MODEL 33

6.1 Space Heat Rejection Characteristics 33

6.2 Data Correlation and Projection to Space-Station Size

$\begin{array}{ll}\text { Systems } & 34\end{array}$

$\begin{array}{lll}7.0 & \text { HYBRID DESIGN } & 39\end{array}$

$\begin{array}{lll}7.1 & \text { Concept Definition } & 39\end{array}$

7.2 Experiment Design Description 41

$\begin{array}{lll}7.2 .1 & \text { Design Approach } & 41\end{array}$

7.2.2 Thermal Performance 41

$\begin{array}{lll}7.3 & \text { Design Modifications } & 52\end{array}$

8.0 HYBRID FABRICATION AND COMPONENT TEST $\quad 55$ 
TABLE OF CONTENTS (CONTINUED)

Section

Page

$\begin{array}{lll}9.0 & \text { HYBRID SYSTEM TEST } & 63\end{array}$

9.1 Test Description and Results 63

9.2 Data Correlation 63

$\begin{array}{lll}10.0 & \text { CONCLUSIONS AND RECOMMENDATIONS } & 69\end{array}$

$\begin{array}{lll}11.0 & \text { REFERENCES } & 71\end{array}$ 


\section{LIST OF ILLUSTRATIONS}

Figure

Page

1 Sketch of space radiator element configurations.

2 Closeup of internal honeycomb structure.

$\begin{array}{lll}3 & \text { Sideflow attached to honeycomb panel heat pipe. } & 7\end{array}$

$4 \quad$ Clapeyron relation for 1-gravity pressure priming. $\quad 8$

$5 \quad$ Fluid flow schematic and operating principle. $\quad 9$

6 Vapor flow path options for subscale radiator constructions. 10

7 Computer model flow diagram for determining performance and sizing honeycomb panel heat pipes.

8 Characteristic performance predictions of the high-capacity honeycomb heat pipe.

9 . Test plan summary.

10 Sketch of wick placement inside panel.

11 Honeycomb heat pipe sample test panels.

12 Large test panel with sideflow $(243.8 \times 11.4 \times 0.79 \mathrm{~cm})$.

13 Radiator panel test sequence.

14 Test convention.

15 Data correlation of sample test panels.

16 Summary of subscale panel test results. 28

17 Large test panel characteristic performance. 29

18 Large VCHP test panel with sideflow $(243.8 \mathrm{~cm} \times 11.4 \mathrm{~cm} \times 0.79 \mathrm{~cm}) . \quad 30$

19 Data correlation of large VCHP panel - segment 6. 32

20 Optimized honeycomb panel system performance curve for space. 35

21 Projected $50 \mathrm{~kW}$ space radiator system using high-capacity integral heat pipe panels. 


\section{LIST OF ILLUSTRATIONS (CONTINUED)}

Figure

Page

22 Hybrid radiator concept.

23 Component hardware available for the hybrid radiator.

$24 \quad$ Hybrid radiator test vehicle.

25 Space radiation cooling capacity.

$26 \quad$ Laboratory cooling capacity.

27 Sideflow heat pipe predicted performance.

28 Hybrid radiator evaporator.

$29 \quad$ Hybrid radiator transport and fin sections.

30 Expected temperature drops $\left({ }^{\circ} \mathrm{C}\right)$ at sideflow to fin interface.

31 Power delivery to radiator fin.

32 Channel-core radiator fin transport capacity.

33 Sizing curves for $3.05 \mathrm{~m}$ hybrid radiator test vehicle.

$34 \quad$ Sideflow thermal plug construction.

35 Hybrid radiator: sideflow transport tubes.

36 Hybrid radiator: close-up of sideflow vapor channel.

37 Hybrid radiator: fluid flow coupler.

38 Hybrid radiator: evaporator and flow headers.

39 Hybrid radiator: liquid crossover to evaporator.

$40 \quad$ Hybrid radiator test vehicle.

41 Hybrid test vehicle (244 cm long).

42 Functional test temperature profile of hybrid test vehicle.

43 Data correlation: transport capacity computer code coupling. 


\subsection{SUMMARY}

The feasibility of performance enhancing the sandwich panel heat pipe was investigated for moderate temperature range $\left(-20\right.$ to $+65^{\circ} \mathrm{C}$, nominal) heat rejection radiators on future space stations and platforms. Primarily a hardware development program, the effort consisted of performance prediction, rework-fabrication, ground test, and data correlation.

Available for rework, and as a starting point for the design and addition of performance enhancement features, was a remnant sandwich panel. The flat panel measured $3.05-\mathrm{m}$ long by $0.114-\mathrm{m}$ wide by $7.9 \mathrm{~mm}$ thick, and consisted of an all welded, stainless steel honeycomb cell structure. Screen wick, which was sintered to all internal surfaces, created the capillary pumping necessary for heat pipe action. A detailed prediction model was generated for the honeycomb panel geometry. The model included possible panel rework features, and it was augmented with the addition of a sideflow feature. A wicked, cold gas reservoir was designed for the temperature control feature. To gain confidence in the computer prediction model, our test plan consisted of evaluating subscale test (30.5-cm long) panel segments which isolated one new feature at a time, followed by build and test of a larger (1.83-m long), final segment. Methanol was used as the heat pipe working fluid. At the subscale panel level, the highest thermal transport of 147 watts was achieved with the addition of a center mounted sideflow, rolled-up wicks inserted into the honeycomb core, and dual vapor channels mounted at the panel edges. A scaled up version, having only an edge-mounted sideflow, transported 103 watts with a temperature difference of $2^{\circ} \mathrm{C}$; as a variable conductance heat pipe, it achieved a temperature control span of $3^{\circ} \mathrm{C}$. Very good tracking between actual data and performance prediction was obtained.

The correlated prediction model was utilized to predict thermal transport capacities of full scale space heat rejection systems. As a result, it was concluded that by close spacing of multiple sideflows, the basic honeycomb panel heat pipe can meet $50 \mathrm{~kW}$ radiator design loads at fin lengths up to $12-\mathrm{m}$. To meet greater design loads, and to also achieve weight savings, would require that the honeycomb panel design be further optimized. An approach which utilizes individually optimized heat pipe components that are integrated into a radiator system is called the hybrid heat rejection system. This concept consists of a honeycomb panel evaporator, a sideflow transport section, and multiple, independent radiating heat pipe fin panels. Together, the honeycomb and sideflow form a closed thermodynamic system (or heat pipe) utilizing the high-transport fluid ammonia, and a common wall interface between the sideflow and the acetone-filled heat pipe fins.

Again utilizing available remnant hardware, a reduced-scope hybrid test vehicle was built and tested. The 2.44-m long heat pipe consisted of a stainless steel honeycomb evaporator with an external fluid header system connecting to an aluminum sideflow leg. 
Proof-of-principle demonstration was achieved with low-vapor pressure acetone, which avoids potential structural containment problems. The test vehicle, basically the hybrid concept without the heat pipe fins, transported 1000 watts before reaching dryout. By structural redesign and by external support of the honeycomb evaporator, a five-fold improvement factor is expected by using ammonia working fluid. Further development work is needed to establish fabrication methods, to build additional radiator test vehicles utilizing re-designed hardware, and to upgrade test methods by using thermal vacuum chambers. Further optimization of the hybrid radiator is possible by consideration of material, structural, weight, and reliability variables. 


\subsection{INTRODUCTION}

Future space stations and space platforms will require highly efficient radiator systems for dissipation of 50 kilowatts and more of waste heat. NASA has sponsored the investigation of sandwich panel heat pipes for this application. The original sandwich panel heat pipe work, ${ }^{1,2}$ started in 1980, consisted of a machine-manufactured stainless steel honeycomb configuration, and was done for Langley Research Center (LaRC) to verify concept feasibility in reducing thermal gradients in airframe-integrated scram jet engine structures. ${ }^{3}$ In 1982 , Johnson Space Center (JSC) began investigation of the concept as applied to high efficiency, ambient temperature space radiator fins. Concept design, build, and test of stainless steel $^{4,5,6}$ and several lightweight aluminum versions ${ }^{7,8}$ have been reported.

The purpose of this program was to utilize a remnant sandwich panel left over from the JSC stainless steel fin and investigate space radiator enhancement features. The program objective was to design, fabricate, test, and evaluate representative segments of heat rejection radiators for future large spacecraft. The program consisted of seven tasks:

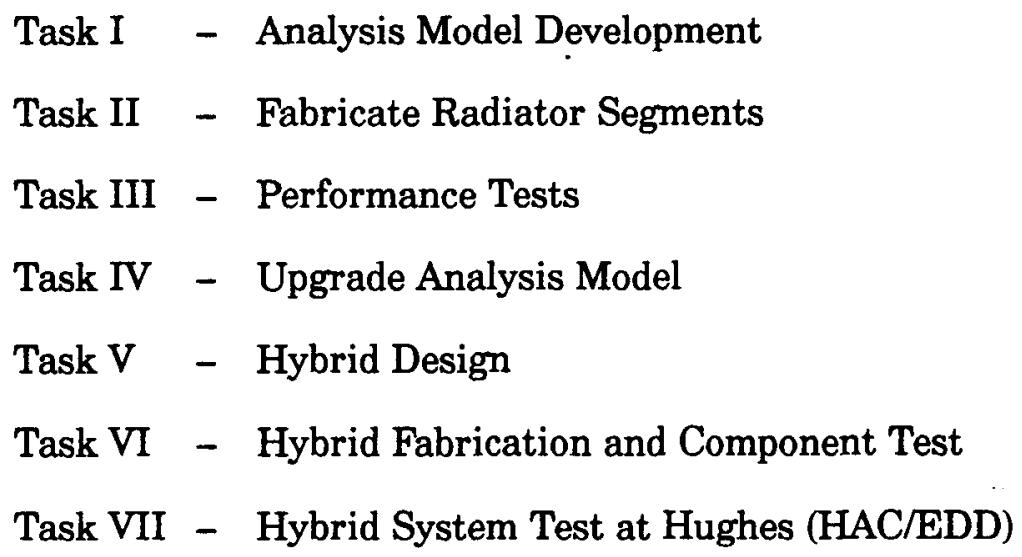

The results of these tasks are presented in Sections 3.0, 4.0, 5.0, 6.0, 7.0, 8.0, and 9.0, respectively. 


\subsection{ANALYSIS MODEL DEVELOPMENT}

The experiment objective was to investigate the honeycomb heat pipe as a space radiator that integrates the functions of heat transport and heat rejection. The coupled heat pipe and the integral heat pipe configurations are shown in Figure 1. For the integral radiator, high performance is achieved by adding an external liquid sideflow that runs in the longitudinal panel direction. Variable radiator panel conductance is achieved by adding a noncondensing gas reservoir. For experimental evaluation, a remnant $3.05-\mathrm{m}$ long by $0.114-\mathrm{m}$ wide by 7.9-mm thick section from the NASA-JSC high efficiency fin program was available for rework. Design features of this panel include an all-welded stainless steel construction, $12.77-\mathrm{mm}$ hexagonal honeycomb cells made of $0.14-\mathrm{mm}$ thick wire mesh laminate (165 x $1400 \mathrm{mesh})$, and one layer of wick ( $120 \times 120 \mathrm{mesh})$ sintered to $0.457-\mathrm{mm}$ thick facesheets. Figure 2 is a close-up photograph of the internal honeycomb structure with the top facesheet removed.

\subsection{SIDEFLOW OPERATION}

The sideflow, which is basically an external channel or artery connected to the main vapor space via branch or cross-over connections, can be incorporated into any heat pipe design to increase thermal transport capacity. Essentially, the sideflow offers low resistance to liquid flow in the direction of heat transfer, thus increasing the thermal transport that can be

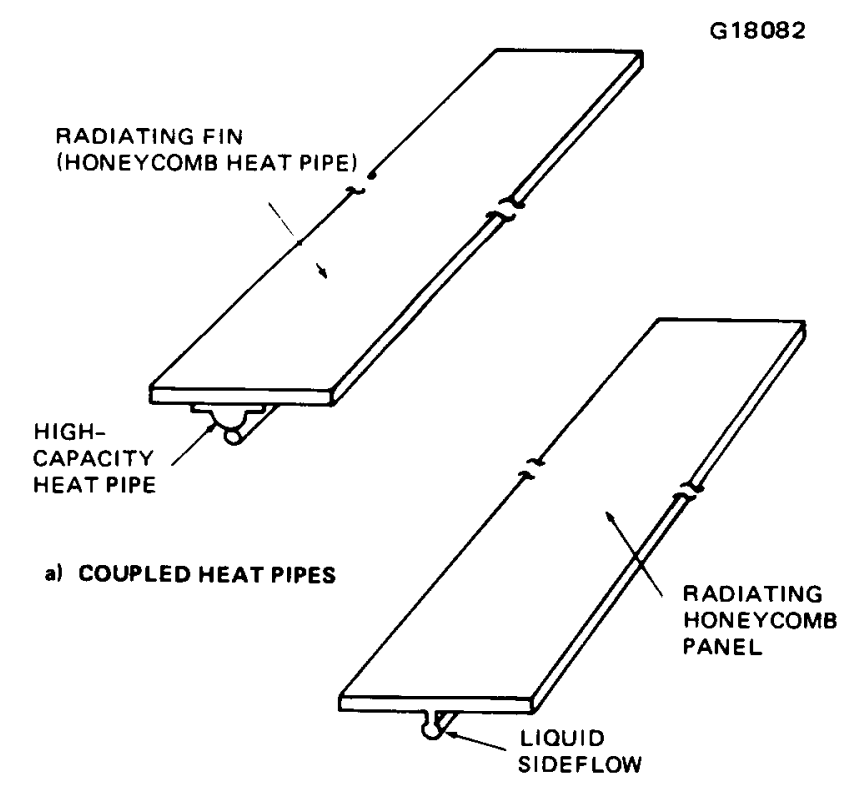

b) INTEGRAL HEAT PIPE

Figure 1 Sketch of space radiator element configurations. 


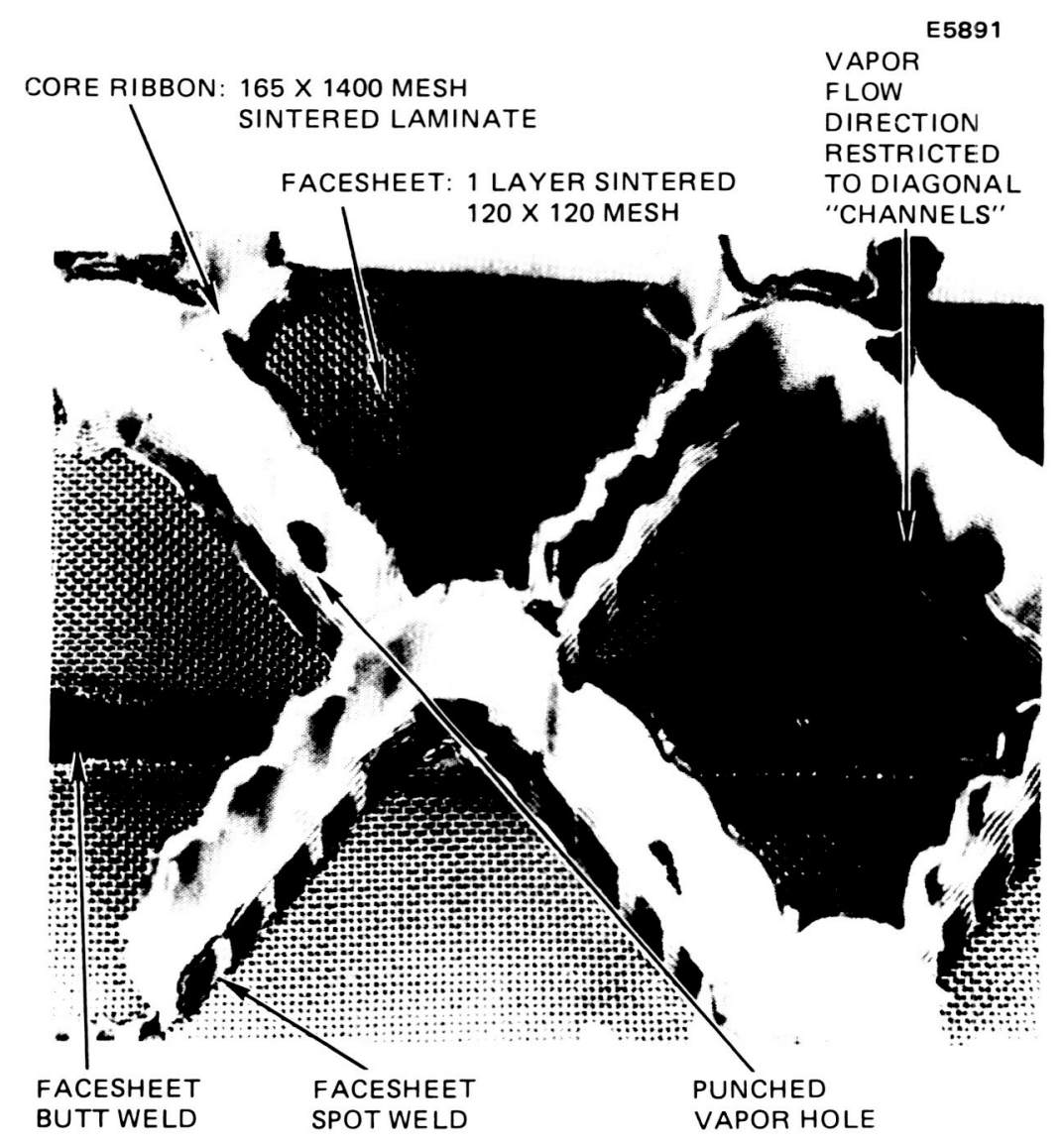

Figure 2 Closeup of internal honeycomb structure. 
sustained by the pumping capillary forces. Since the honeycomb cell core of the remnant panel produces large pressure drops, a sideflow addition creates a parallel path of transverse flow that is expected to substantially increase capacity. The basic configuration and relevant design parameters are illustrated in Figure 3.

Two design features are essential for proper sideflow operation: sufficient subcooling and phase change facilitation. The degree of pressure (Clapeyron) priming that can be achieved is dependent on how much the liquid in the sideflow is subcooled relative to liquid in the main vapor region of the honeycomb, and on the temperature difference that can be maintained across the porous thermal plugs. The difference in vapor pressure between the two temperature states provides the driving potential that causes liquid to flow into and completely fill (or "prime") the sideflow. The variation of vapor pressure with temperature along the saturation line can be described by the Clausius-Clapeyron relation. This powerful priming mechanism is shown by curves in Figure 4 for the candidate fluids, ammonia and methanol. The amount of subcooling achieved depends on conditions at the sideflow and branch tubes. Ultimately, this will be due to radiation in space; however convective cooling can be used for ground experiments. Porous thermal plugs are needed at the interface regions between saturated vapor and subcooled liquid. At the condenser, the plug imposes a thermal resistance that abruptly changes the fluid from a saturated vapor, through the mixture region to a saturated liquid, and on to a subcooled liquid. The pressure drop associated with

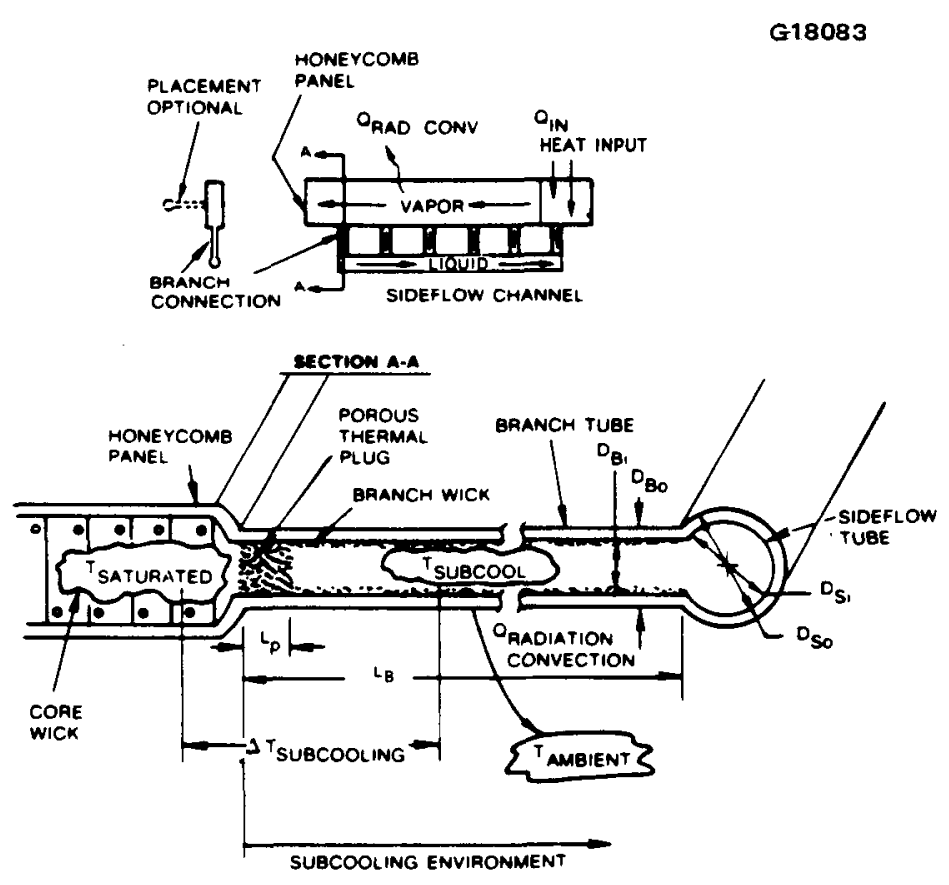

Figure 3 Sideflow attached to honeycomb panel heat pipe. 


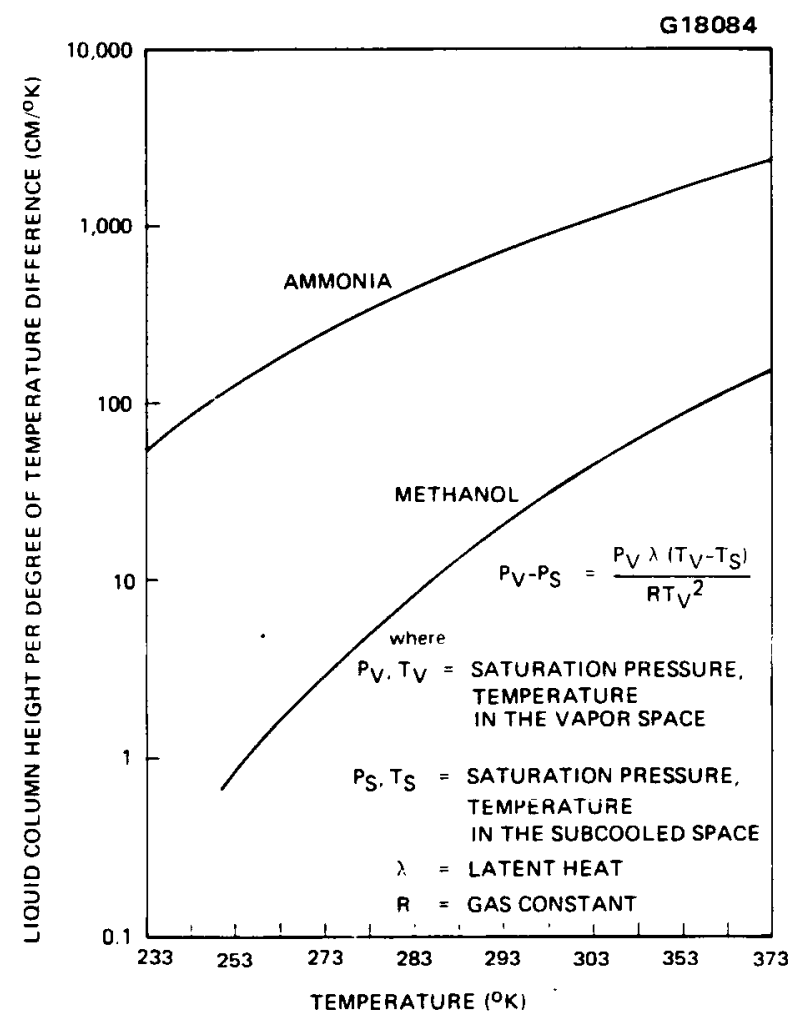

Figure 4 Clapeyron relation for 1-gravity pressure priming.

the condenser plugs should be kept to a minimum by using shorter, large-pore wicks, since a decrease in state pressure will delay the onset of subcooled conditions. At the evaporator, however, longer fine-pore wicks are required for a pressure drop sufficient to facilitate the change from subcooled liquid to vapor and, at the same, time thermally isolate liquid in the sideflow from evaporator heating.

\subsection{VARIABLE CONDUCTANCE OPERATION}

Introducing a fixed amount of noncondensible gas into a heat pipe is a common technique for accomplishing passive control of the vapor temperature as heat load and/or sink conditions fluctuate. Thus, the radiator panel is expected to maintain its operating temperature within a prescribed range.

\subsection{PREDICTION MODEL DEVELOPMENT}

The hydrodynamic limits to heat pipe operation can be predicted analytically with the aid of empirical relationships. Prediction accuracy of all except the simplest configuration is often based on the degree to which experimental data is correlated with the model. Due to the 
complex internal geometry of the honeycomb panel and the experimental stage of the sideflow concept, it was felt that prediction model development should be linked to a series of tests on subscale panel constructions.

\subsubsection{Analytical Model}

Details of the analysis and modeling approach has been documented and previously reported, as "High Capacity Sandwich Panel Heat Pipe: Computer Model Document." This section summarizes the modeling approach.

A fluid flow schematic showing pressure differences $(\Delta \mathrm{P})$ within the honeycomb panel having an edge mounded sideflow is illustrated in Figure 5. The sideflow heat pipe operating principle is characterized by two differential pressure balance relationships that must be simultaneously satisfied. The primary relationship describes the capillary pumping limit, which requires the evaporator wall wick capillary pressure rise to overcome the cumulative viscous pressure losses in the honeycomb core, porous plugs, branch and sideflow tube, plus the gravity head loss due to elevation differences between the evaporator and condenser sections and internal vapor space heights. To establish proper sideflow priming, namely,

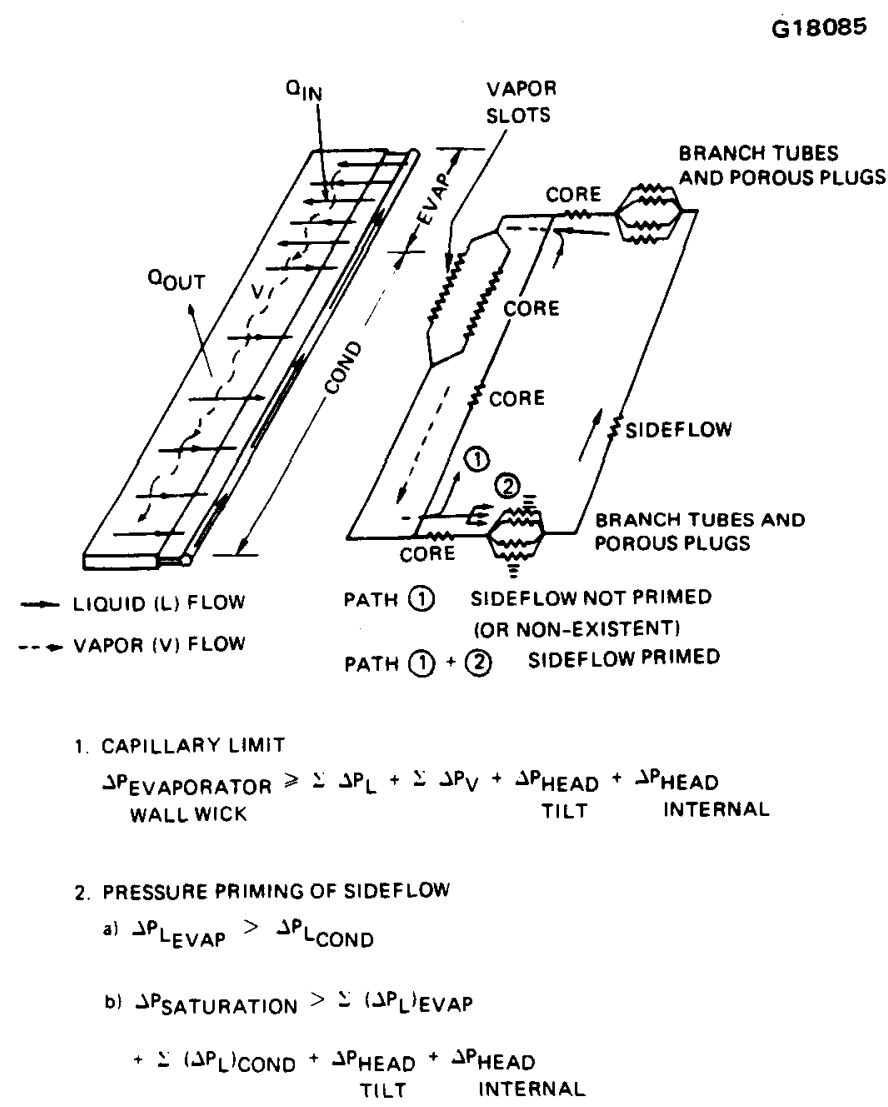

Figure 5 Fluid flow schematic and operating principle. 
circulation of liquid from condenser to evaporator, the pressure losses in the evaporator sideflow must exceed those in the condenser sideflow. Then, pressure priming must overcome cumulative liquid viscous pressure losses in porous plugs, branch and sideflow tubes, and grayity heads. A sideflow that is not fully primed will result in premature heat transport limitation (evaporator dry-out).

In addition to the capillary and priming limits, entrainment within the various flow passages of honeycomb geometry can become limiting as heat transport levels become greater. Vapor flow path directions based on several rework and design options for subscale panel constructions are shown in Figure 6. The entrainment limit prediction is directly proportional to the available cross-sectional area in the vapor flow path. Note that vapor flow is primarily crosswise to liquid flow. Hence, entrainment correlations based on typical heat pipes where vapor flow is counter to liquid flow may not be applicable. In the cross flow scheme, entrainment limits should increase over those in counterflow configurations. Unless reworked, the as-built panel (having insufficient vapor holes in the honeycomb cell walls ${ }^{6}$ )

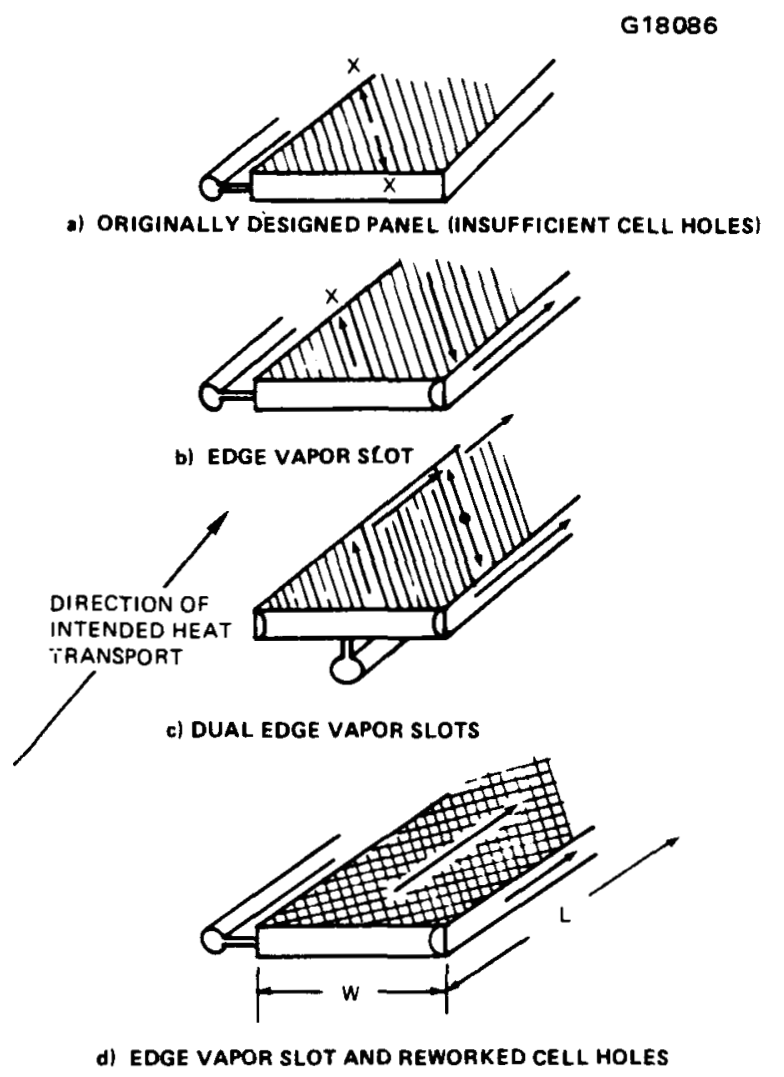

Figure 6 Vapor flow path options for subscale radiator constructions. 
entrainment limit of essentially nil, since vapor cannot travel in the full longitudinal direction between evaporator and condenser.

\subsubsection{Computer Modeling}

A computer program was written that was based on the analytical model of the honeycomb heat pipe with sideflow. Previous hydrodynamic performance modeling, done for the existing NASA Johnson honeycomb radiator fin, produced a good match between prediction and. measurement. ${ }^{5}$ This performance model incorporated "effective" liquid flow resistance parameters for each honeycomb cell and was correlated with respect to liquid and vapor flow tortuosity factors and composite wick pumping pore radii. For the current work, the model was expanded to incorporate critical design features of the sideflow addition and panel rework options.

The computer program computes hydrodynamic limits of the honeycomb heat pipe for specified working fluid, operating temperatures, and panel geometry. The model incorporates design parameters based on the available, as-built (remnant) honeycomb panel, and in addition has options for selecting parameters for several panel reworks features that enhance performance. The honeycomb heat pipe radiator panel analysis model uses BASIC programming language, and a diskette has been prepared for running on an IBM PC/XT/AT using DOS 2.0. It is an interactive type of program, asking user questions and providing explanations and input selections. The program calculates performance limits of the honeycomb panel heat pipe when used as either a radiator fin or as an integral radiator transport plus fin configuration (refer to Figure 1). In addition, the program contains a subroutine for sizing a variable conductance feature of the radiator panel. A computer model flow diagram is shown in Figure 7.

Complete details of the computer program are contained in the document "High Capacity Sandwich Panel Heat Pipe: Computer User Manual." It contains lists of input and output variables, a program listing, and a printout of an example computer run.

\subsection{TYPICAL ANALYTICAL RESULTS}

A preliminary series of computer optimization runs was made to check performance feasibility of panel rework enhancement features. Early assessment indicated that the major pressure drop component contributing to capillary pumping limitations was liquid travel in the transverse panel direction, to and from the sideflow connections (refer to Figure 5). As an option to minimize this pressure drop, a series of parallel low-resistance flow paths was modeled to represent inserted wicks. Fabrication of this option would consist of drilling holes into the honeycomb in the transverse panel direction, and inserting rolled-up or plug-type 


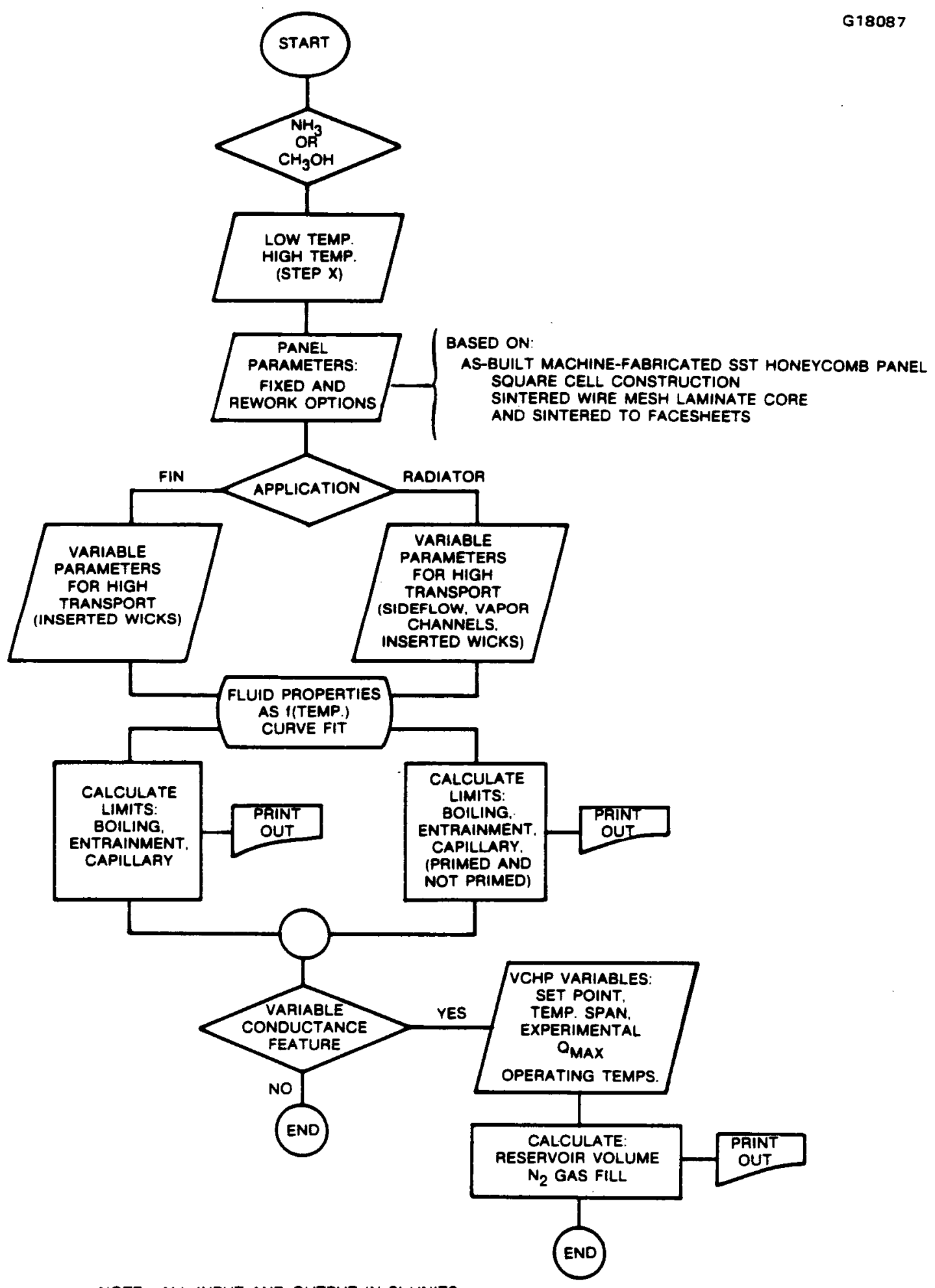

NOTE: ALL INPUT AND OUTPUT IN SI UNITS

Figure 7 Computer model flow diagram for determining performance and sizing honeycomb panel heat pipes. 
wicks as direct extensions of the sideflow porous plugs. These inserted wicks, however, would seriously hamper cross-flowing (longitudinal panel direction) vapor, affecting both capillary and entrainment limits. Thus, a fabricated vapor slot at the edge of the panel opposite the liquid sideflow becomes necessary.

Computed results of Figure 8 illustrate the effect of varying key parameters for the highcapacity panel design on heat transport capacity $\left(Q_{\max }\right)$. A baseline honeycomb panel measuring $3.05-\mathrm{m}$ long by $0.152-\mathrm{m}$ wide and having the parameters indicated as (B) in Figures 8(a) through 8(e) was used for this series of optimization runs. Enhancement features including sideflow, inserted wicks, and vapor slots are also indicated. Note in Figure 8(a) that the heat transport levels off with increases in sideflow and branch tube diameters. Thus, standard tube diameters near the knee of the curve were selected. Performance is not strongly sensitive to porous thermal plug lengths, branch tube lengths [Figure 8(b)], or branch tube spacing [Figure 8(c)]. Therefore, a somewhat longer than baseline length for the porous plug was selected to ensure sufficient subcooling. As can be seen in Figure 8(d), performance is strongly affected by the reduction in pressure drop provided by the addition of inserted wicks. Note that predicted performance without any inserted wicks is very low relative to the selected spacing of one for every branch tube connection. The need for an increase in vapor flow area is apparent from Figure 8-(e) External vapor area can be added as needed via an added edge slot, so sufficient area was selected to place entrainment above the capillary limit throughout the complete operating temperature range. The results of optimization and values of selected parameters are then shown in the upgraded performance limit curves of Figure 8(f).

\subsection{PANEL SCALING INVESTIGATION}

The performance results from these panel segment investigations will subsequently be projected to large, full-scale space radiator systems. A nominal $50-\mathrm{kW}$ system would consist of 20 reference panels, each dissipating $2.5 \mathrm{~kW}$ of thermal energy. A rationale is needed for selection of subscale test panel sizes, heat input and output areas, and sequence of added features, in terms of performance benefits and of credibility of scaling the results to much larger radiator panels via a correlated prediction model. The key parameters that need to be addressed are: panel dimensions [length (L) and width (W)], heat pipe lengths [evaporator $\left(\mathrm{L}_{\mathrm{e}}\right)$, condenser $\left(\mathrm{L}_{\mathrm{c}}\right)$, and effective $\left(\mathrm{L}_{\mathrm{eff}} \mathrm{]}\right.$, and the performance limitations of boiling $\left(\mathrm{Q}_{\mathrm{b}}\right)$, capillary $\left(Q_{c}\right)$, and entrainment $\left(Q_{e}\right)$.

Panel Dimensions - For reference, the size of a full-scale space radiator panel is taken as $15.24-\mathrm{m}$ long by $30.5-\mathrm{cm}$ wide with a $0.914-\mathrm{m}$ long evaporator. The remnant panel available for test purposes measures $3.05-\mathrm{m}$ long by $0.114-\mathrm{m}$ wide. Since several performance 

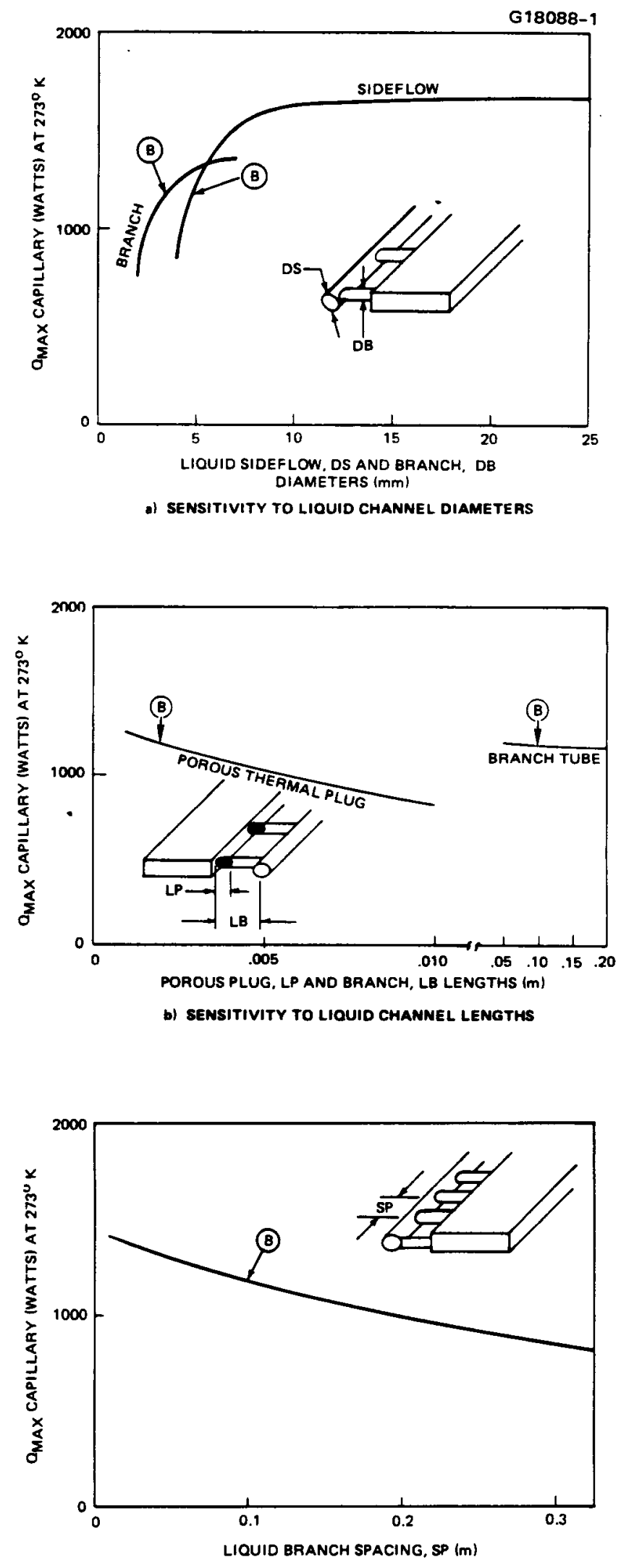

c) SENSITIVITY TO LIOUID CMANNEL SPACING

Figure 8 Characteristic performance predictions of the high-capacity honeycomb heat pipe. 


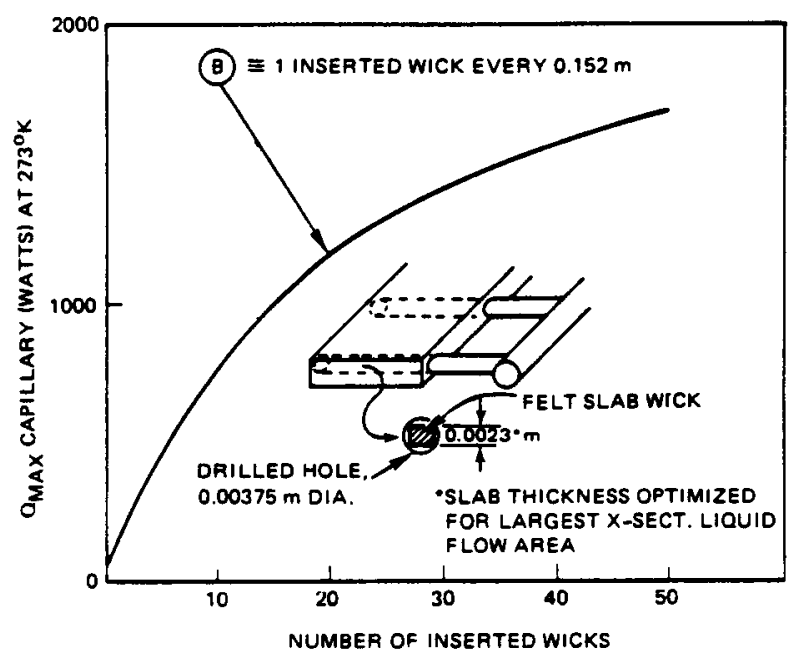

d) CAPACITY ENHANCEMENT OF INSERTED WICKS

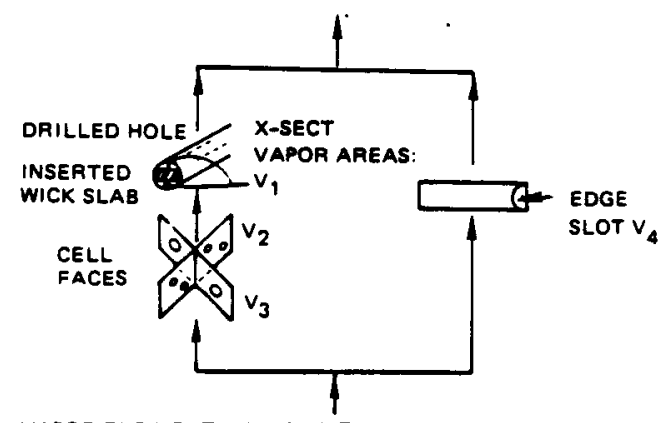

VAPOR FLOW PATH IN LONGITUDINAL PANEL DIRECTION

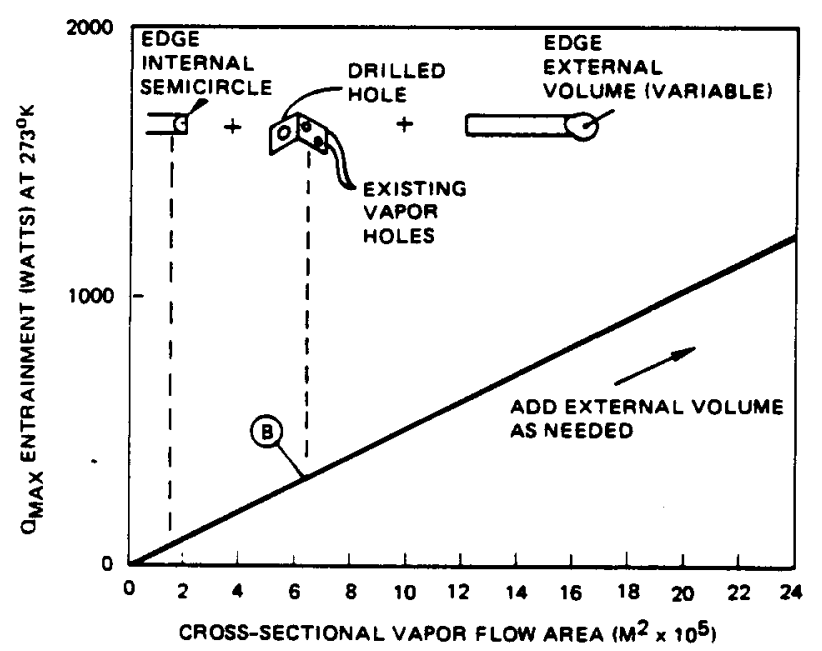

-) capacity vs. vapor space

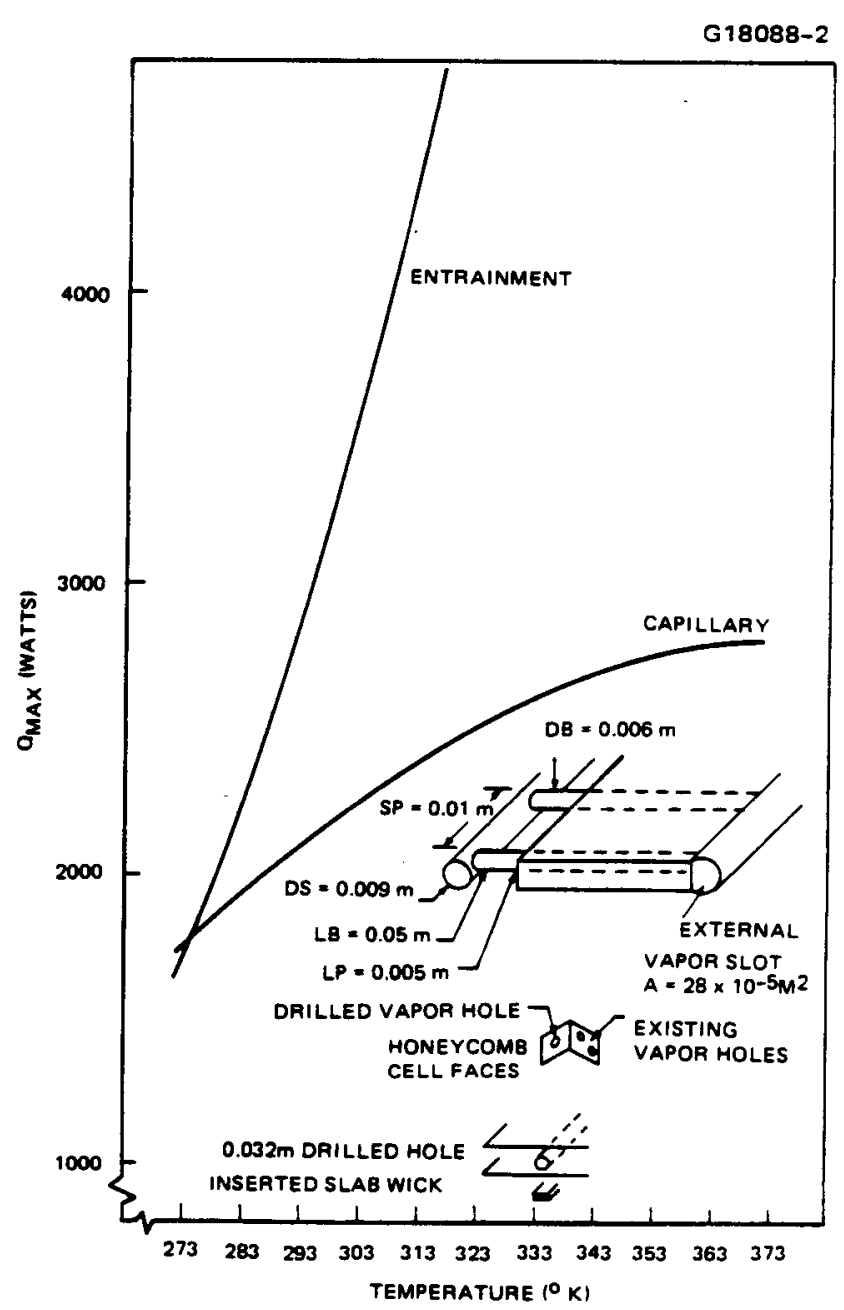

f) PAEDICTED PERFORMANCE LIMITS - UPGRADED PANEL

Figure 8 (Continued). 
enhancement features were investigated during the analysis, the fabrication and test of just one new feature at a time would aid interpretation of experimental results. It was therefore decided to cut several $30.5-\mathrm{cm}$ long segments from the remnant panel, isolate critical design features, and test each as an individual heat pipe sample prior to selection of large panel features. If four $30.5-\mathrm{cm}$ long sample test panels are built, then the remaining final test panel length becomes $1.83-\mathrm{m}$.

Evaporator and Condenser Lengths - Aspect ratios of 0.06 for Le/L and 3 for Le/W are obtained from the reference panel. It is possible to fix Le/L for sizing test panel evaporator lengths; however, fixing Le/W makes the sample test panels too narrow for practical fabrication.

Boiling Limit - High heat fluxes at the panel evaporator can result in a dry-out condition. Existing laboratory data for a similar methanol and stainless steel heat pipe combination indicate a boiling limit of between 2 and $5 \mathrm{~W} / \mathrm{cm}^{2} .{ }^{9}$ Table 1 shows the predicted boiling limits for a range of test panel sizes with $\mathrm{Le} / \mathrm{L}$ fixed at 0.06 and $\mathrm{Le} / \mathrm{W}$ ratios varied between values based on actual hardware width and the reference value of 3 . To avoid potential boiling limits, the nominal evaporator lengths of sample and final test panels were chosen to be $7.62-\mathrm{cm}$ and $30.5-\mathrm{cm}$, respectively. If during testing, a panel evaporator dry-out is reached as

TABLE 1

PREDICTED EVAPORATOR BOILING LIMITS

\begin{tabular}{|c|c|c|c|c|c|}
\hline Panel & $\mathrm{W}, \mathrm{cm}$ & Le, $\mathrm{cm}$ & $\begin{array}{l}\text { Ae, } \mathrm{cm}^{2} \\
(\mathrm{~W} \times \mathrm{Le})\end{array}$ & $\begin{array}{l}\mathrm{Q} / \mathrm{Ae} \\
\mathrm{W} / \mathrm{cm}^{2}\end{array}$ & $\mathrm{Qb}, \mathrm{W}$ \\
\hline $\begin{array}{l}\text { Sample Test } \\
(\mathrm{L}=0.305-\mathrm{m})\end{array}$ & $\begin{array}{r}11.40 \\
0.61\end{array}$ & $\begin{array}{l}1.83 \\
1.83\end{array}$ & $\begin{array}{r}20.86 \\
1.12\end{array}$ & $\begin{array}{l}4.0(\max ) \\
4.0(\max )\end{array}$ & $\begin{array}{l}83 \\
4.5\end{array}$ \\
\hline $\begin{array}{l}\text { Final Test } \\
(\mathrm{L}=1.83-\mathrm{m})\end{array}$ & $\begin{array}{r}11.40 \\
3.63\end{array}$ & $\begin{array}{l}10.90 \\
10.90\end{array}$ & $\begin{array}{r}124.30 \\
39.60\end{array}$ & $\begin{array}{l}4.0(\max ) \\
4.0(\max )\end{array}$ & $\begin{array}{l}497 \\
158\end{array}$ \\
\hline $\begin{array}{l}\text { Reference } \\
(\mathrm{L}=15.24-\mathrm{m})\end{array}$ & 30.50 & 91.40 & 2788 & 0.9 (actual) & \\
\hline \multicolumn{6}{|c|}{$\begin{array}{l}\text { Note: Assume experimental boiling heat flux limit }\left(Q / A_{e}\right)_{b}=4 \mathrm{~W} / \mathrm{cm}^{2} \text {. } \\
\text { Then } Q_{b} \text {, predicted }=A_{e} \times\left(Q / A_{e}\right)_{b} \text {. }\end{array}$} \\
\hline
\end{tabular}


as a result of high input heat flux prior to a longitudinal thermal transport limit $\left(Q_{c}\right.$ or $\left.Q_{b}\right)$, then Le can be lengthened to increase heat input area.

Capillary Limit - As already mentioned, the majority of overall pressure drop for the test panels is due to liquid flow resistance through the honeycomb core to and from the liquid sideflow (refer to Figure 5). Note that the liquid travel path through the honeycomb core is predominantly in the panel width direction. As a result, the capillary thermal transport limit for test panel sizes is inversely related to panel width and directly related to panel length; i.e., the "skinnier" and longer the panel, the higher its capacity. That the capillary transport capacity should get larger as the panel length increases may be surprising. A close look at actual cases shows that, although the vapor pressure drop through the core and the liquid pressure drop through the sideflow both increase with panel length, the liquid pressure drop through the core width, decreases. The transverse liquid flow area in the honeycomb core increases with panel length. This flow-splitting process actually reduces the associated pressure drop component, offsetting the other increases. Only when the panel becomes very long, do the pressure losses due to friction in longitudinal flow paths become large enough to decrease performance. It is evident that the standard reciprocity relationship, Qmax x Leff = Constant, does not hold for the sideflow honeycomb heat pipe. This is a direct result of a cross-sectional liquid flow area that varies with heat pipe length.

Entrainment Limit - For entrainment not to limit performance of the panel segments, sufficient vapor flow area within the honeycomb core must be provided. The original panel, having vapor holes punched in every second cell wall only, cannot provide a continuous vapor travel path between opposite ends of the evaporator and condenser because of the diagonal direction of the holes. Holes can be drilled through the closed cell walls in the test segments to correct this situation. In this instance, the entrainment limit will increase directly as the panel width increases, but remains constant with panel length. It is proposed to add a vapor channel to the panel edge as one of the performance enhancements. This addition will affect two performance limitations: the capillary, since vapor flow pressure drops will be reduced, and the entrainment, since additional cross-sectional vapor flow area is provided. The entrainment limit is a much stronger function of vapor area than is the capillary limit. Longer sideflow panels, which become entrainment limited as the capillary limit increases with length, benefit the most from a vapor channel addition. 


\subsection{PERFORMANCE TEST PLAN}

Performance testing was planned (Figure 9) in sequence of increasing thermal transport capacity, as predicted by the analysis model. The variable conductance feature was to be added to the panels after verification of transport features. Final design of the remaining, large panel was to evolve from the knowledge gained by reworking, testing, correlating data, and scaling of the sample heat pipe segments. Although ammonia has superior working fluid properties compared to methanol, burst pressure testing on panel test coupons ${ }^{5}$ determined that only methanol could safely be used for testing above about $44^{\circ} \mathrm{C}$. Thus, all honeycomb panel test vehicles will be processed with methanol working fluid only.

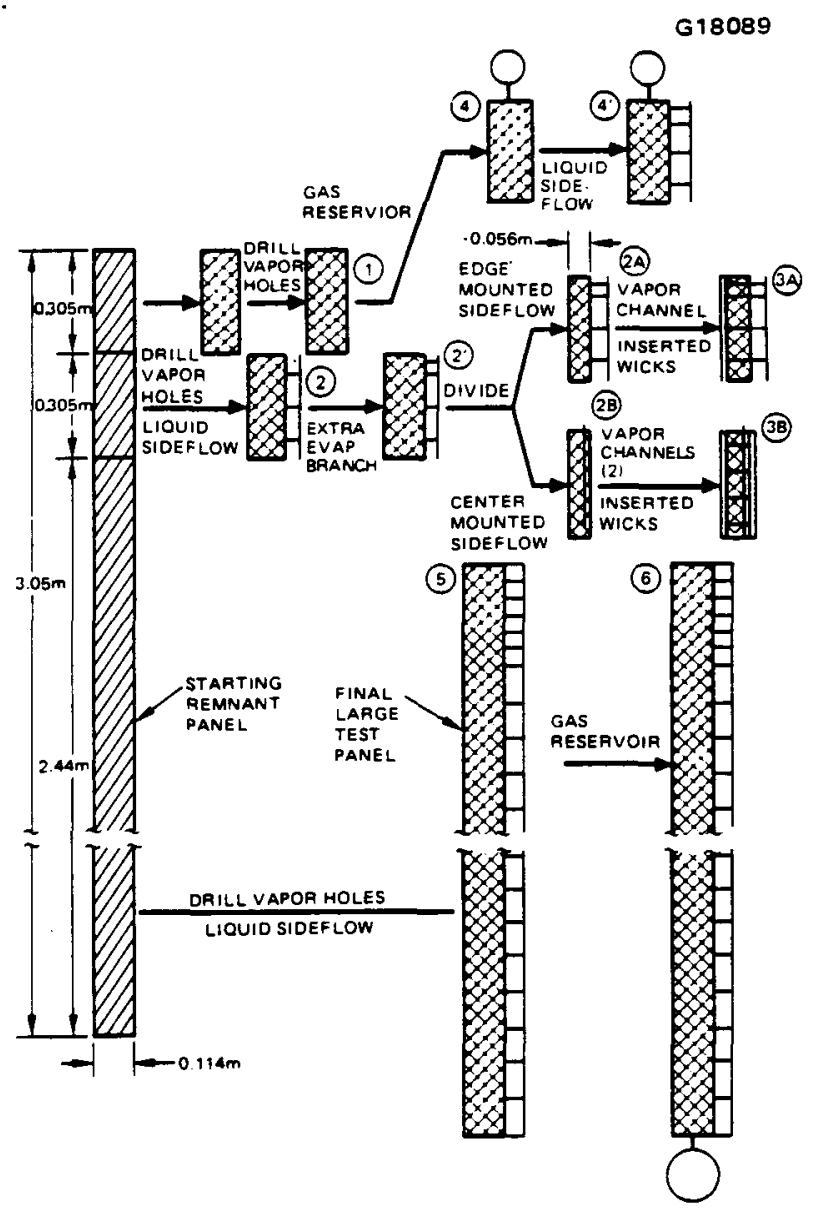

Figure 9 Test plan summary. 


\subsection{FABRICATION OF RADIATOR SEGMENTS}

\subsection{FABRICATION METHODS}

By using an extended 2.057-mm diameter drill bit, additional vapor holes were reworked throughout the entire remnant panel. This permitted vapor communication between cells in all directions, and allowed vapor to flow longitudinally though the entire panel. The rework closely reproduced the original panel design condition for fluid travel within the honeycomb cell structure. Stainless steel materials were used exclusively for all add-ons to the remnant panel. Standard tube diameters and plate thicknesses were used for all sideflow, vapor channel, edge plate, and gas reservoir constructions. Joining was done by manual gas tungsten arc welding (GTAW). Edge plates and vapor channels were fully lined with single layers of 250 mesh screen attached by spot welding, primarily to prevent occurrence of hot spots near evaporator heaters. As shown by Figure 10, thermal plugs and inserted wicks were made of rolled layers of 150 mesh screens and placed into both the branch tubes and the $5.08-\mathrm{mm}$

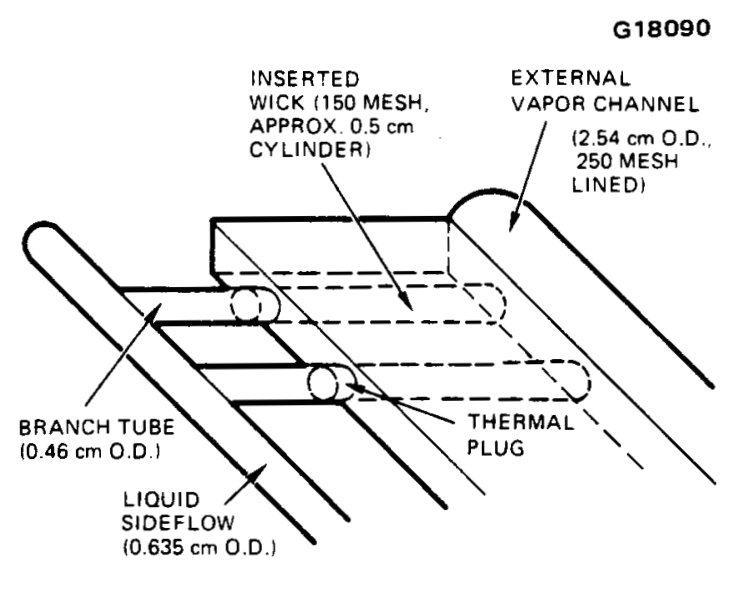

a) EDGE MOUNTED LIOUID SIDEFLOW AND VAPOR CHANNEL

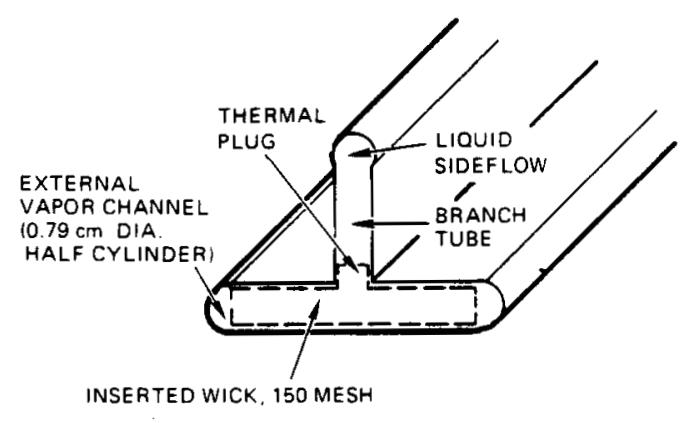

b) CENTER MOUNTED LIOUID SIDEFLOW WITH DUAL EDGE VAPOR CHANNELS

Figure 10 Sketch of wick placement inside panel. 
diameter reworked vapor holes in the core. Contact between inserted and honeycomb core wicks, essential for people liquid communications, was enhanced by unraveling the outer layers of the rolled wicks and letting them make spring contact with the honeycomb cell walls. The processing port, used for filling, purging and sealing of methanol working fluid and nitrogen control gas was attached to the end of the sideflow tube.

Continual improvements in fabrication, fluid and gas charge inventory optimization, and testing techniques occurred as work progressed. For example, processing of the complex heat pipe system was simplified by incorporation of a unique liquid trap and expansion volume reservoir. This process controller permitted in-site fluid and gas fill optimization and purging of unwanted noncondensible gas.

\subsection{FABRICATION METHODS}

Table 2 describes the actual test articles and their build sequence. A large amount of sample panel rework was possible, utilizing only two $30.5-\mathrm{cm}$ long sections of the original remnant panel. This left a 2.44-m long section available for construction of the final test panel.

Photographs of the individual sample test panels and the fully instrumented final test panel (without gas reservoir) are shown in Figures 11 and 12, respectively. 


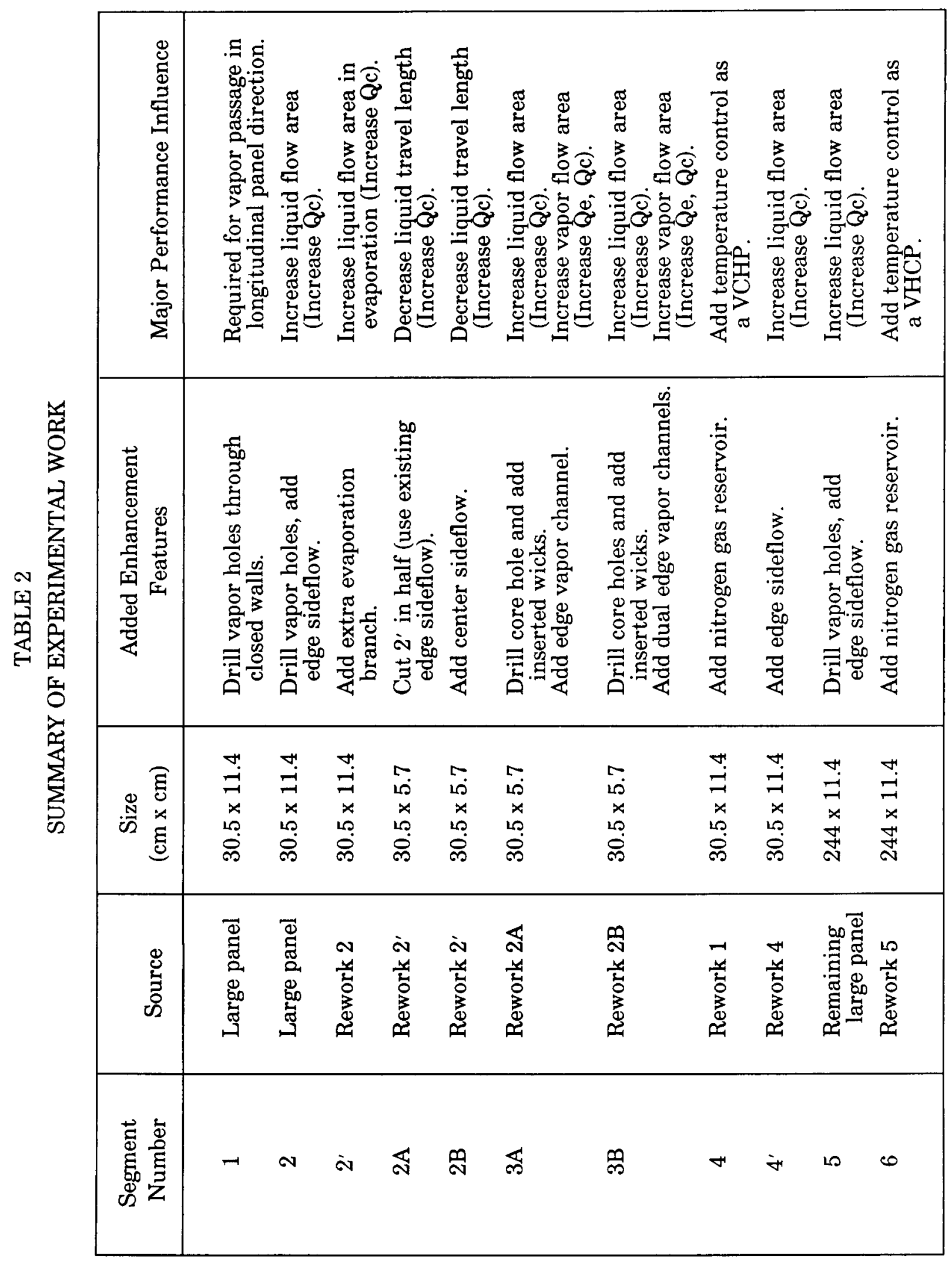




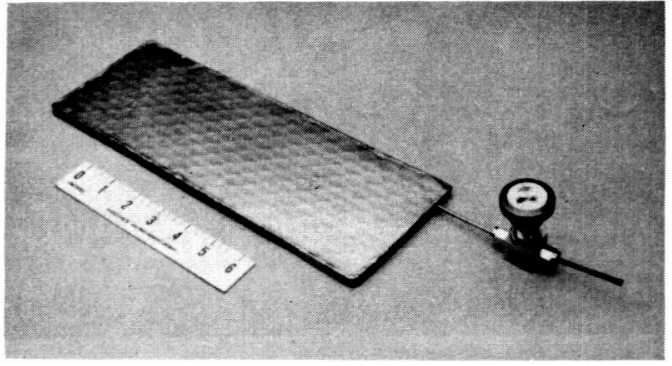

a) BASELINE: DRILLED VAPOR HOLES IN CLOSED CELL FACES $(30.5 \mathrm{~cm} \times 11.4 \mathrm{~cm} \times 0.79 \mathrm{~cm}$ panel) - SEGMENT 1

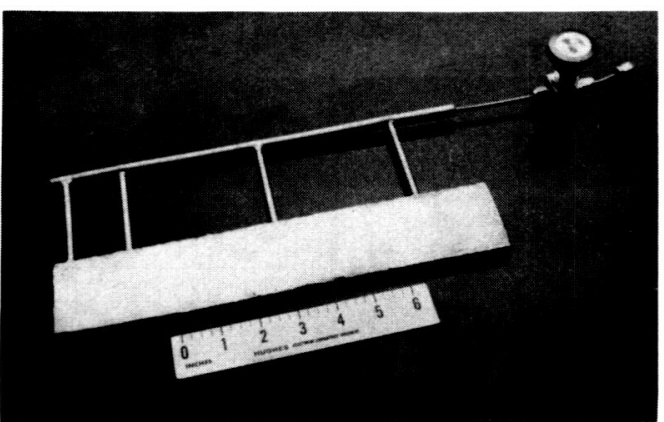

c) EDGE-MOUNTED SIDEFLOW $(30.5 \mathrm{~cm} \times 5.7 \mathrm{~cm} \times 0.79 \mathrm{~cm}$ panel) - SEGMENT 2A

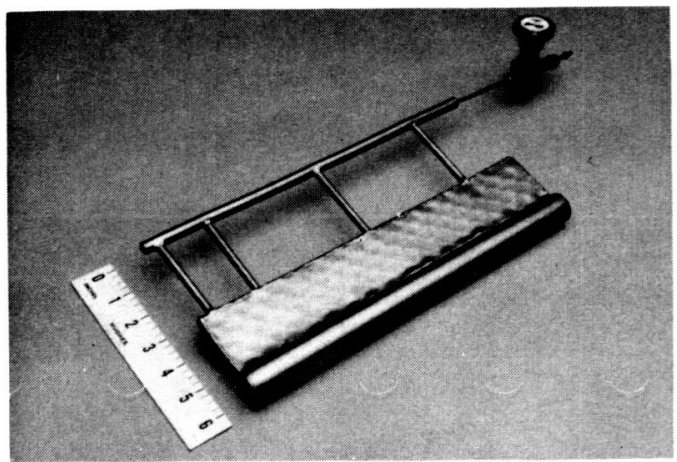

e) EDGE-MOUNTED SIDEFLOW INSERTED TRANSPORT WICKS VAPOR CHANNEL $(30.5 \mathrm{~cm} \times 5.6 \mathrm{~cm} \times 0.79 \mathrm{~cm}$ panel) - SEGMENT $3 A$

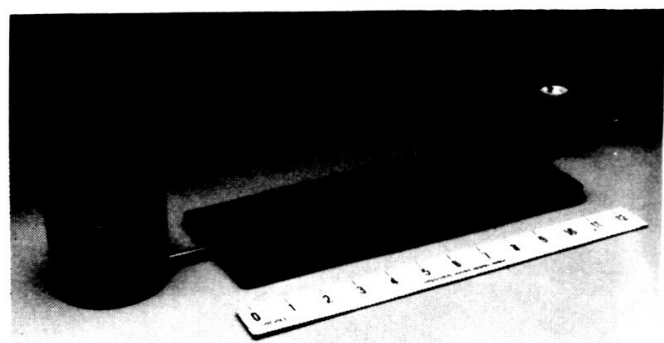

g) BASELINE VCHP $(29.2 \mathrm{~cm} \times 11.4 \mathrm{~cm} \times 0.79 \mathrm{~cm}$ panel) SEGMENT 4

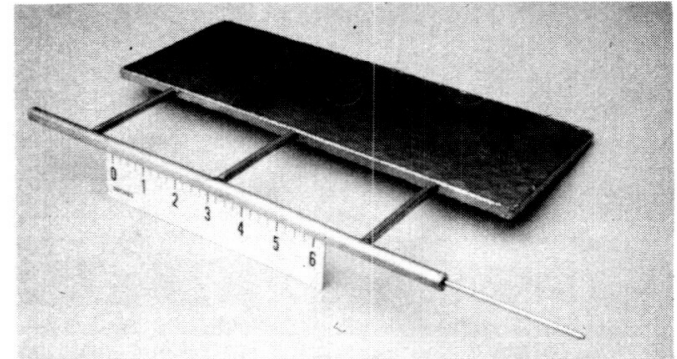

b) EDGE-MOUNTED SIDEFLOW - SEGMENT 2

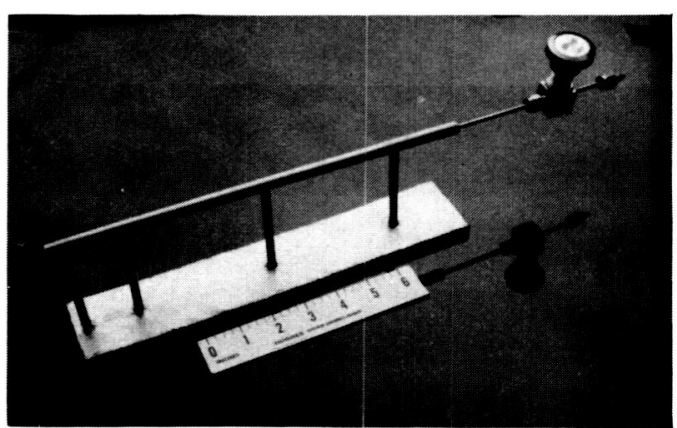

d) CENTER-MOUNTED SIDEFLOW - SEGMENT 28

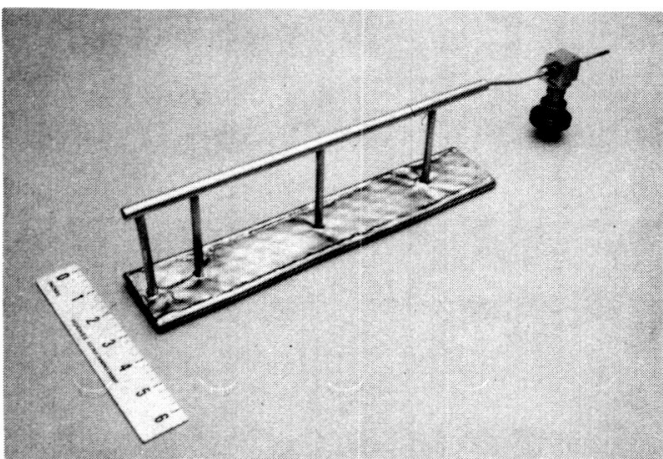

f) CENTER-MOUNTED SIDEFLOW. INSERTED TRANSPORT WICKS. DUAL VAPOR CHANNELS - SEGMENT 3B

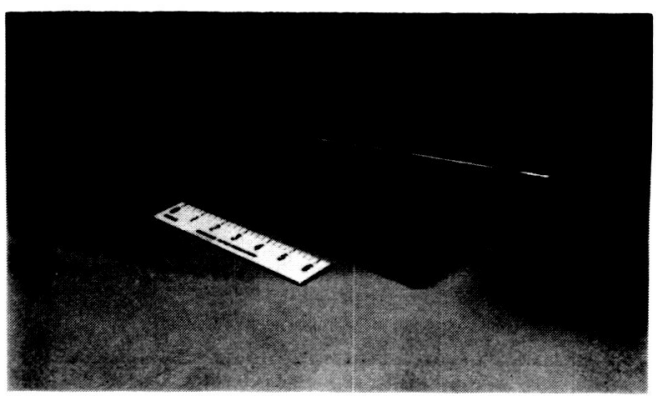

h) EDGE-MOUNTED SIDEFLOW VCHP - SEGMENT 4 (PRIOR TO FINAL ASSEMBLY)

Figure 11 Honeycomb heat pipe sample test panels. 


\section{ORIGINAL PAGE IS}

E6893

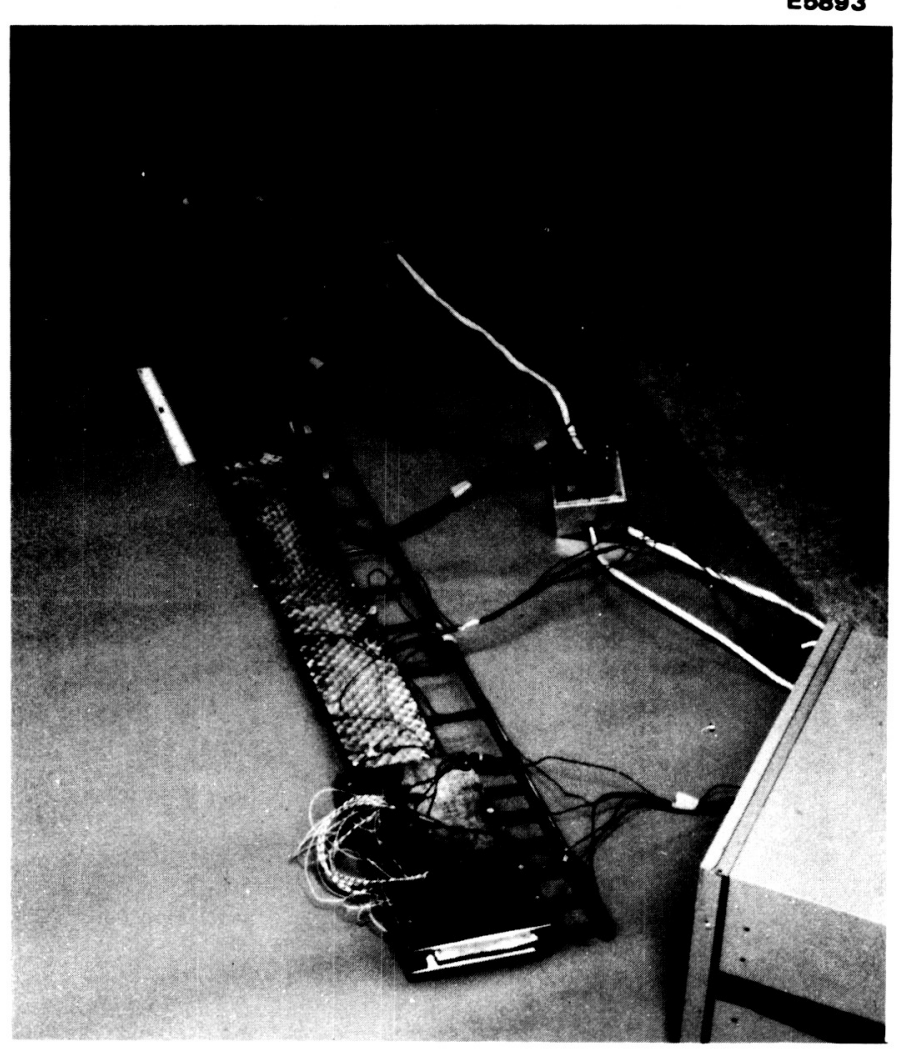

Figure 12 Large test panel with sideflow $(243.8 \times 11.4 \times 0.79 \mathrm{~cm})$. 


\subsection{PERFORMANCE TESTS}

\subsection{TEST DESCRIPTION}

Because of the large amount of planned testing, the test set-up was kept as simple as possible. Operating temperature for the heat pipe panel segments was chosen to be 40 to $60^{\circ} \mathrm{C}$. Varying air flow rates of laboratory ambient or refrigerated air provided sufficient condenser cooling of all test articles. Heat input to the evaporator consisted of tape-on electrical resistance heaters for low power panels and cartridge heaters inside aluminum blocks for higher power panels, well insulated and mounted on the top panel surface. Between 25 and 45 chromel-constantan (Type E) thermocouples were attached to the heat pipes with Kapton tape and insulated with felt backing. Heat input was determined from current and voltage measurements, and several strip chart recorders were used to obtain temperature data.

Individual radiator segments were tested in the sequence shown in Figure 13. Initial calculated fill charges of 100 percent were based on methanol saturation tests using residual honeycomb panel materials, adding sideflow volumes, and correcting fill fluid density for

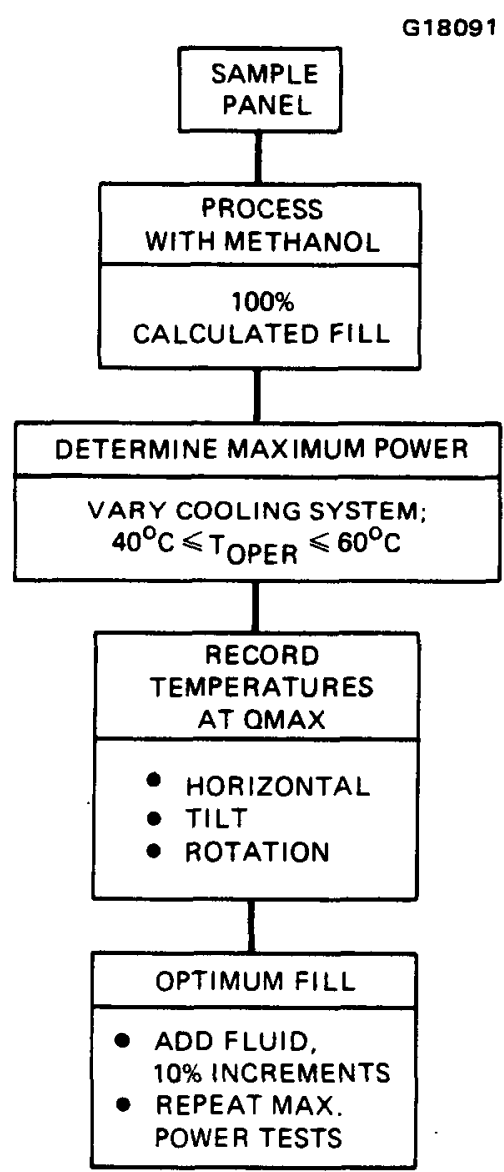

Figure 13 Radiator panel test sequence. 
maximum operating temperature. Fluid fill was then optimized by utilizing the process controller while the heat pipe was operated under design thermal loads and fully instrumented. The convention used for panel orientation ( $\alpha$, tilt and $\phi$, rotation) is shown in Figure 14. Jack stands with low thermal conductance teflon standoffs and gauge blocks were used to set tilt and rotation during test. A large carpenter's level gauge was used to check orientations; however, accuracy was often dictated by the degree of bending or warping present from panel rework operations. Dryout power was indicated by thermocouples mounted on the panel bottom side directly opposite the heaters.

\subsection{TEST RESULTS}

Good correlation between data and predicted performance is achieved if an "effective" pore radius of $43 \times 10^{-6} \mathrm{~m}$ is used for the composite wick construction, as shown by Figure 15(a) for sample $2 \mathrm{~B}$. A heat flux of about $3.5 \mathrm{~W} / \mathrm{cm}^{2}$ produces a boiling limit for the sintered wick honeycomb construction [see Figure 15(b)], closely matching previous laboratory data.

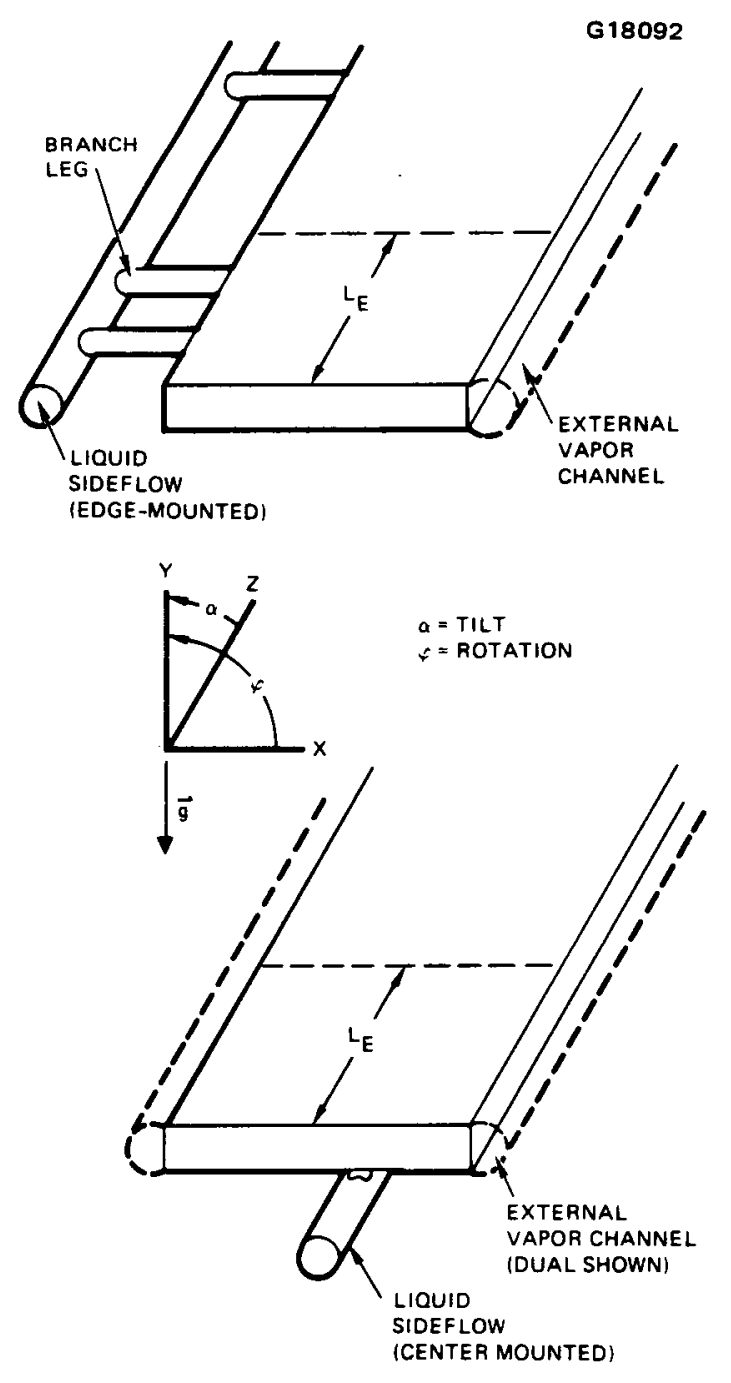

Figure 14 Test convention. 


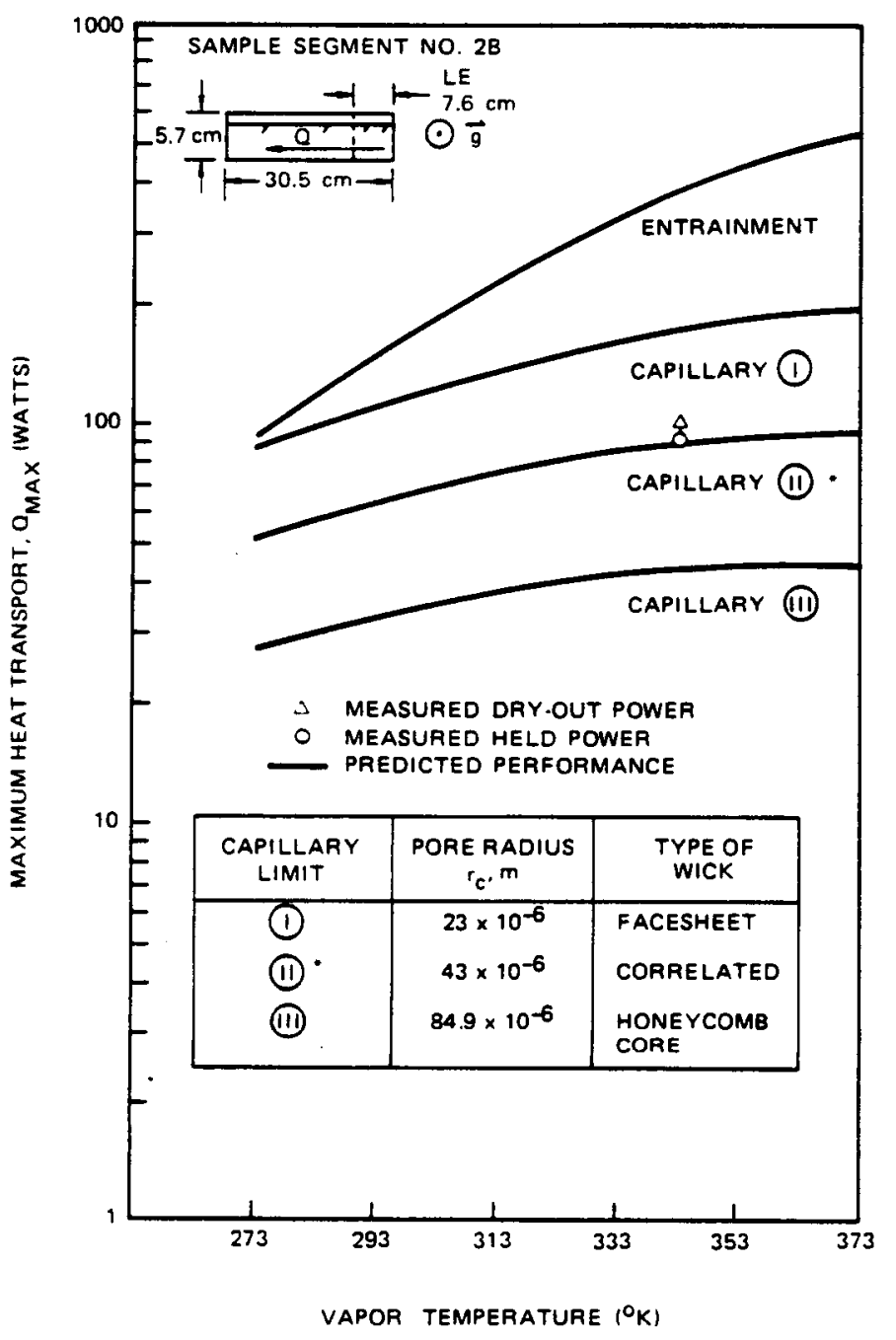

a) THERMAL TRANSPORT LIMITS FOR SAMPLE 28

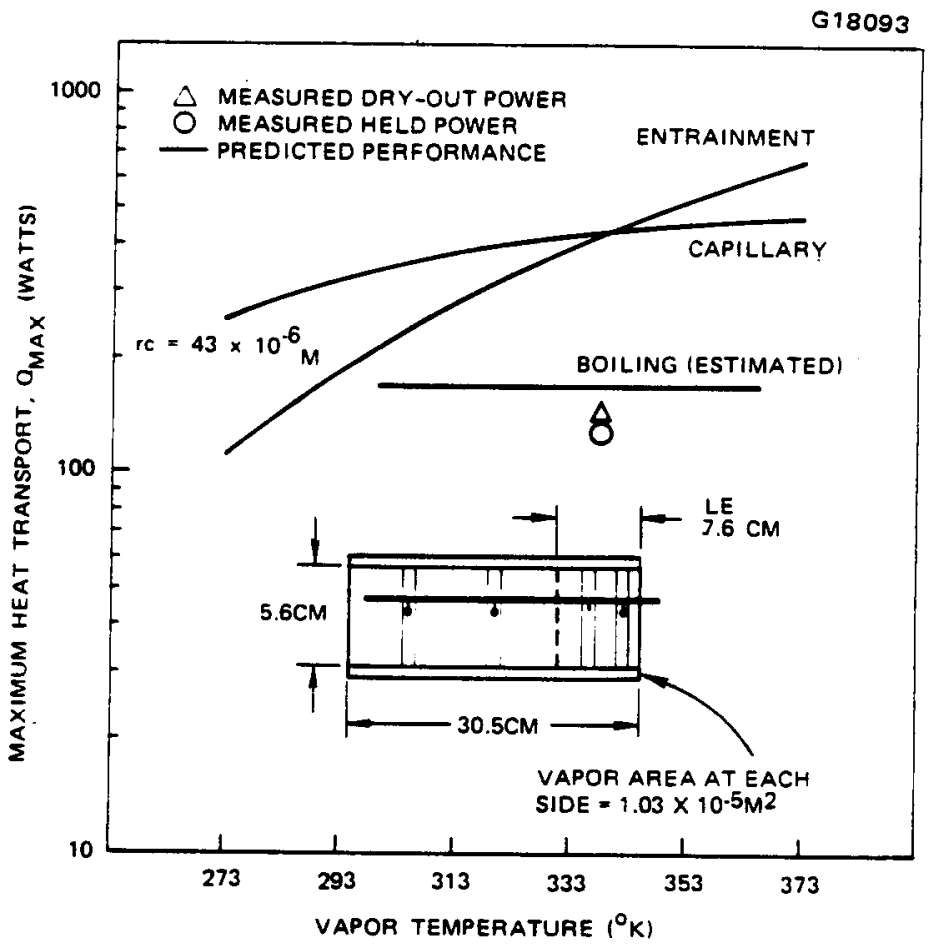

b) THERMAL TRANSPOAT LIMITS FOR SAMPLE 38

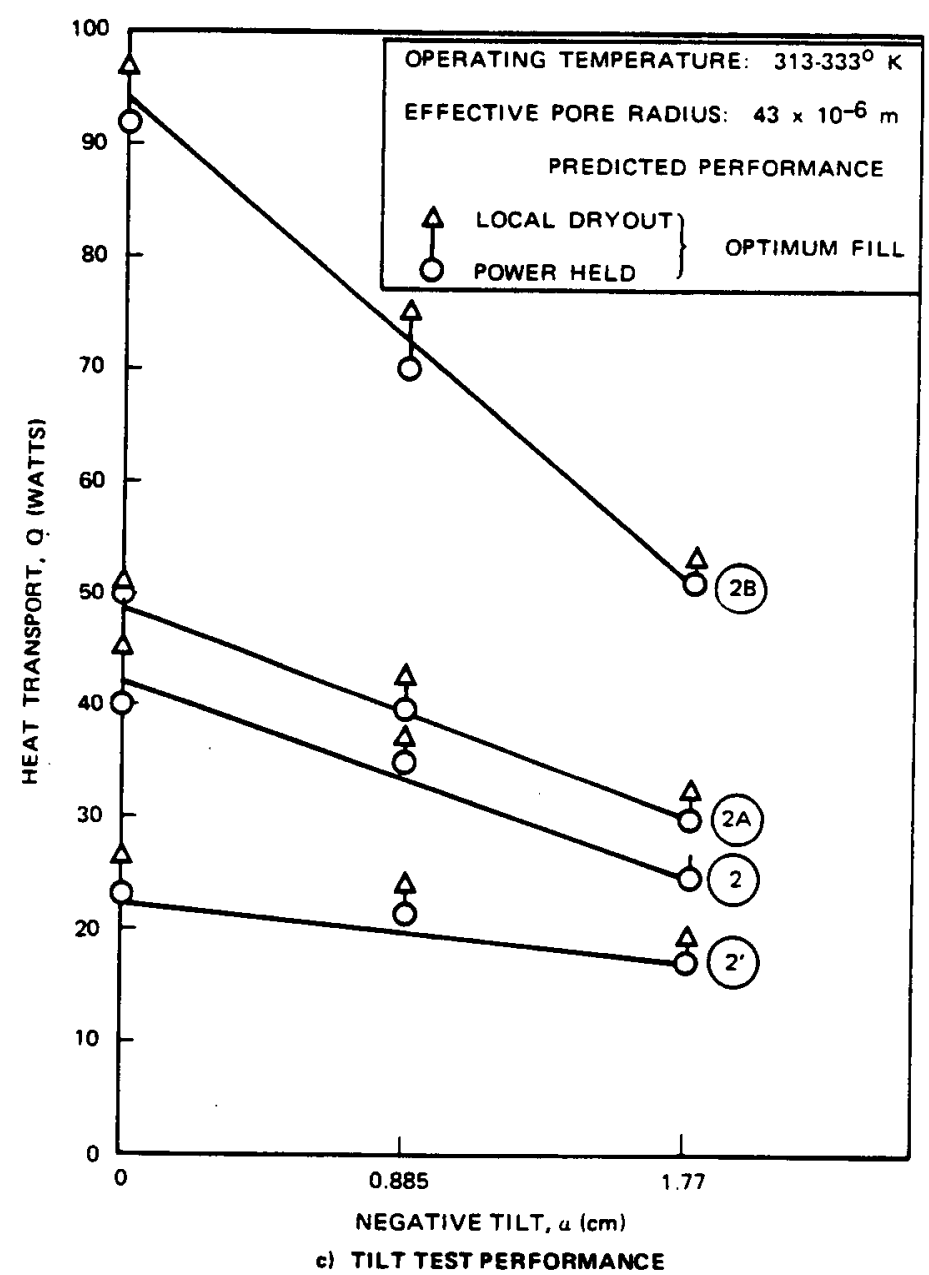

Figure 15 Data correlation of sample test panels. 
Full-scale panels having $3 \mathrm{~A}$ and $3 \mathrm{~B}$ configurations are expected to be capillary or entrainment limited, because the available evaporator area sufficiently overcomes boiling problems. As can be seen from Figure 15(c), a large degree of tilt is possible before partial depriming of the sideflow occurs and localized dryout occurs. This behavior would facilitate ground testing of space hardware. Figure 16 summarizes the maximum power performance of the various sample panels. The increasing power trend is apparent. The first five panel segments (also the two VCHP segments) were capillary limited; the remaining two panels became boiling limited at about $3.5 \mathrm{~W} / \mathrm{cm}^{2}$. A maximum power of $147 \mathrm{~W}$ was measured for panel $3 \mathrm{~B}$, having center mounted liquid sideflow, inserted wicks, and dual vapor channels.

A 2.44-m long scaled-up version of the 2 ' configuration, having an edge mounted side-flow and decreased evaporator branch spacing, was built for final test panel evaluation. Maximum transport capacity of $103 \mathrm{~W}$ at level orientation is plotted in Figure 17(a), which also shows predicted transport capacity for both sideflow primed and unprimed cases. This sideflow addition exhibits a transport capacity improvement of 35 times that of the 244-cm honeycomb panel without sideflow. This is much more than the two times performance improvement observed between the same configurations but smaller sample panels $2^{\prime}$ and 1 (refer to

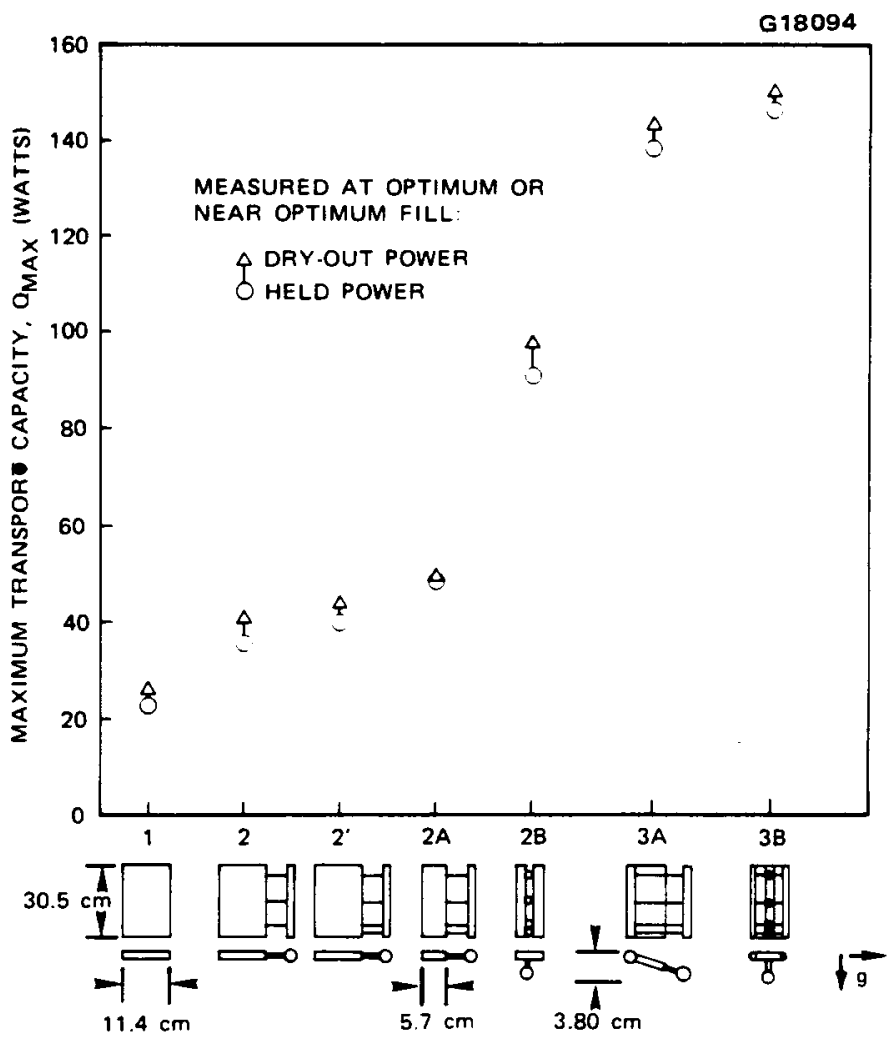

Figure 16 Summary of subscale panel test results. 

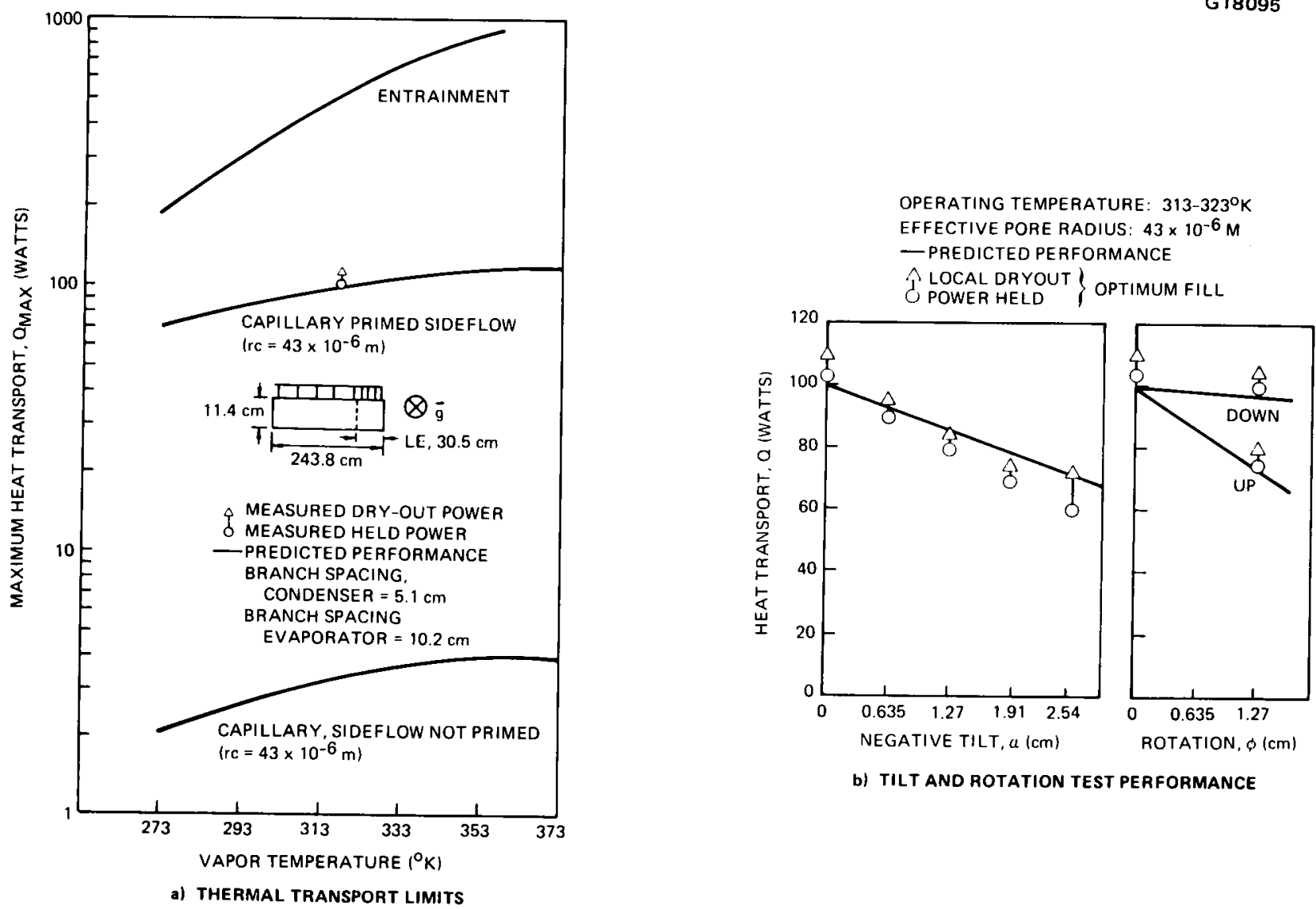

b) TILT AND ROTATION TEST PERFORMANCE
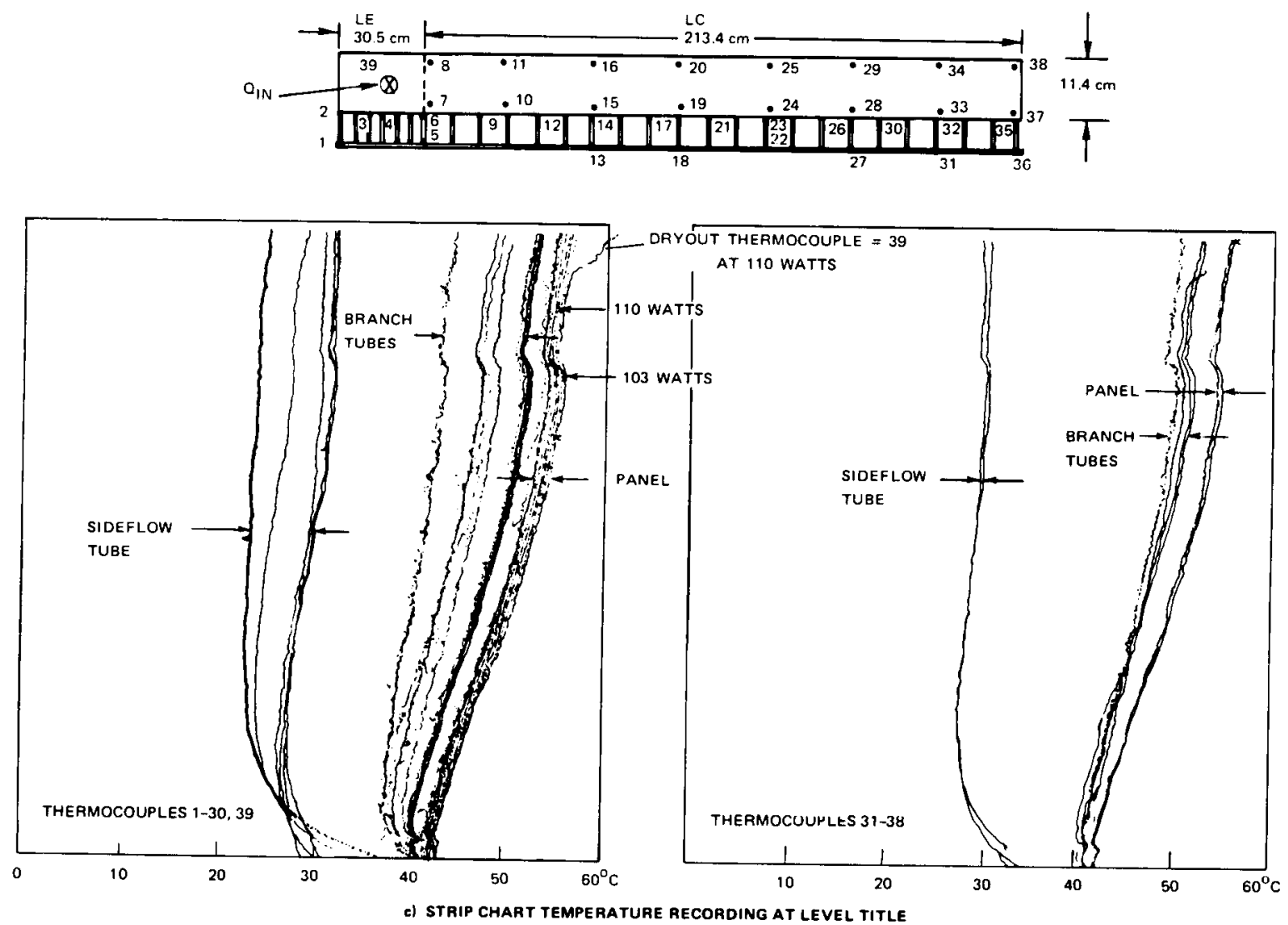

Figure 17 Large test panel characteristic performance. 


\section{ORIGINAL PAGE IS \\ OF POOR QUALITY}

Figure 16). As can be seen from Figure 17(b), a large degree of adverse orientation is possible before partial depriming of the sideflow and therefore localized dryout occur. This behavior would facilitate ground testing of space hardware. In all cases, the prediction model correlates well with actual performance. The entire honeycomb panel was measured isothermally within $2^{\circ} \mathrm{C}$ at maximum power, as shown by the strip chart temperature traces in Figure 17(c). Subcooling between sideflow liquid and core vapor is approximately $25^{\circ} \mathrm{C}$. Sensible heating of this highly subcooled liquid should delay the onset of evaporator wall superheating and, thus, boiling.

A nitrogen filled reservoir was added to the final test panel for the temperature control experiment. The fully instrumented VCHP panel, with sideflow, gas reservoir, and process controller, is shown in Figure 18. Identical transport performance as the panel without reservoir was observed. The VCHP sizing model utilized inputs of experimental power and temperature of the panel without reservoir, and desired temperature control span. The methodology for computing reservoir size and control gas fill based on a selected temperature

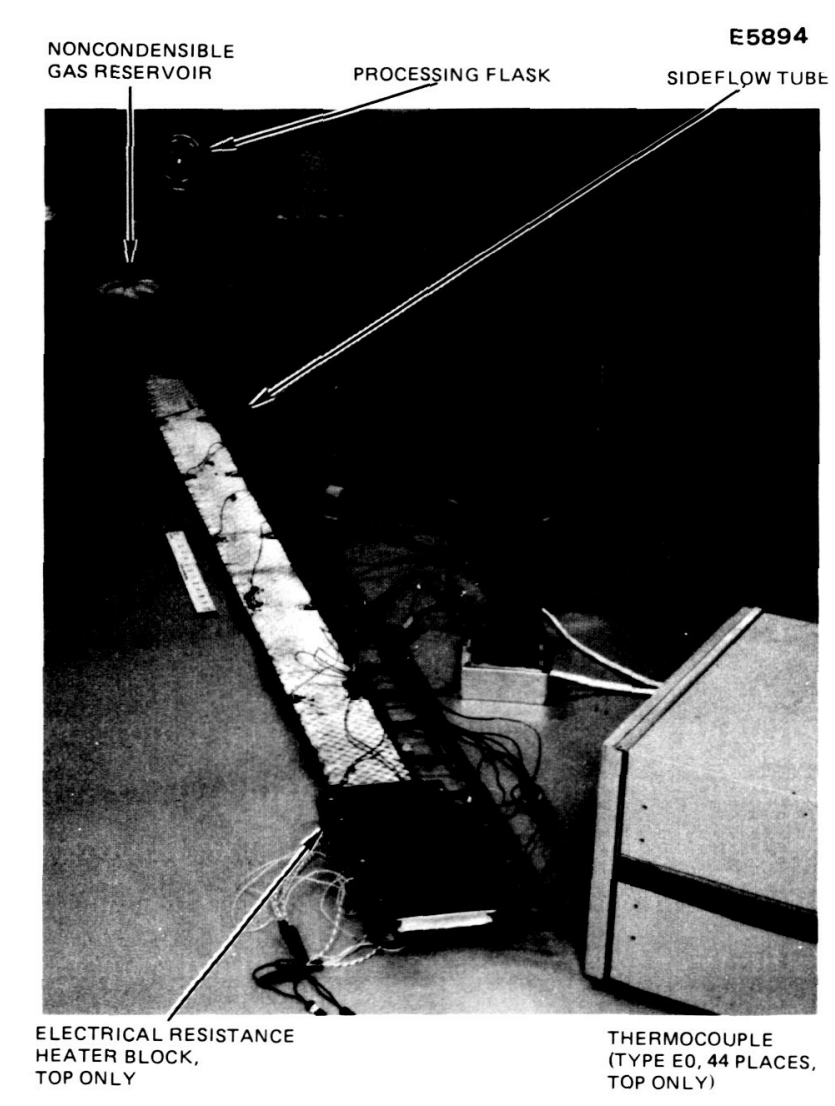

Figure 18 Large VCHP test panel with sideflow $(243.8 \mathrm{~cm} \times 11.4 \mathrm{~cm} \times 0.79 \mathrm{~cm})$. 
control span is summarized in Figure 19, which also shows actual temperature control behavior. Changing environmental conditions accounted for the small downward shift in panel operating temperatures. The actual temperature control span of $3^{\circ} \mathrm{C}$, however, is identical to prediction. Thus, there is good correlation between sizing model prediction and experiment.

Selections of the final panel features were dictated by both performance results and fabrication experience with the sample panels. Although the panels with inserted wicks and vapor channels, $3 \mathrm{~A}$ and $3 \mathrm{~B}$, produced the largest thermal transport, rework fabrication of this type was deemed too difficult and time consuming for the large panel. An equivalent high-transport configuration could best be achieved through a fresh-start redesign of the honeycomb core. The prediction model's capability for tracking performance from small $30.5-\mathrm{cm}$ to larger $244-\mathrm{cm}$ panels was verified using a simpler rework configuration. Thus, confidence is gained for credible scaling of any of the tested configurations to full-scale space radiator systems. 
OBSERVED WITHOUT RESERVOIR - SEGMENT 5

$T_{\text {SINK }}=295^{\circ} \mathrm{K}$

Toperating AT $50 \mathrm{~W}=304^{\circ} \mathrm{K}$

TOPERATING AT QMAX OF $103 \mathrm{~W}=314^{\circ} \mathrm{K}$

CALCULATED $h$, OVERALL HEAT TRANSFER COEFFICIENT CONDENSER TO LABORATORY

$A I R=9.6 \mathrm{~W} / \mathrm{m}^{2}-{ }^{\circ} \mathrm{K}$

DESIRED TEMPERATURE CONTROL SPAN:

$50 \mathrm{~W}$... . 311 $1^{\circ} \mathrm{K}$ (ACTUAL 309 $\mathrm{K}$ )

$100 \mathrm{~W}$.... 314 ${ }^{\circ} \mathrm{K}$ (ACTUAL 3120K)

CALCULATED RESERVOIR VOLUME $=2.34 \times 10^{-3} \mathrm{~m}^{3}$

CALCULATED NITROGEN GAS FILL $=5.97 \times 10^{-1}$ GRAM
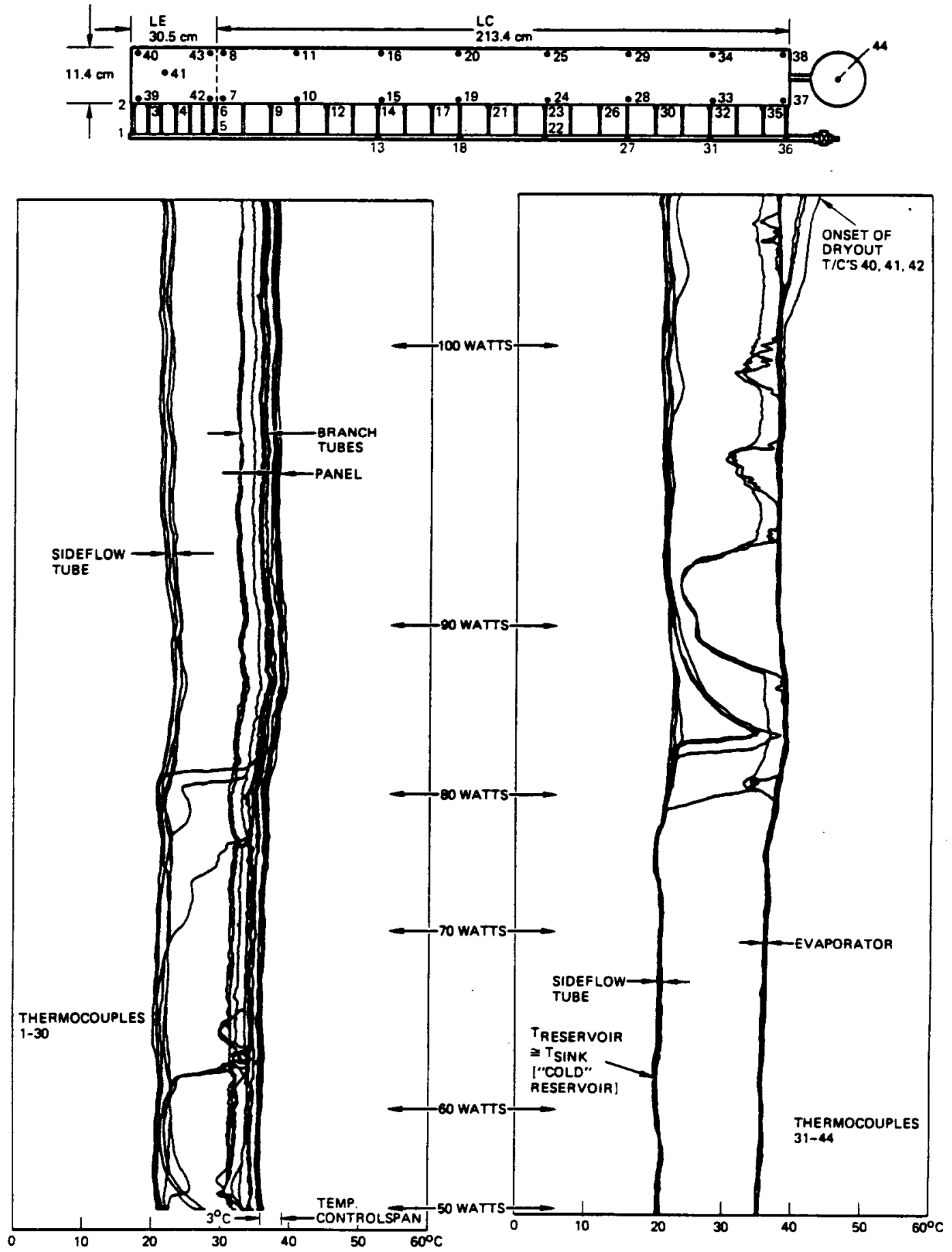

Figure 19 Data correlation of large VCHP panel - segment 6. 


\subsection{UPGRADE ANALYSIS MODEL}

In the previous section, test results were used to correlate the heat pipe analysis model. In this section, thermal performance predictions are made for large, space station size systems which reject $50 \mathrm{~kW}$ thermal, nominal.

\subsection{SPACE HEAT REJECTION CHARACTERISTICS}

When projecting any heat pipe based thermal control system to space operations, limitations of the heat pipe operating temperature must be understood. In a laboratory test environment on earth, the operating temperature of the heat pipe device can be readily varied by adjusting the coolant sink. Thus, heat pipe performance over various operating temperatures can be evaluated. A performance curve that relates maximum power delivered to the heat pipe before dryout can be displayed as a function of temperature. If these heat transfer limitations are capillary in nature, they will be a function both of fluid properties that vary with temperature, and internal pressure drop limitations. Whether the heat pipe will actually operate at its maximum condition is determined by whether the actual condenser sink condition can be ideally matched to that condition which yields the maximum power, i.e., operating temperature. Particularly in space, the chances are that they won't.

In space, thermal power dissipation is limited by radiation heat transfer, which, for a near isothermal surface (such as a heat pipe radiator) is:

$$
\mathrm{q}=\operatorname{AF\sigma e}\left(\mathrm{T}^{4}-\mathrm{T}_{\infty}^{4}\right)
$$

where

$$
\begin{aligned}
& \mathrm{q}=\text { heat transfer rate } \\
& \mathrm{A}=\text { condenser surface area } \\
& \mathrm{F}=\text { radiation view factor, assume } 1.0 \\
& \mathrm{\sigma}=\text { Stefan-Boltzmann constant } \\
& \mathrm{e}=\text { surface emissivity, assume } 0.85 \\
& \mathrm{~T}=\text { condenser surface temperature } \\
& \mathrm{T}_{\infty}=\text { temperature of deep space, assume } 0 \mathrm{~K} .
\end{aligned}
$$

For a given configuration and surface properties, the heat dissipation rate is directly proportional to condenser surface area and proportional to the fourth power of the condenser surface temperature. Thus, heat rate, surface area, and surface temperature form a set of 
design variables, any two of which can be independent. One can then see direct limitations being placed on the radiative sink. At less than about $450^{\circ} \mathrm{K}$, the radiative sink is not as efficient as the forced convective sink in the laboratory. Therefore, in a space heat pipe application, severe limitations will be placed on the operating conditions. That is, for a given desired heat dissipation rate, a given condenser area will result in a fixed surface temperature and, therefore, a fixed operating temperature. The relationship between the actual operating temperature in space, and the laboratory performance curve will now be presented in an effort to project laboratory work to full-scale space system designs.

\subsection{DATA CORRELATION AND PROJECTION TO SPACE-STATION SIZE SYSTEMS}

For the LaRC integral heat pipe radiator, the computer prediction model was correlated with data from a range of subscale test vehicle sizes $(0.305 \mathrm{~m}$ to $2.44 \mathrm{~m}$ lengths) and several enhancement features.

For a baseline space station system, $50 \mathrm{~kW}$ will be selected as the thermal duty. As was seen in Figure 15(a), the developed computer model closely correlates the experimental data in the $2 \mathrm{~B}$ panel configuration, which has center-mounted sideflows closely spaced together. The computer model will now be used to scale up to a space-station sized system. Figure 20 represents a series of optimized performance curves for a $0.0508-\mathrm{m}$ wide methanol filled honeycomb panel of $2 \mathrm{~B}$ configuration, with the exception that the panel height is increased to avoid entrainment limitations. The series of system curves represents the effects in the variation of condenser lengths on panel performance. Condenser lengths of 6.096, 12.192, 15.24, and 21.336-m are shown. Also represented on each figure are the actual operating curves that depict the energy balance between input heat flux and radiative energy dissipation.

Each set of curves can be interpreted as follows: wherever the actual, steady-state operating curve, i.e., radiation energy balance, lies below the optimized system maximum transport curve, the heat pipe will successfully operate. Only at the intersection points of the two curves, however, will the system operate at its maximum transport rate for a given temperature. For the most part, the operating system will be undersized; that is, if the operating curve is less than the system curve, the actual operating condition will result in a lower transport capacity (at a given temperature) than the system would be able to produce with a different condenser heat sink. When the operating curve lies above the system curve, the heat pipe will dry out. This is because the input heat rate results in an operating temperature with a corresponding maximum system heat rate that is lower than the actual input heat rate. Therefore, on each figure, the actual operating band is defined. When the condenser length is $21.336 \mathrm{~m}$, Figure 20(d), there is no operating band. This heat pipe panel will not operate in space at any temperature. 
ORIGINAL PAGE IS

OF POOR QUALITY

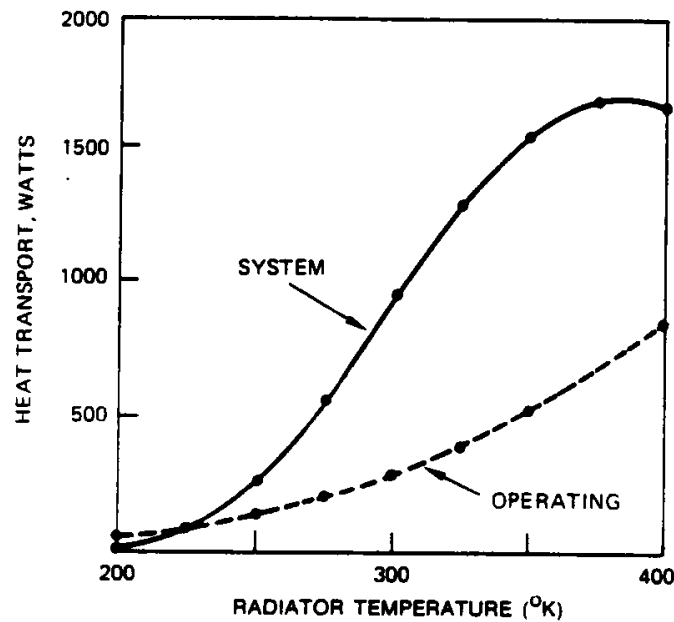

a) O VS T FOR $6.006 \mathrm{~m}$ CONDENBER

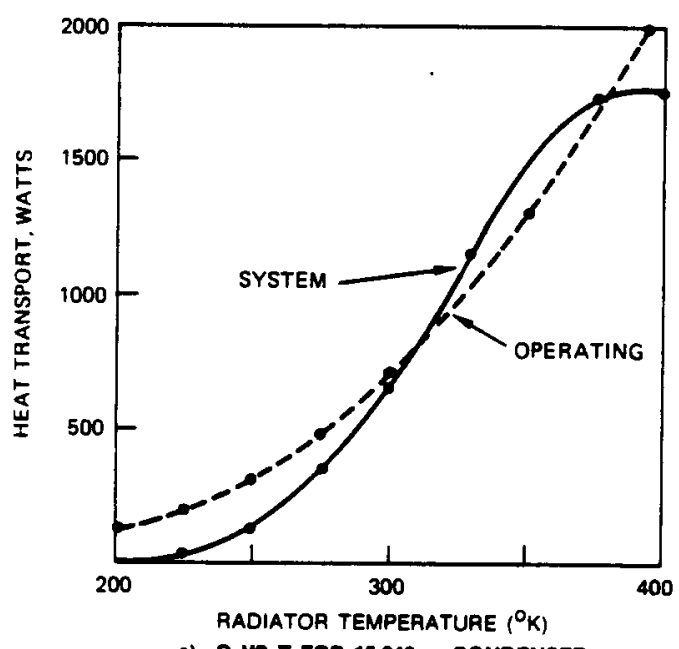

C) O VS T FOA $15.240 \mathrm{~m}$ CONDENBER

COMMON DATA

EVAPORATOR LENGTH $=0.9144 \mathrm{~m}$

PANEL WIDTH $(W)=0.0508 \mathrm{~m}$

BRANCH TUBE SPACING, EVAP $=0.0127 \mathrm{~m}$

BRANCH TUBE SPACING. COND $=0.1016 \mathrm{~m}$

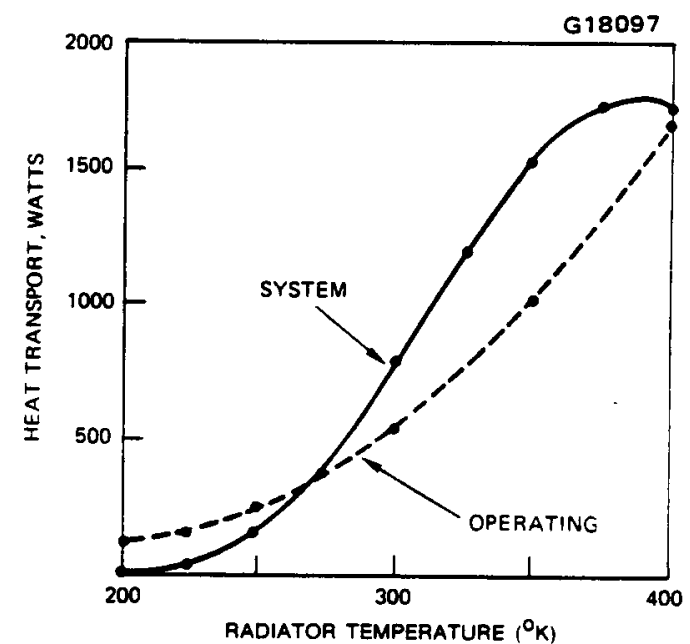

D) O VS T FOR $12.192 \mathrm{~m}$ CONOENSER

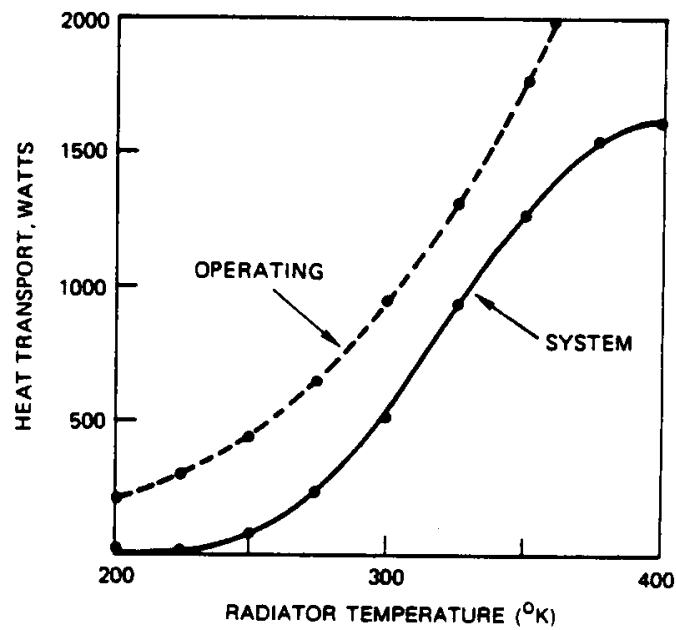

d) O VS T FOR $21.333 \mathrm{~m}$ CONDENSER

CONFIGURATION 2B:

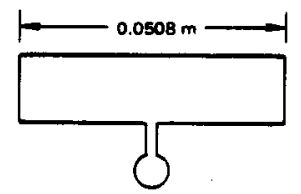

Figure 20 Optimized honeycomb panel system performance curve for space. 
Care should also be taken to avoid undersizing the system, as shown in Figure 20(a) for the $6.096 \mathrm{~m}$ long condenser. In this figure, the operating curve is much lower than the system curve; hence, the heat pipe panel will never operate near the rated system capacity. For the heat pipe panel with condenser lengths of 12.192 and $15.24 \mathrm{~m}$, Figures $20(\mathrm{~b})$ and (c), respectively, the systems perform much better, with their operating curves being much closer to their system curves. If the operating curve lies too close to the system curve, the design would not be recommended because, if there were any errors in developing the system curve (such as model estimations), the error latitude would be too small and the system might not work because it may actually be lower than the operating curve.

Table 3 tabulates the rated panel power as a function of condenser length and operating temperature. It shows that a design load of $50 \mathrm{~kW}$ at $0^{\circ} \mathrm{C}$ radiator operating temperature can be met with the existing stainless steel honeycomb core configuration and methanol working fluid, if the sideflows are closely spaced together and panel lengths are kept under about $12 \mathrm{~m}$. Each $12 \mathrm{~m} \times 0.0503 \mathrm{~m}$ panel section containing one center-mounted sideflow is projected to transport and dissipate $400 \mathrm{~W}$ of energy at $0^{\circ} \mathrm{C}$. At lengths greater than $12 \mathrm{~m}$, the radiative energy dissipation exceeds the radiator transport capacity over much of its operating temperature range; thus, the longer panels are not expected to operate in space. The width of a discrete panel can be any multiple of the sideflow spacing distance; for example, we can fabricate a discrete panel $30.5 \mathrm{~cm}$ wide by joining six $5.08 \mathrm{~cm}$ wide sections. A $50 \mathrm{~kW}$ system would then require 21 of these discrete panels to be assembled in a building block fashion (Figure 21). To meet radiator design loads greater than $50 \mathrm{~kW}$ or at panel lengths greater than $12 \mathrm{~m}$, a higher thermal transport capacity is required. Although

TABLE 3

RATED RADIATOR PANEL POWER

\begin{tabular}{|c|l|l|l|l|}
\hline \multirow{2}{*}{ Condenser Length, $\mathrm{m}$} & \multicolumn{4}{|c|}{ Operating Temperature } \\
\cline { 2 - 5 } & $-20^{\circ} \mathrm{C}$ & $0^{\circ} \mathrm{C}$ & $50^{\circ} \mathrm{C}$ & $90^{\circ} \mathrm{C}$ \\
\hline 6.096 & $150 \mathrm{~W}$ & $200 \mathrm{~W}$ & $375 \mathrm{~W}$ & $575 \mathrm{~W}$ \\
12.192 & No good & 400 & 775 & 1200 \\
15.240 & No good & No good & 1000 & 1475 \\
21.336 & No good & No good & No good & No good \\
\hline
\end{tabular}




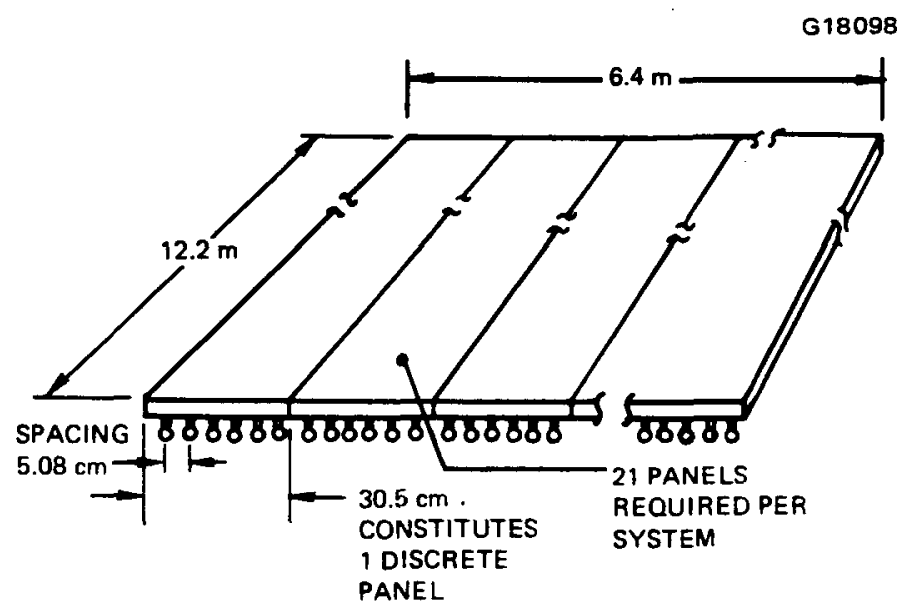

- STAINLESS STEEL HONEYCOMB (UNMODIFIED) CORE

- METHANOL WORKING FLUID

Figure 21 Projected $50 \mathrm{~kW}$ space radiator system using high-capacity integral heat pipe panels.

ammonia has superior fluid properties than methanol, its high vapor pressure does not allow its use within the unrestrained flat panel structure. The design parameters of the integral radiator that limit thermal transport are those contributing to liquid flow pressure drop in its travel path between evaporation and condensation regions of the panel and the sideflow. This supposition was tried and tested in subscale test vehicles (the configuration 3B) by drilling holes through the core in a transverse direction and inserting rolled-up screen wicks. The increased liquid flow area reduced the pressure drop and created a greater than double improvement in transport capacity, in regard to the as-built honeycomb core configuration. A thick-channel core with channels oriented in the transverse panel direction should accomplish similar performance enhancement, and its fabrication is feasible. The integral radiator could undergo additional optimization by joining panels with different wick materials: coarse pore at the condenser and fine pore at the evaporator. Thus, at best, an optimized $12 \mathrm{~m}$ long, $50 \mathrm{~kW}$ integral radiator is expected to have a maximum sideflow spacing of about $15 \mathrm{~cm}$. However, the integral honeycomb radiator is restrained in both transport length and fin length (spacing distance between sideflows) at the $50 \mathrm{~kW}$ level. The next generation of space radiator systems will be required to transport higher power levels $(100 \mathrm{~kW})$ over possibly longer distances. In addition, improvements will be sought in system weight and thermal efficiency. 


\subsection{HYBRID DESIGN}

The objective of this task is to review the current test program, test results, and analysis model from the standpoint of designing an optimized experimental panel which is compatible with testing in the NASA-JSC test bed facility. The result was a novel concept called the "hybrid" radiator, consisting of individually optimized heat pipe components. A proof-ofprinciple experiment is defined in this section. The following Sections 8.0 and 9.0 describe the fabrication sequence and the ambient air testing undertaken in a Hughes laboratory. The current program ended prior to any thermal vacuum performance testing at JSC, as was originally planned.

\subsection{CONCEPT DEFINITION}

The LaRC honeycomb panel heat pipe work has resulted in significant insight into development of future space radiators. The hybrid honeycomb panel heat rejection system concept takes the optimization process started with the integral honeycomb heat pipe panel one step further. Space radiator functions of heat acquisition, heat transport, and heat rejection are individually optimized, and performance factors of thermal transport, thermal efficiency, and weight are improved.

The hybrid radiator concept utilizes several heat pipe components, as illustrated in Figure 22. Dimensions given are an initial estimate for a subscale proof-of-principle prototype.

Expanded Evaporator - The expanded evaporator consists of stainless steel honeycomb material to withstand high clamping pressures with the thermal bus heat exchanger. Since the evaporator typically experiences the greatest heat flux levels in the radiator system, the sintered facesheet wicks and core wicks of the honeycomb effectively enhance evaporation film coefficients and reduce thermal resistance. In addition, the sintered wick can be made of fine pores, which increases capillary pumping head.

Sideflow Heat Pipe - Vapor flow within the evaporator converges to a common external vapor header, which then leads to the transport leg. The evaporator and transport leg form a closed thermodynamic system, with the transport leg functioning as its condensing section. The transport leg is of the sideflow design, where the vapor channel and liquid return channel are separated by cross-over tubes. The dual-channel transport leg has very high capacity and has effective priming characteristics because of subcooling of the liquid. Vapor condenses in the vapor channel, as a result of heat sinking from the radiator fins, and returns to the evaporator by way of the liquid sideflow. Ammonia, a high-capacity fluid, can be used for this closed system. The evaporator and transport leg can be structurally designed to contain the high pressure that ammonia vapor exhibits. 


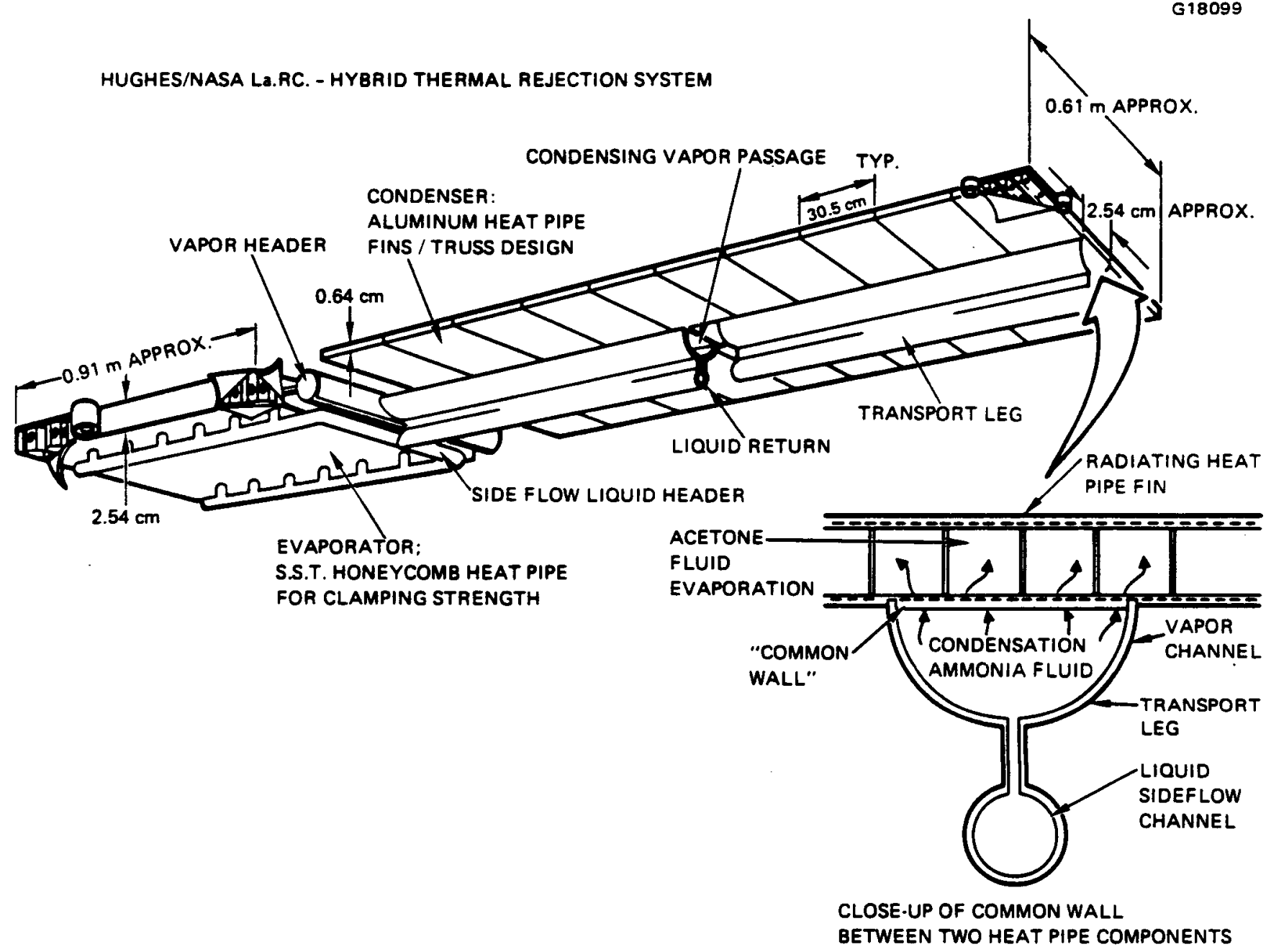

Figure 22 Hybrid radiator concept.

Heat Pipe Panel Radiator Fins - The heat pipe heat rejection fins interface with a flat section of the transport leg via a common wall. The common interface wall is an integral construction of transport leg and fins, such that fluid condenses on one surface (in the vapor channel) and fluid evaporates on the other (in the fins). In this way, the overall thermal resistance of this interface is reduced. Each heat pipe fin is a separate system, thus minimizing system damage from micrometeoroid penetration. Lightweight aluminum facesheets and truss core can be used for the fins, in conjunction with low-pressure acetone working fluid. Grooves, which offer low resistance to liquid flow, can be used to provide sufficient capillary pumping in the fins. 


\subsection{EXPERIMENT DESIGN DESCRIPTION}

Design of the initial hybrid radiator test vehicle was entirely based on utilization of remnant component hardware. Modifications to the existing hardware designs are related primarily to its integration into the hybrid system. Table 4 summarizes the results of recent Hughes space radiator development programs that have remnant hardware available for hybrid construction. Additional development of the sideflow as a discrete high transport radiator element has occurred under contract ${ }^{10}$ to Wright Patterson Air Force Base (WPAFB), and both JSC and WPAFB have funded work on several versions of a lightweight aluminum heat pipe fin element. Component hardware available for integration and construction of the hybrid radiator is shown in Figure 23.

\subsubsection{Design Approach}

Major performance characteristics of the hybrid radiator relate to: the available system cooling capacity, the heat acquisition and transport heat pipe capacities, and the radiating fin heat pipe capacities. Design of the hybrid radiator test vehicle requires matching individual component performance characteristics to achieve overall system optimization. The performance matching design approach is described by Table 5 . Sizing curves for each of these performance factors are prepared, based largely on measured performance data and correlated prediction models of existing component hardware. Heat pipe capacities are highly dependent on operating temperature, which for the space radiator is considered to be in the range -20 to $65^{\circ} \mathrm{C}$. Individual component sizing curves are then integrated into an overall set of hybrid system operating curves, which represent performance as a function of operating temperature. The result is a conceptual design of the $3.05 \mathrm{~m}$ long ground hybrid test vehicle that uses available hardware (Figure 24).

\subsubsection{Thermal Performance}

Performance predictions and the sizing methodology of the hybrid radiator test vehicle are described in the following sections.

Cooling Capacity - In a laboratory test environment on earth, operating temperature and thermal power dissipation rate of the heat pipe radiator can be readily varied by adjusting the coolant sink (assuming availability of various laboratory cooling methods). It is thus possible to ideally match condenser sink conditions in the laboratory to obtain the maximum thermal transport capacity of the radiator at its corresponding operating temperature. In space, however, it is entirely possible for the heat pipe transport capacity to exceed the radiative dissipation capacity for part or all of the operating temperature range, thus being radiation heat transfer limited. Calculated space radiation cooling capacities based on a $-65^{\circ} \mathrm{C}$ effective space sink temperature and a heat pipe fin efficiency $(\eta)$ of unity are shown 


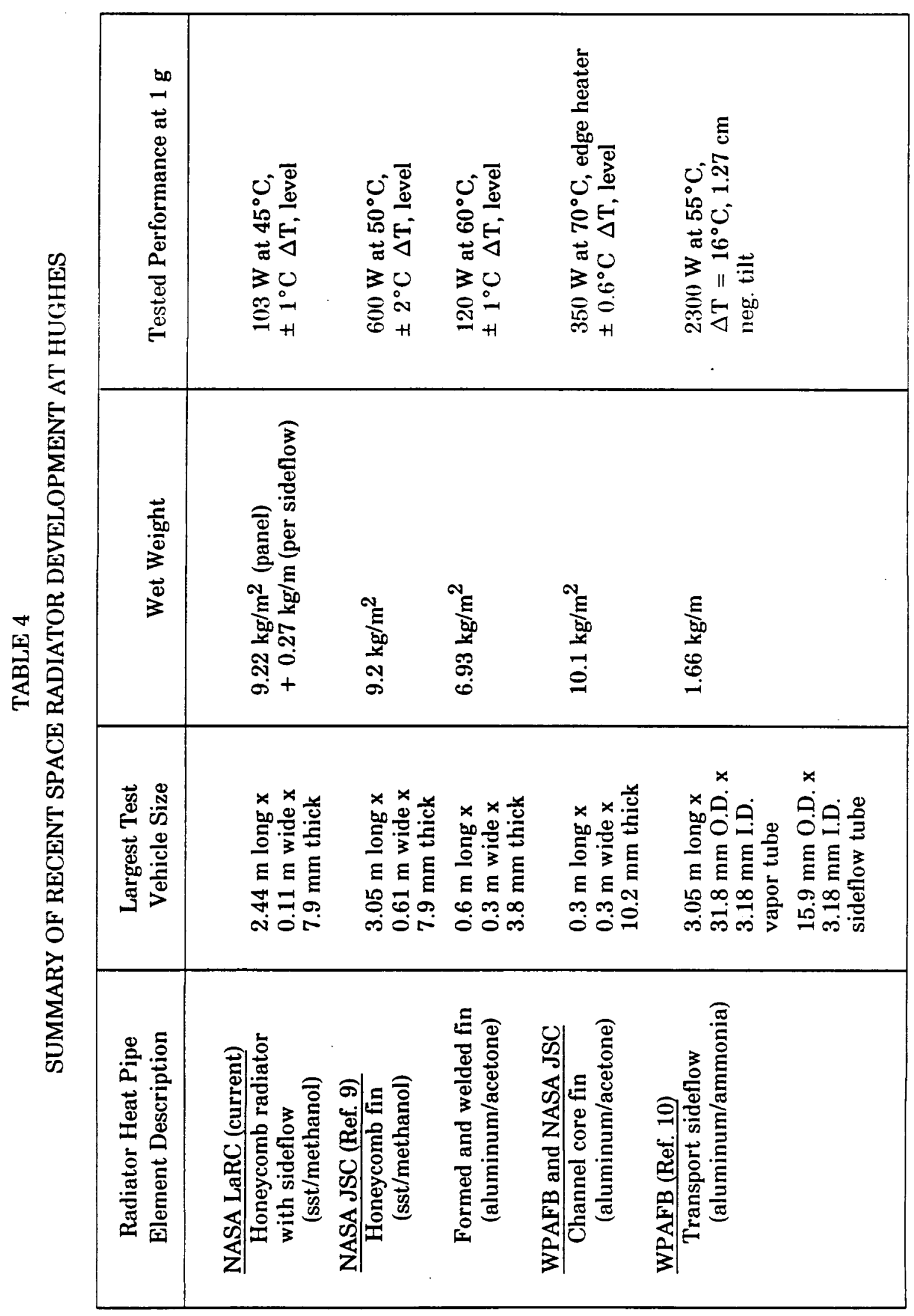




\section{ORIGINAL PAGE IS OF POOR QUALITY}

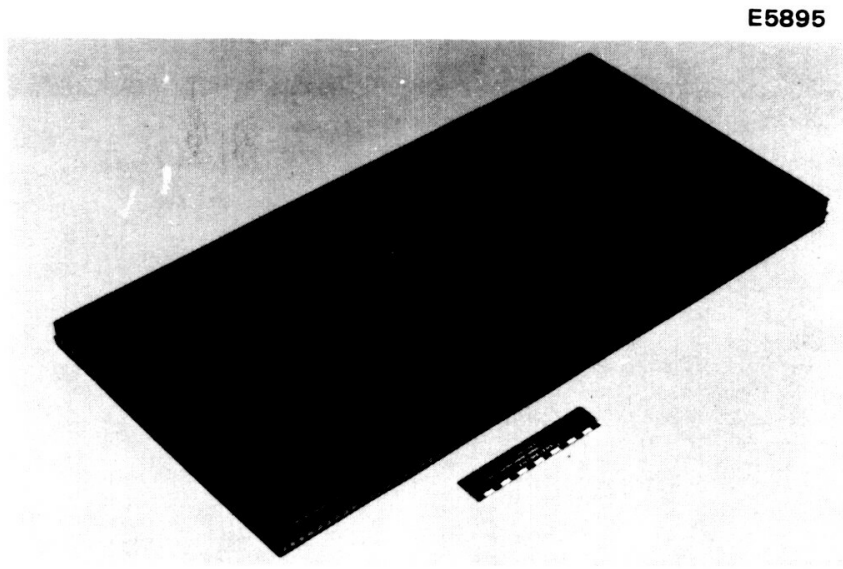

a) STAINLESS STEEL HONEYCOMB SANDWICH PANEL MATERIAL (NaLRC).

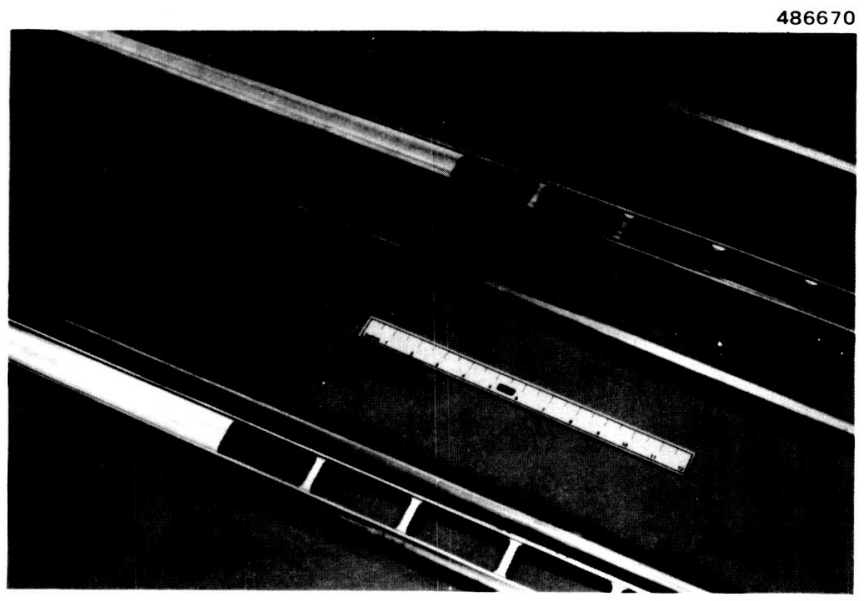

b) EXPERIMENTAL SIDEFLOW HEAT PIPE PIECE PARTS (WPAFB).

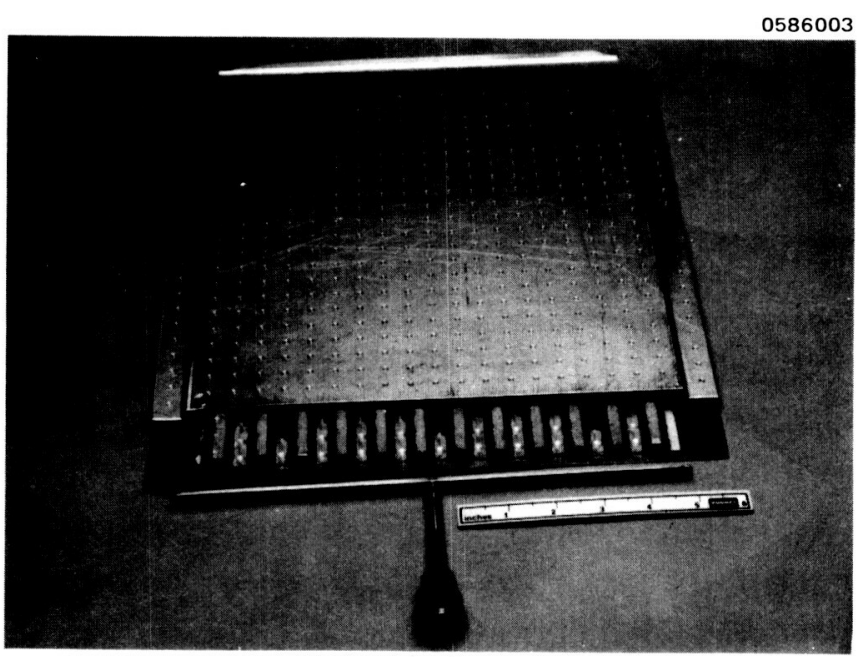

c) ALUMINUM CHANNEL CORE PANEL PIECE PARTS (NaJSC AND WPAFB)

Figure 23 Component hardware available for the hybrid radiator. 


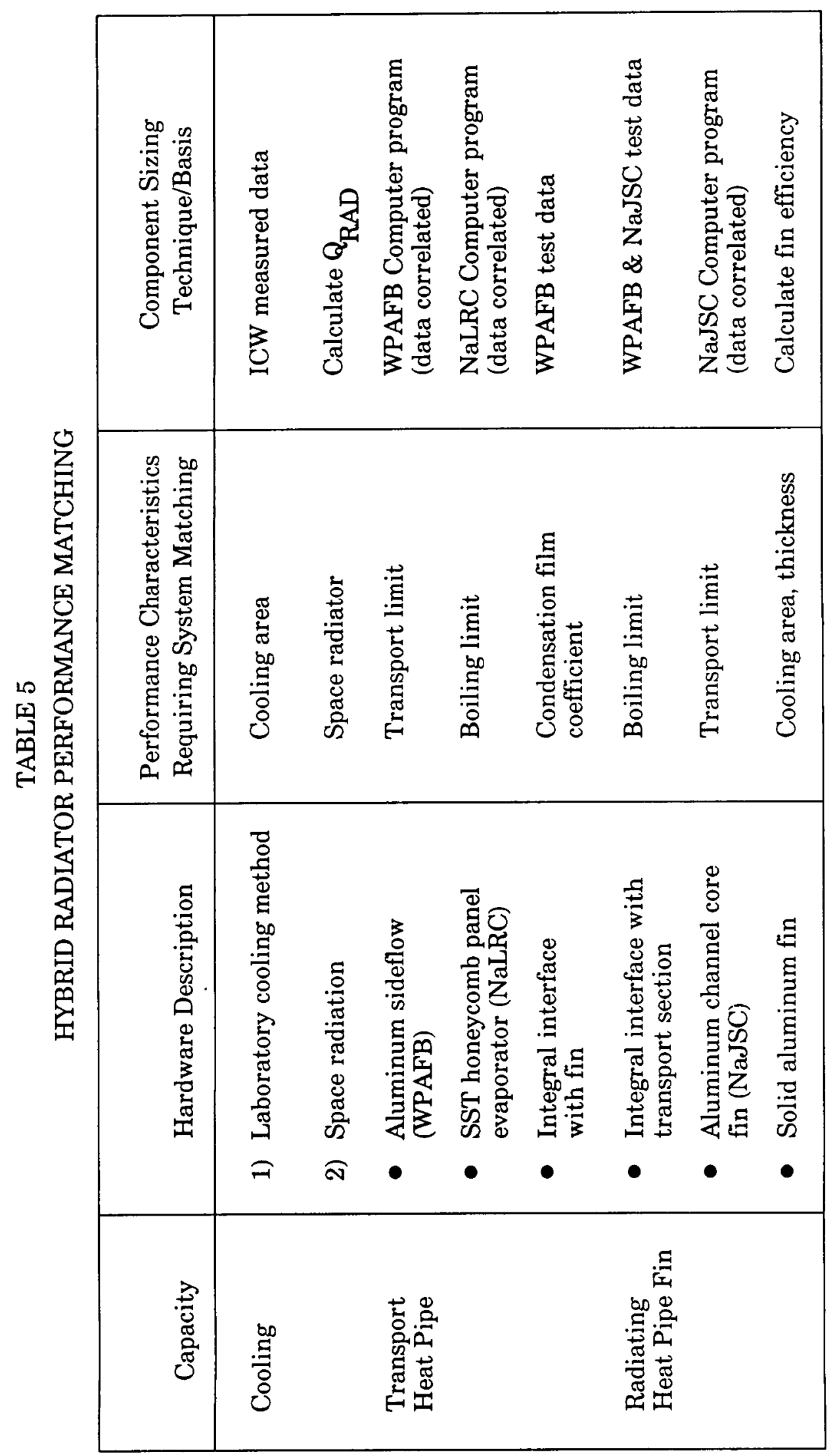




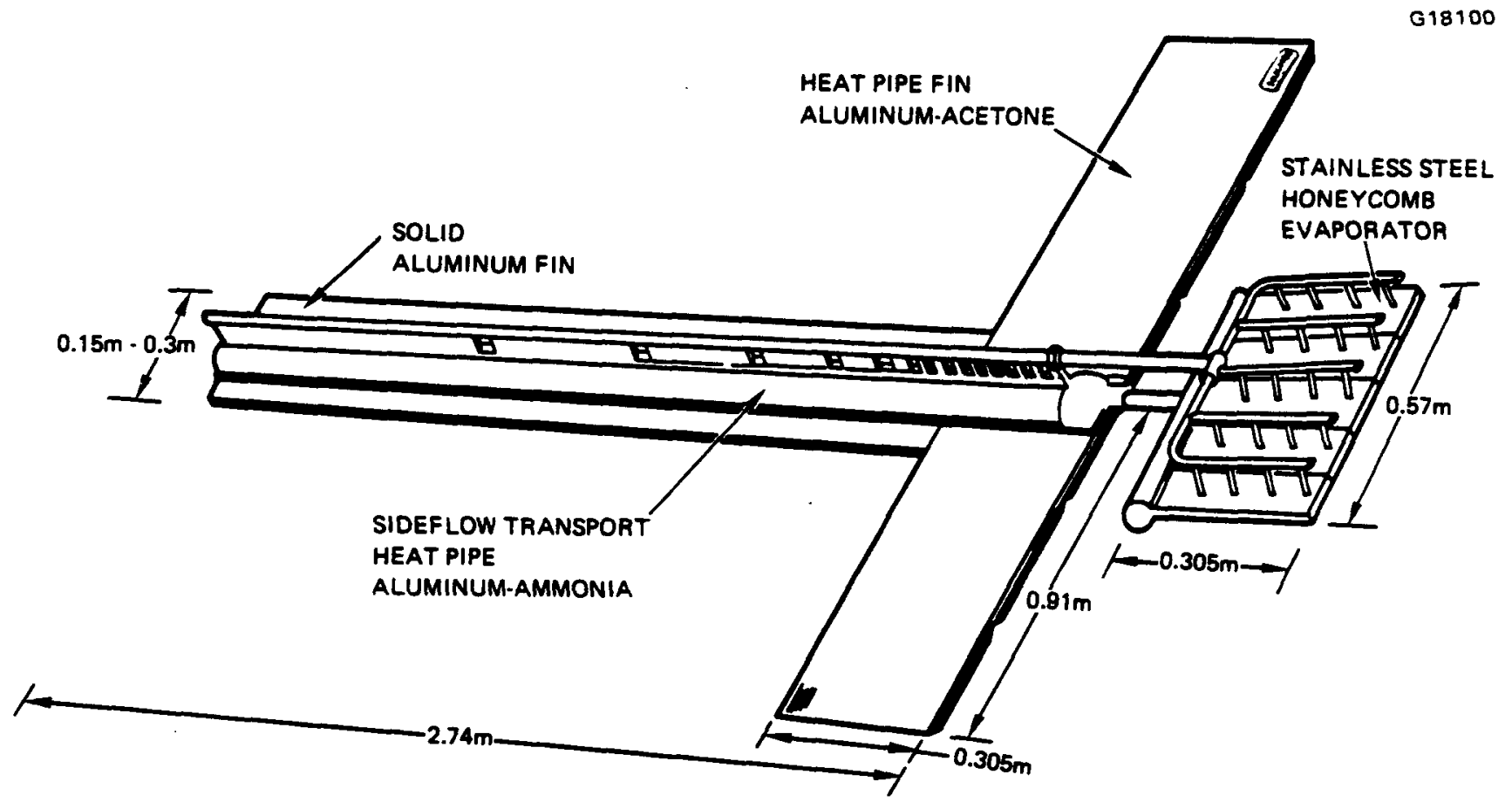

Figure 24 Hybrid radiator test vehicle.

in Figure 25 for a $3.05 \mathrm{~m}$ long panel and several widths. A range of laboratory cooling capacities for a $3.05 \mathrm{~m}$ long by $0.305 \mathrm{~m}$ wide panel, based on both water and air cooling heat transfer coefficients $(\mathrm{h})$ and assuming a constant sink temperature $\left(\mathrm{T}_{\text {sink }}\right)$ of $9^{\circ} \mathrm{C}$, is presented in Figure 26. The measured h value of $584 \mathrm{~W} / \mathrm{m}^{2}{ }^{\circ} \mathrm{K}$ is calculated from WPAFB sideflow heat pipe cooling data ${ }^{13}$ utilizing $9^{\circ} \mathrm{C}$ industrial chilled water (ICW) at full flow through aluminum blocks clamped via a thermal grease interface onto the condenser surface. Comparison of the cooling methods confirms that available laboratory cooling has substantially greater capacity than does radiation in space.

Transport Element Capacity - Utilizing the computer prediction model developed under WPAFB contract, ${ }^{10}$ the maximum transport capacity of the sideflow heat pipe based on capillary and entrainment limits can be calculated. This is shown in Figure 27 for both the correlated as-built version ( $9500 \mathrm{~W}$, maximum) and for a version having higher permeability felt metal wicks at the condenser ( $14500 \mathrm{~W}$, maximum). However, the current performance model does not reflect design changes to the hybrid because of the addition of a honeycomb expanded evaporator and the incorporation of grooves as the wicking medium at the condensation surface of the common wall between transport and fin elements. At this time, an estimate of hybrid transport capacity can be made by assuming it is equivalent to the as-built WPAFB sideflow. 

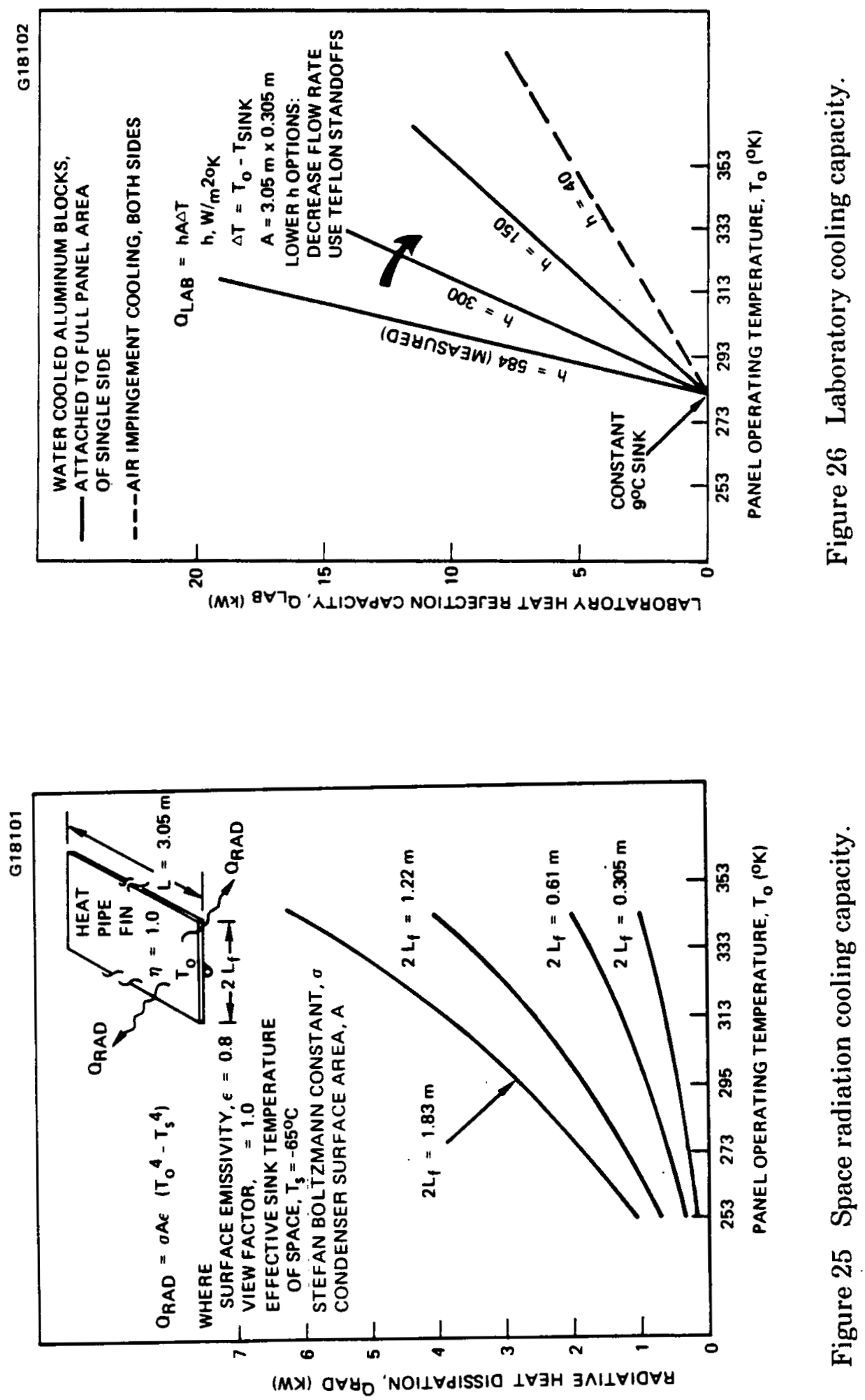

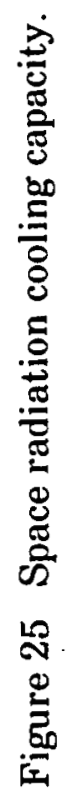




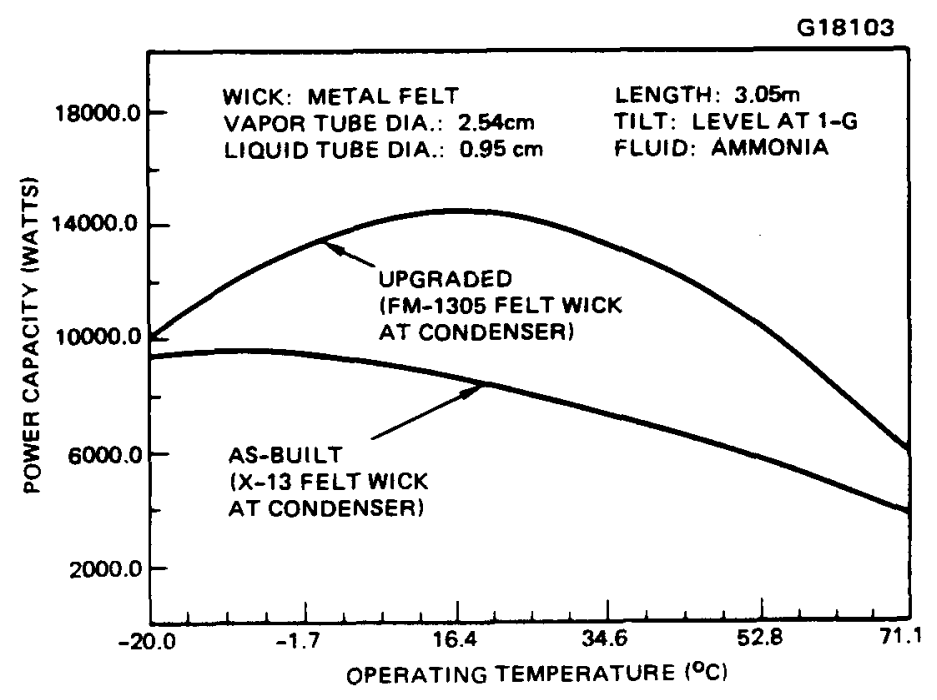

Figure 27 Sideflow heat pipe predicted performance.

An evaporator heat flux limit of $3.5 \mathrm{~W} / \mathrm{cm}^{2}$ for methanol on stainless steel was measured for the NASA LaRC subscale honeycomb sections having a liquid sideflow and vapor header configurations.3A (3B Based on this, a boiling heat flux limit of $5 \mathrm{~W} / \mathrm{cm}^{2}$ can be conservatively predicted for the higher-capacity ammonia working fluid when used with the hybrid. The available remnant honeycomb panel (measuring $2.44 \mathrm{~m}$ long by $0.11 \mathrm{~m}$ wide) can be configured into a segmented expanded evaporator that is connected by liquid sideflow and vapor channel headers (Figure 28). With an evaporator surface area of $1740 \mathrm{~cm}^{2}$, a single-sided heat input of about $9000 \mathrm{~W}$ can be achieved. It is not expected to limit transport capacity of the hybrid test vehicle.

By flattening and thus increasing the effective heat transfer area, and by grooving the condensation side of the hybrid common wall (see Figure 29), a substantial improvement in sideflow-to-fin element temperature drop is expected. Experimental condensation and evaporation film coefficients based on felt wick at the cylindrical condenser surface (WPAFB sideflow) and grooves at the flat evaporator surface (JSC and WPAFB lightweight heat pipe fin) have been calculated to be $5300 \mathrm{~W} / \mathrm{m}^{2}{ }^{\circ} \mathrm{K}$ and $28,000 \mathrm{~W} / \mathrm{m}^{2}{ }^{\circ} \mathrm{K}$, respectively. Utilizing these film coefficients, a temperature drop comparison (Figure 30) of two types of common wall constructions is made. A relatively small temperature drop penalty (about 10 percent) is expected when solder is used to join discrete sideflow and fin elements at the common wall. Grooved condensation surfaces will, in general, provide enhanced heat transfer relative to surfaces with screen or felt wick attached only by spring or contact pressure (not sintered to the surface), thus making the calculated condensation temperature drop conservative. 


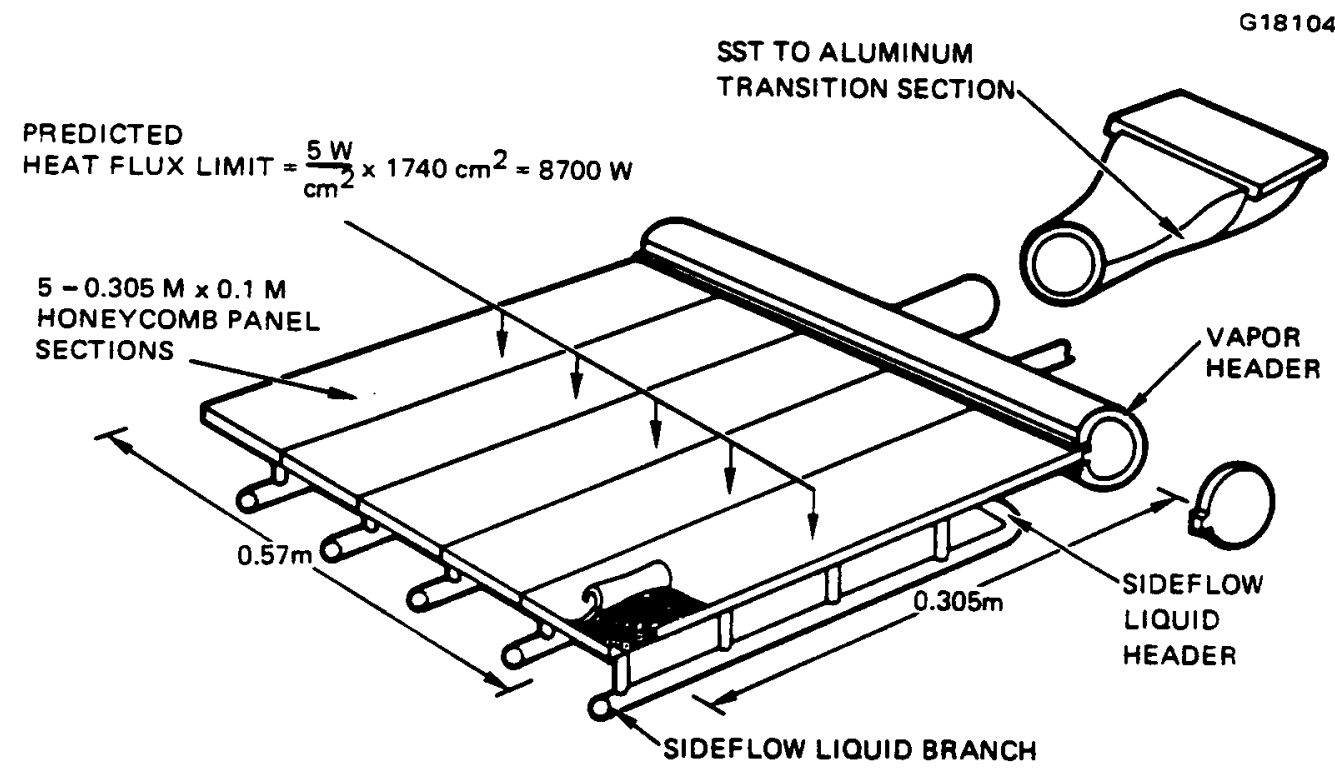

Figure 28 Hybrid radiator evaporator.

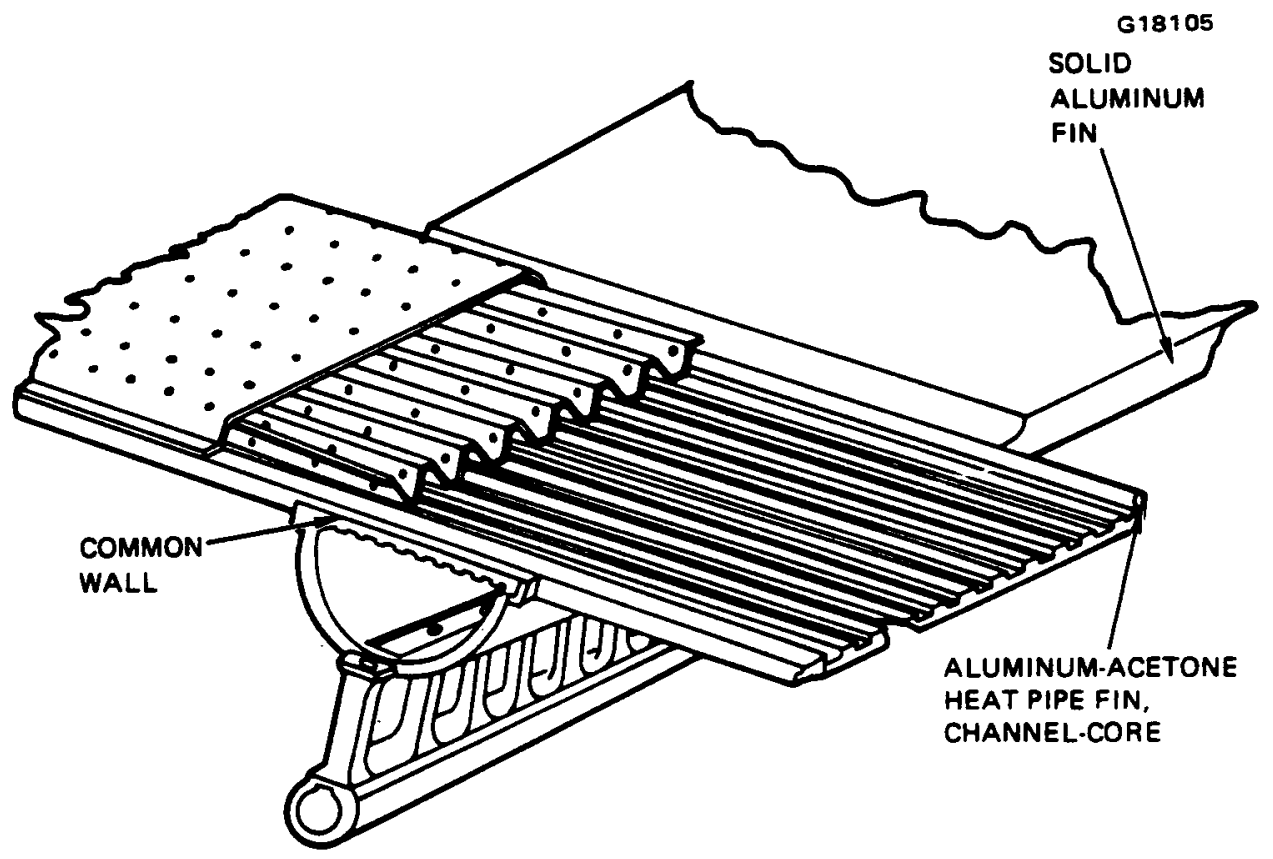

Figure 29 Hybrid radiator transport and fin sections. 
BASIS: $3.05 \mathrm{~m}$ LONG HYBRID RADIATOR

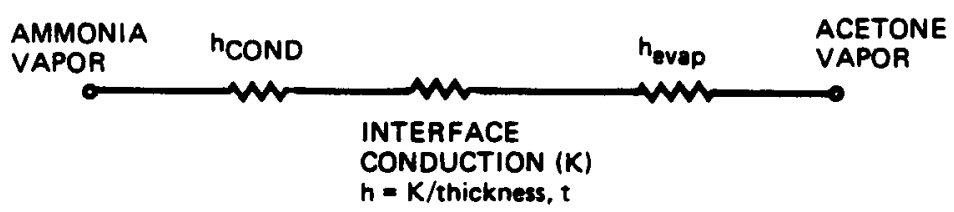

\begin{tabular}{|l|c|c|c|c|c|c|}
$\begin{array}{c}\text { COMMON } \\
\text { WALL } \\
\text { CONFIGURATIONS }\end{array}$ & $\begin{array}{c}\text { NH3 } \\
\text { CONDENSATION } \\
h=5300\end{array}$ & $\begin{array}{c}\text { ALUMINUM } \\
\text { CONDUCTION } \\
t=1.02 \mathrm{~mm} \\
h=233,000\end{array}$ & $\begin{array}{c}\text { SOLDER } \\
\text { CONTACT COND. } \\
t=0.076 \mathrm{~mm} \\
50 \% \text { VOIDS } \\
h=70,000\end{array}$ & $\begin{array}{c}\text { ALUMINUM } \\
\text { CONDUCTION } \\
t=0.76 \mathrm{~mm} \\
h=311,000\end{array}$ & $\begin{array}{c}\text { ACETONE } \\
\text { EVAPORATION } \\
h=28,000\end{array}$ & $\begin{array}{c}\text { TOTAL } \\
\text { TOTAL }\end{array}$ \\
\hline JOINED WALLS & 4.04 & 0.09 & 0.31 & 0.07 & 0.8 & 5.3 \\
\hline SINGLE WALL & 4.04 & 0.09 & - & -- & 0.8 & 4.9
\end{tabular}

Figure 30 Expected temperature drops $\left({ }^{\circ} \mathrm{C}\right)$ at sideflow to fin interface.

Fin Element Capacity - An objective of hybrid radiator development is to couple longer heat pipe fins to shorter transport heat pipe element lengths. For a given radiator system size, potential weight savings result from shorter and fewer transport heat pipes and fewer thermal bus heat exchangers. ${ }^{8,9}$ Increases in thermal transport capacities of both fin and transport heat pipe elements must, therefore, be demonstrated.

A typical building-block radiator system comprises redundant panel segments containing a transport element and a number of fin elements. For example, the $50-\mathrm{kW}$ radiator system for the current NASA space station design is comprised of twenty $2.5-\mathrm{kW}$ panel segments, each measuring $14.6 \mathrm{~m}$ long and $0.305 \mathrm{~m}$ wide. ${ }^{11} \mathrm{~A}$ heat pipe fin can be constructed in independent segments for reliability, and the width is selected to be $0.305 \mathrm{~m}$ for current sizing purposes. The center of each $0.305 \mathrm{~m}$ wide section of fin is delivered $50 \mathrm{~W}$ of power from the transport element. Thus, the heat pipe fin capacity must be sufficient to transport $25 \mathrm{~W}$ in each direction. Tradeoff curves in Figure 31 illustrate power levels delivered to each fin section for variable lengths and power levels of a radiator panel segment. It can be seen that more demanding future radiator requirements (such as shorter and higher capacity transport elements that require higher fin capacities) can be met with a nominal heat pipe fin capacity of $200 \mathrm{~W}$. This allows radiator lengths to decrease by one-half and require that radiator capacities double. Using the results of the aluminum channel core heat pipe fin developed for JSC and WPAFB, a transport limit prediction for the $0.305 \mathrm{~m}$ wide hybrid fin can be made as a function of fin length (Figure 32). As illustrated, a power level of $200 \mathrm{~W}$ is within 

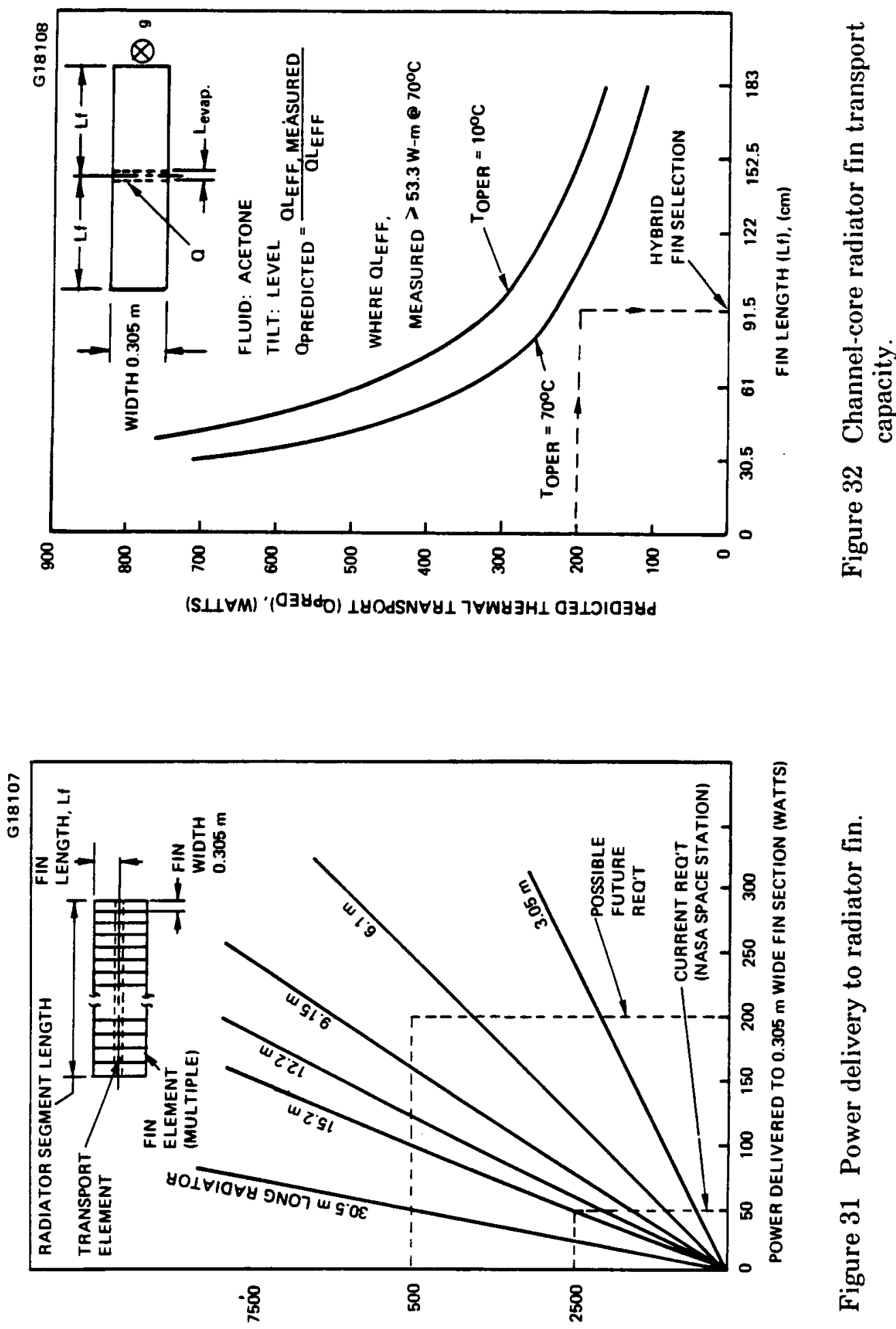

告

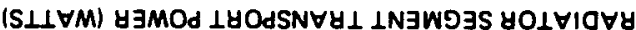


the capacity of a $91.5 \mathrm{~cm}$ long (on each side of the center-located transport element) channelcore radiator fin. Based on limited hardware remnants, two $0.305 \mathrm{~m}$ wide by $91.5 \mathrm{~cm}$ long heat pipe fins can be incorporated into the hybrid radiator test vehicle, with the remaining fin being constructed from solid aluminum.

Hybrid Radiator Capacity - Overall sizing curves for the $3.05 \mathrm{~m}$ long hybrid radiator test vehicle are shown in Figure 33. It is composed of individual component capacities as previously described. One operating point occurs at the intersection of the maximum laboratory cooling capacity and the ammonia transport heat pipe capacity; the other occurs at the intersection of a reduced capacity laboratory cooling (to match potential space radiation) and the acetone heat pipe fin transport capacity. Because of the subscaled length of the hybrid radiator, the transport capacities of the two heat pipe elements are not matched. This requires operation of the test vehicle at two distinct points to match maximum capacities of each element. For a full-scale radiator, longer transport lengths will reduce the amount of thermal power delivered by the transport heat pipe, additional fin elements will increase

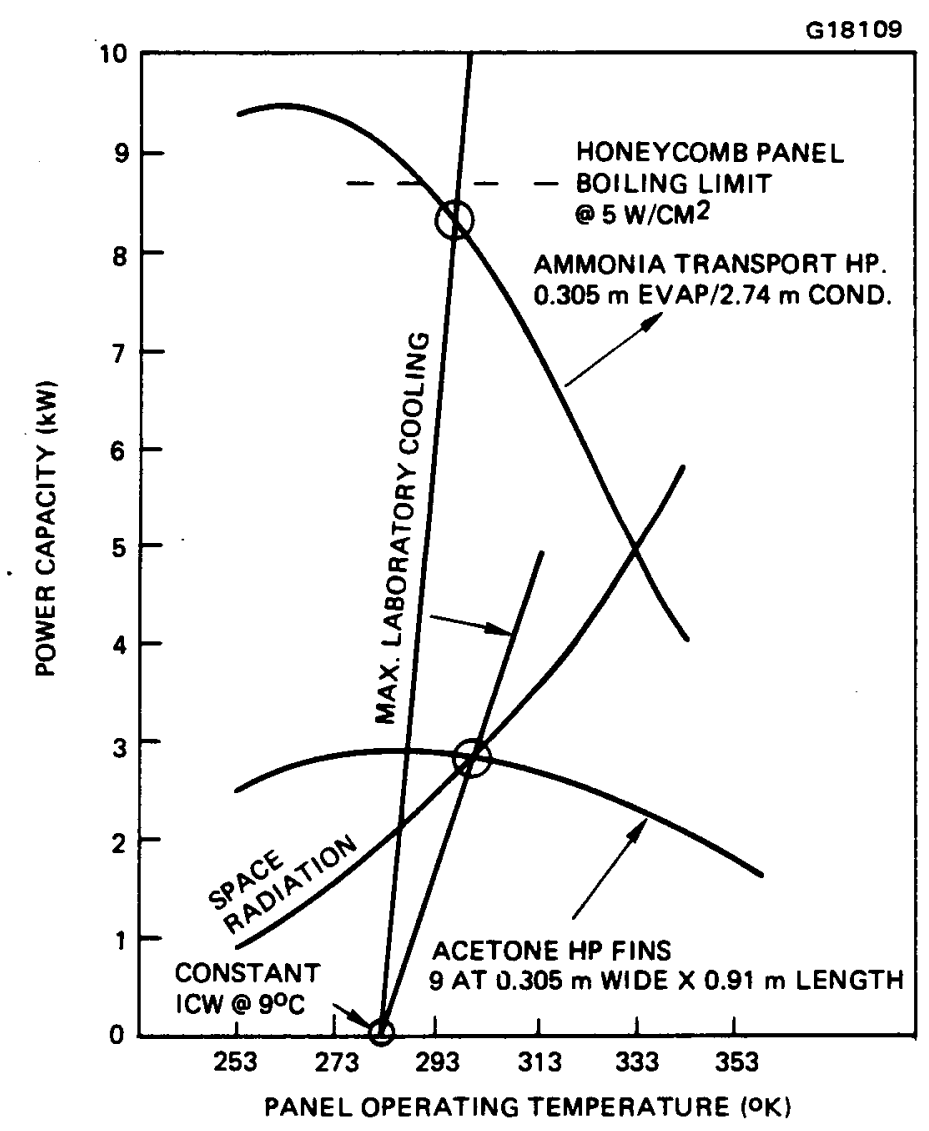

Figure 33 Sizing curves for $3.05 \mathrm{~m}$ hybrid radiator test vehicle. 
their combined capacities, and an overall matching into just one optimum operating point will occur.

\subsection{DESIGN MODIFICATIONS}

The design basis for the hybrid radiator has been outlined in the previous section. We reviewed it in light of compatibility and integration requirements of the JSC test bed facility, and of its fabricability in view of project scope. Design modifications of hybrid test vehicle resulted; they are described as follows:

Size limitations - Usable dimensions of the available thermal vacuum test station at JSC are 1.4-m diameter by $2.9-\mathrm{m}$ length. For hybrid test vehicle manufacture, we selected a 2.13-m transport length plus a $0.305-\mathrm{m}$ long evaporator section, for a total length of $2.44 \mathrm{~m}$.

Pressure Test Requirements - The original hybrid concept specified ammonia working fluid for the evaporator and transport sections to achieve high transport capacities. Ammonia exhibits high saturated vapor pressures (e.g., $427 \mathrm{psi}$ at $65^{\circ} \mathrm{C}$ ). The same honeycomb panel material has previously been burst pressure tested ${ }^{9}$ and failed at 250 psig internal pressure. Note, also, that the available remnant panel has seen considerable cutting and welding rework and thus has thermal stresses and warpage present. Our original plan, therefore, was to design a permanently attached support plate for the honeycomb panel evaporator, integral with cartridge heater elements (potentially, a structural redesign of the honeycomb panel core could eliminate the need for external support).

NASA-JSC requires formal pressure testing to demonstrate safety before the hybrid can be tested in their thermal-vacuum chambers. Pressure testing can be accomplished several ways:

1. Do analysis per ASME Boiler Code (design with $4 \mathrm{X}$ safety factor), and proof pressure test at $1.5 \mathrm{X}$ for hydrostatic or $1.25 \mathrm{X}$ for pneumatic (show no leaks).

2. Do a burst test: Pressure to $1 \mathrm{X}, 2 \mathrm{X}, 3 \mathrm{X}, 4 \mathrm{X}$ and check for deflection and leaks; then increase pressure in increments of 50 psi until the vehicle bursts.

Due to the complex nature of the hybrid (i.e., many varied welds), analysis is not feasible. We therefore considered building a representative subscale hybrid radiator and burst testing it. Upon further study, we concluded that in order to faithfully reproduce, in the subscale panel, all the structural members and the weld joints of the large panel, a significant quantity of duplicate pieceparts are required. Since a burst pressure test vehicle was not originally planned for, the extra hardware is not available. Additional parts machining and fabrication was not feasible in view of project scope. As a result, we selected to build only the 
full-size panel and to use acetone testing at Hughes only. Acetone has a much lower vapor pressure than does ammonia, but its transport capacity is poor. Table 6 compares the two working fluids. A benefit of using acetone is that it will not require an external evaporator support. Data correlation of hybrid performance using acetone will give some credibility to performance predictions using ammonia.

Common Wall Construction - Developing a method to construct a common wall type of interface between transport and radiating heat pipes involves considerable design engineering and proof-of-principle hardware, based upon welding/joining experimentation at coupon and subscale levels. Although the concept is potentially feasible, the scope of the current program is insufficient to accomplish this. Thus, a downsizing of the hybrid concept to just its transport and evaporator sections was made.

Radiating Fin Construction - Mechanically coupling flat panel heat pipes (or solid aluminum) fins to the round geometry of the available sideflows transport section imposes additional effort to design and fabricate transitional saddles with interstitial materials at the interface. This effort would not accomplish any new technology relative to the hybrid radiator concept. Therefore, we decided to proof-of-principle test the downsized hybrid without any attached fins.

TABLE 6

COMPARISON OF AMMONIA AND ACETONE AS HYBRID RADIATOR WORKING FLUIDS

\begin{tabular}{|l|c|c|c|c|}
\hline \multirow{2}{*}{ Fluid } & \multicolumn{2}{|c|}{ Compatibility* } & \multirow{2}{*}{$\begin{array}{c}\text { Liquid Transport } \\
\text { Factor @ } 65^{\circ} \mathrm{C} \\
\mathrm{W} / \mathrm{m}^{2}\end{array}$} \\
\cline { 3 - 4 } Ammonia & $\begin{array}{c}\text { Vapor Pressure } \\
@ 65^{\circ} \mathrm{C}, \mathrm{M} / \mathrm{m}\end{array}$ & $\mathrm{Sst}$ & Aluminum & $\begin{array}{c}0.2941 \times 10^{7} \\
(427 \mathrm{psi})\end{array}$ \\
Acetone & $\begin{array}{l}0.1350 \times 10^{6} \\
(19.6 \mathrm{psi})\end{array}$ & $\mathrm{C}$ & $\mathrm{C}$ & $0.2854 \times 10^{11}$ \\
\hline
\end{tabular}

*Note: Working fluid within hybrid radiator design must be compatible with both stainless steel and aluminum 


\subsection{HYBRID FABRICATION AND COMPONENT TEST}

Piece parts for hybrid radiator construction are of three types: existing, rework existing, and new. Existing piece parts consisted of the aluminum sideflow transport assembly. The large VCHP honeycomb test panel with sideflow (see Figure 18) was reworked by cutting it into strips for hybrid evaporator assembly. Both the transport sideflow and the evaporator honeycomb components have previously been tested. New piece parts consist of various stainless steel flow tubes and a machined vapor and liquid flow header coupler for the transition between transport and evaporator sections. All aluminum joints were electron beam (EB) welded; all stainless steel joints were tungsten inert gas (TIG) welded, and aluminum to stainless steel transition joints were inertia welded. Thermal plugs within the sideflow crossover tubes (504 plugs at the 2.13-m long transport section, and 155 at the $0.305-\mathrm{m}$ long evaporator section) were made by rolling layers of stainless steel screen as shown by Figure 34.

Photographs showing design and fabrication details, and dimensions, are attached in Figures 35 through 40 . Due to extensive reworking of available remnant panel hardware, and as a result of using heat generating TIG welding to join honeycomb plus sideflow branch sections into the evaporator panel, some panel warpage resulted. A maximum panel height of $1.27 \pm 0.25 \mathrm{~cm}$ was measured due to this warpage. This doubles the height of internal gravity head as compared to perfectly flat honeycomb panel. A nominal (first-cut) fluid fill was determined using representative wick pieces, saturating them with acetone, and calculating the required total charge mass.

PRECEDING PAGE BLANK NOT FILMED 

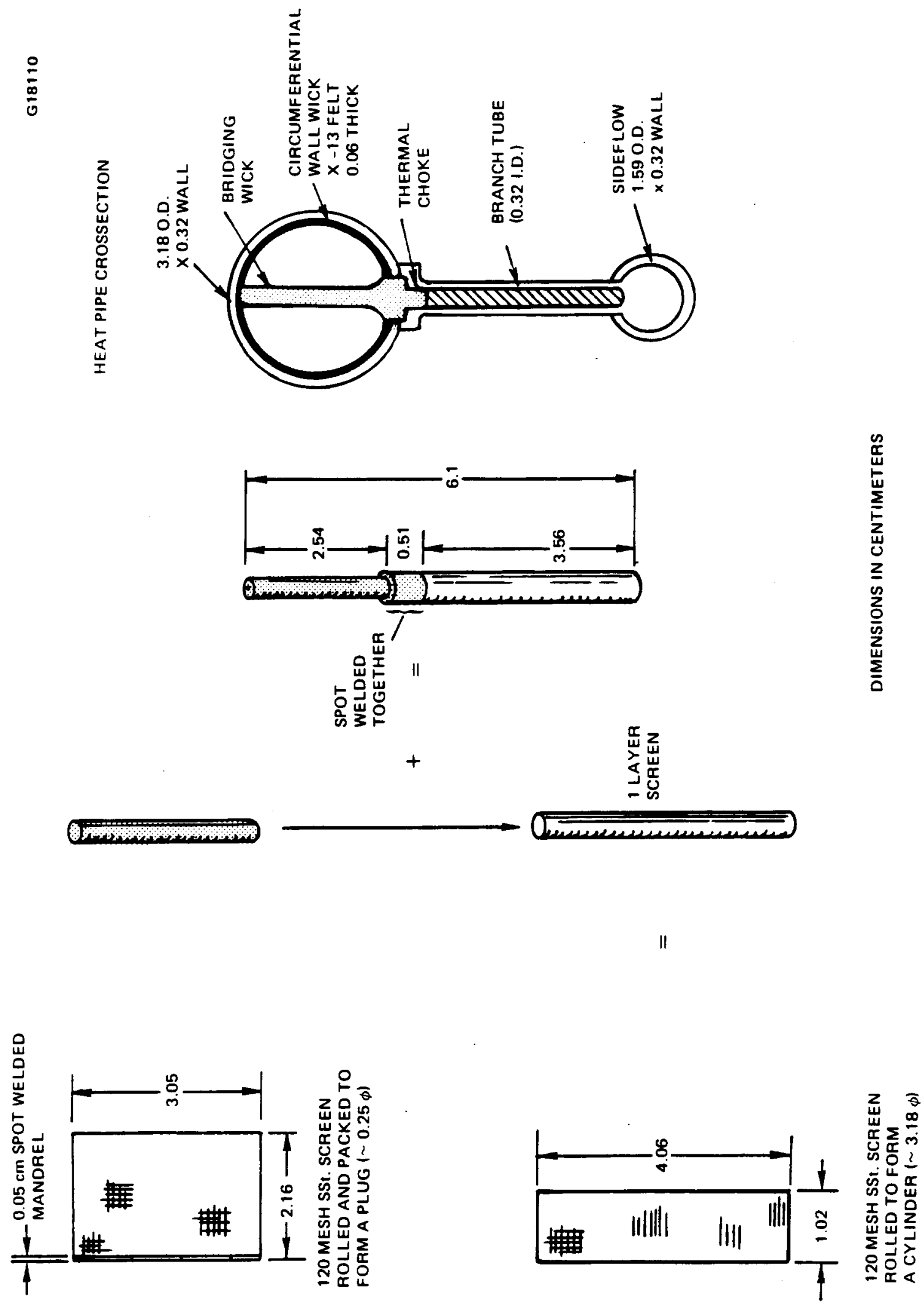
ORIGINAL PAGE IS

OF POOR QUALITY

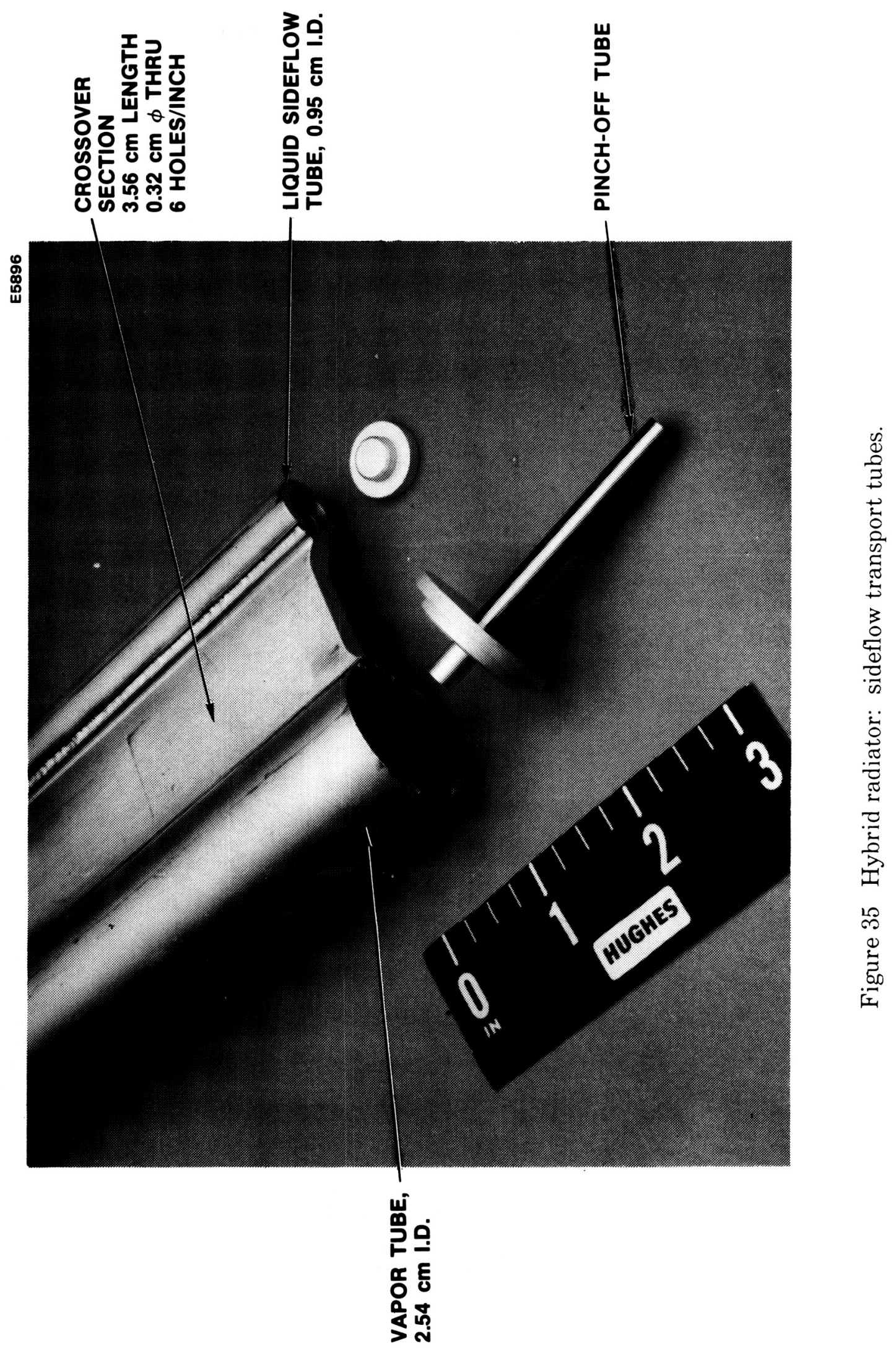




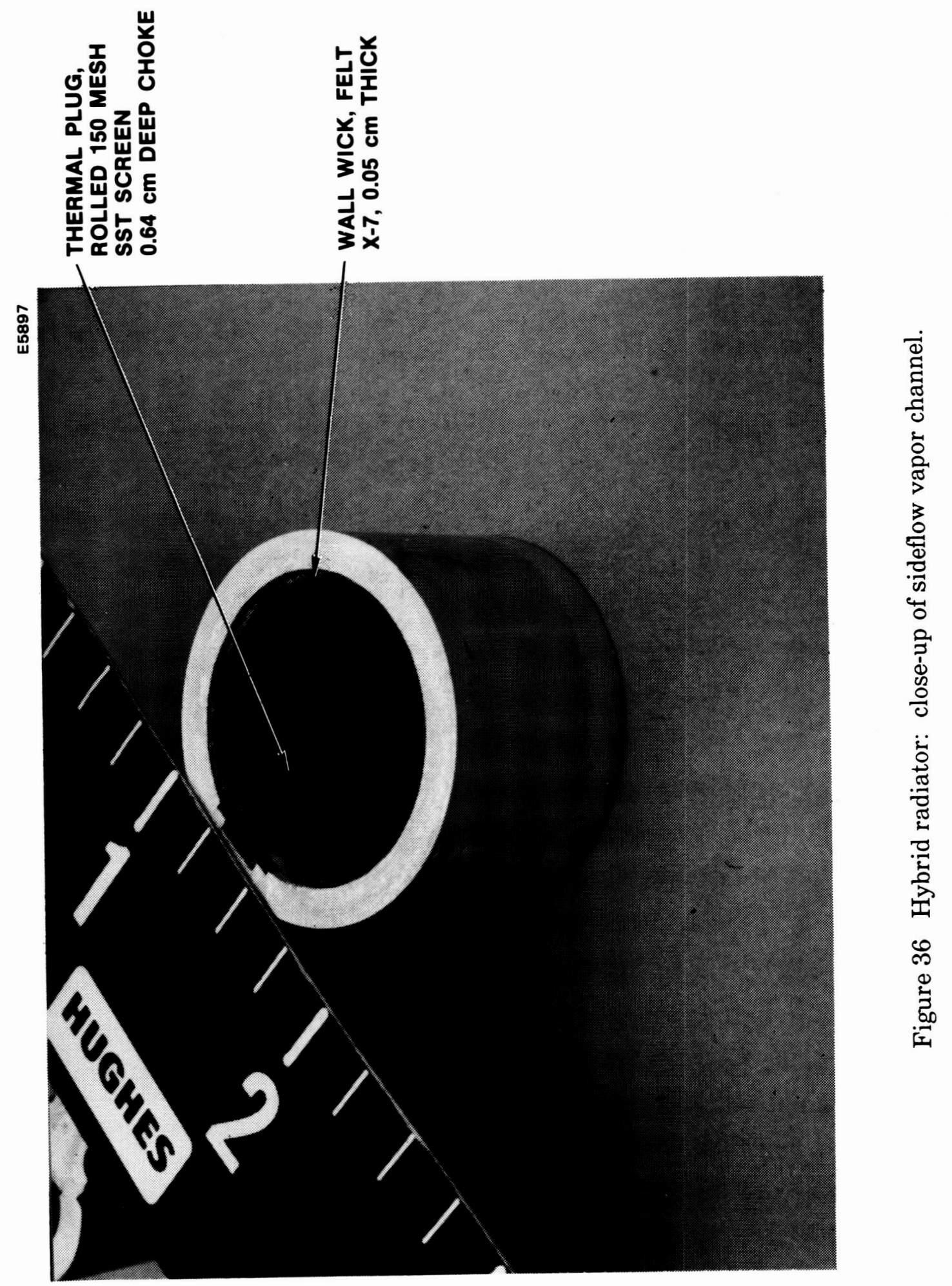


ORIGINAL PAGE IS

OF POOR QUALITY

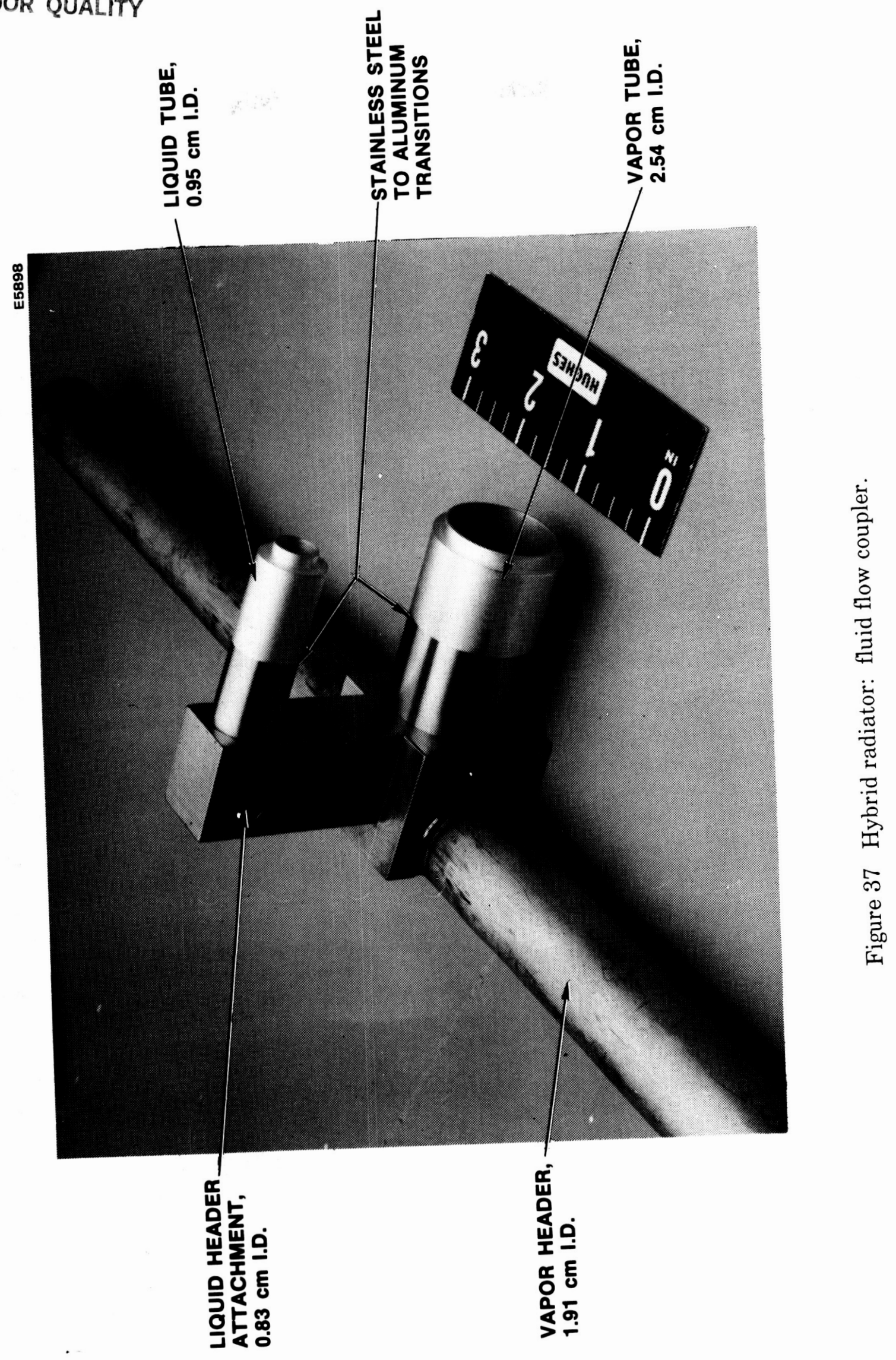




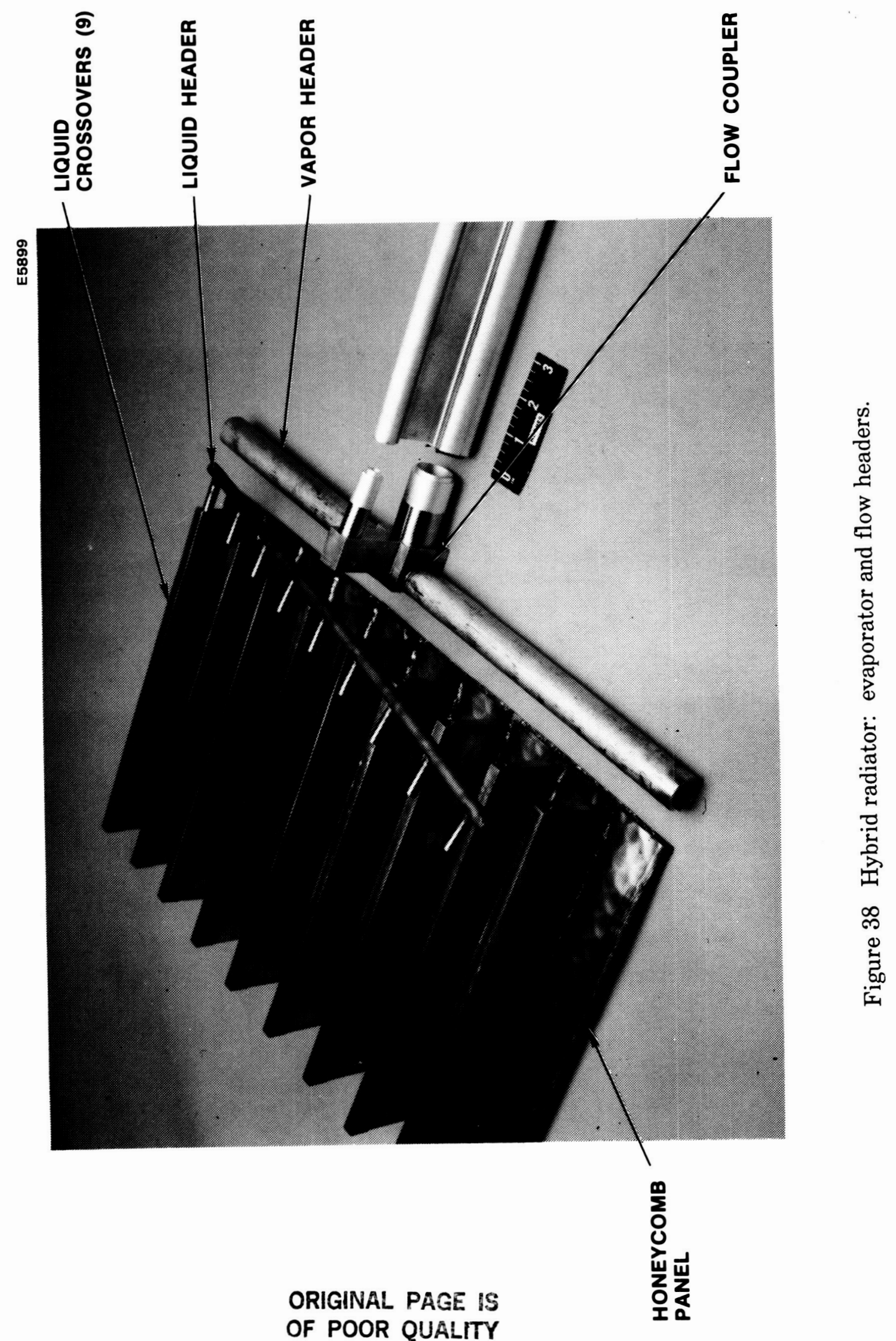




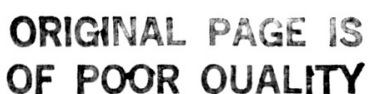

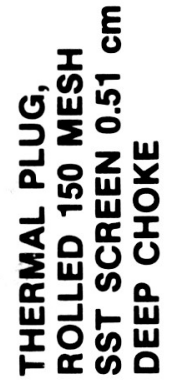

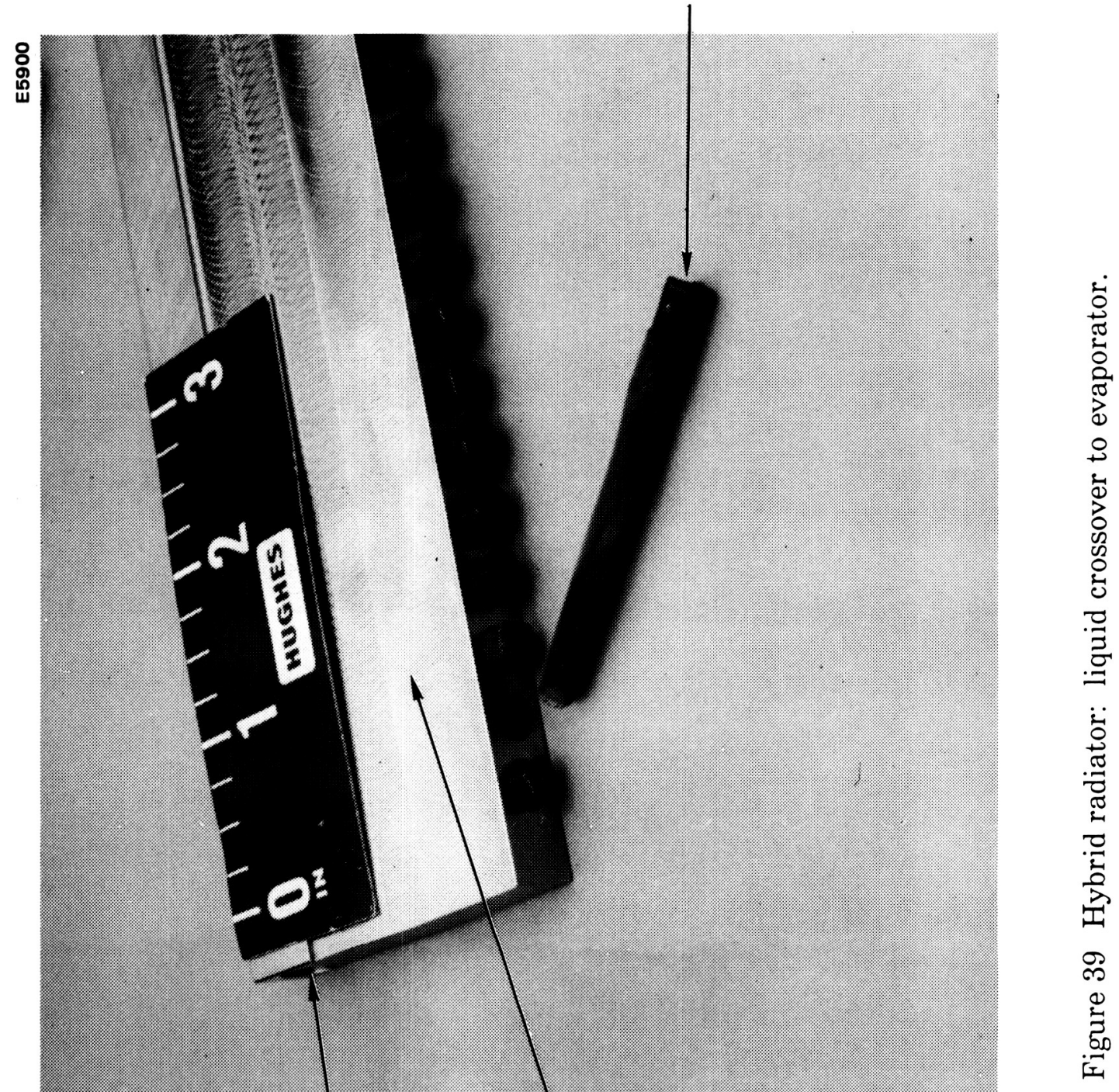




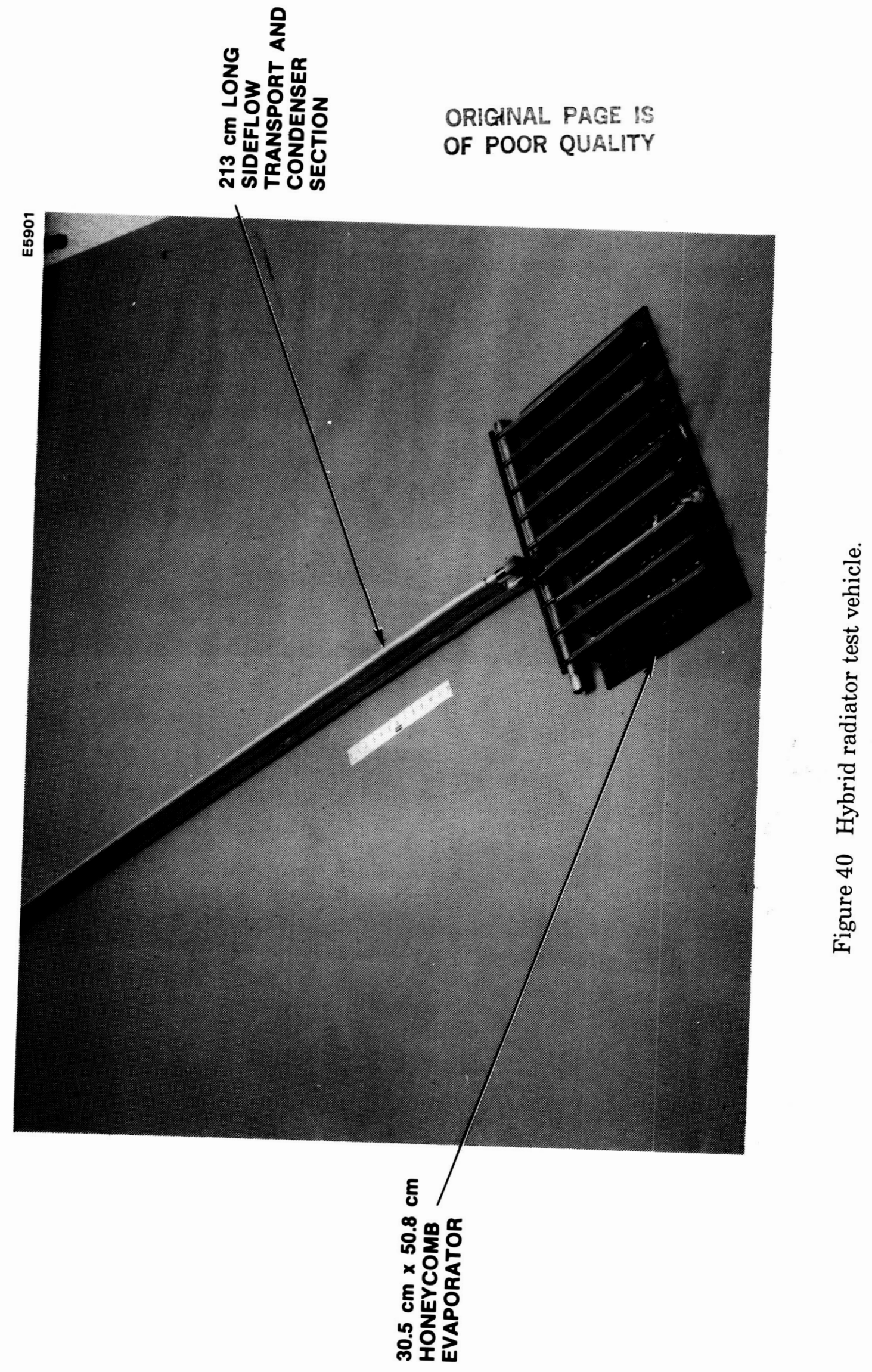




\subsection{HYBRID SYSTEM TEST}

The 2.44-m long hybrid radiator experimental panel was functional tested in the development laboratory of the Hughes Thermal Devices Department. The objective of the test was to establish proof-of-principle performance of the panel design which will provide baseline data for any continuing work.

\subsection{TEST DESCRIPTION AND RESULTS}

A functional test was done on the laboratory bench in an ambient air environment. At the 0.305-m long honeycomb panel evaporator, resistance heaters were taped to the top side (opposite the sideflow crossovers) and then well insulated. A 0.305-m long machined aluminum coolant plate was attached to the far end of the aluminum sideflow tubes. Methanol coolant was pumped through a temperature-controlled heat exchanger to the condenser plates. Thirty Type $\mathrm{K}$ thermocouples were welded onto the test vehicle, including the "dryout" thermocouple located at the highest point on the warped panel (T/C No. 26). The instrumented hybrid test vehicle is shown in Figure 41. A tilt of $0.635-\mathrm{m}$ with evaporator up, was necessary in order to limit transport capacity of the test vehicle because of burn-out limitations of the tape-on heaters (approximately $1250 \mathrm{~W}$ rating). A strip-chart recording of temperature profiles near the dry-out point at maximum power of the test vehicle is shown in Figure 42. Following a power-held condition of $900 \mathrm{~W}$, a partial dry-out due to elevated temperature of T/C No. 26 was observed at $1000 \mathrm{~W}$ of input power. Excessive temperature depression is visible at the condenser end of the test vehicle (T/Cs 1, 7, 10,11,2); it is the result of liquid slugging due to excess fluid and possibly some noncondensible gas. Further fluid fill optimization work using the process controller ("super burper") developed earlier under this program is necessary to establish the correct fill as a function of operating conditions (including tilt, condenser length, and power level).

\subsection{DATA CORRELATION}

The general approach for data correlation of the hybrid test vehicle consists of utilizing existing prediction codes, inputting as-built parameters, perform approximations to couple the codes, and then comparing results with single test point data.

Computer prediction codes (IBM PC-based) exist for the high capacity honeycomb panel heat pipe (HPRAD) and for the round sideflow heat pipe (SFHP). HPRAD has been developed and data correlated during the course of this project and fully documented. SFHP was developed and data correlated during our recent WPAFB work. ${ }^{10}$ Although true coupling of these two codes into one hybrid code is needed, it would require additional funding. Therefore, the current prediction model consists of "bracketing" true hybrid performance by making 


\section{ORIGINAL PAGE IS \\ OF POOR QUALITY}

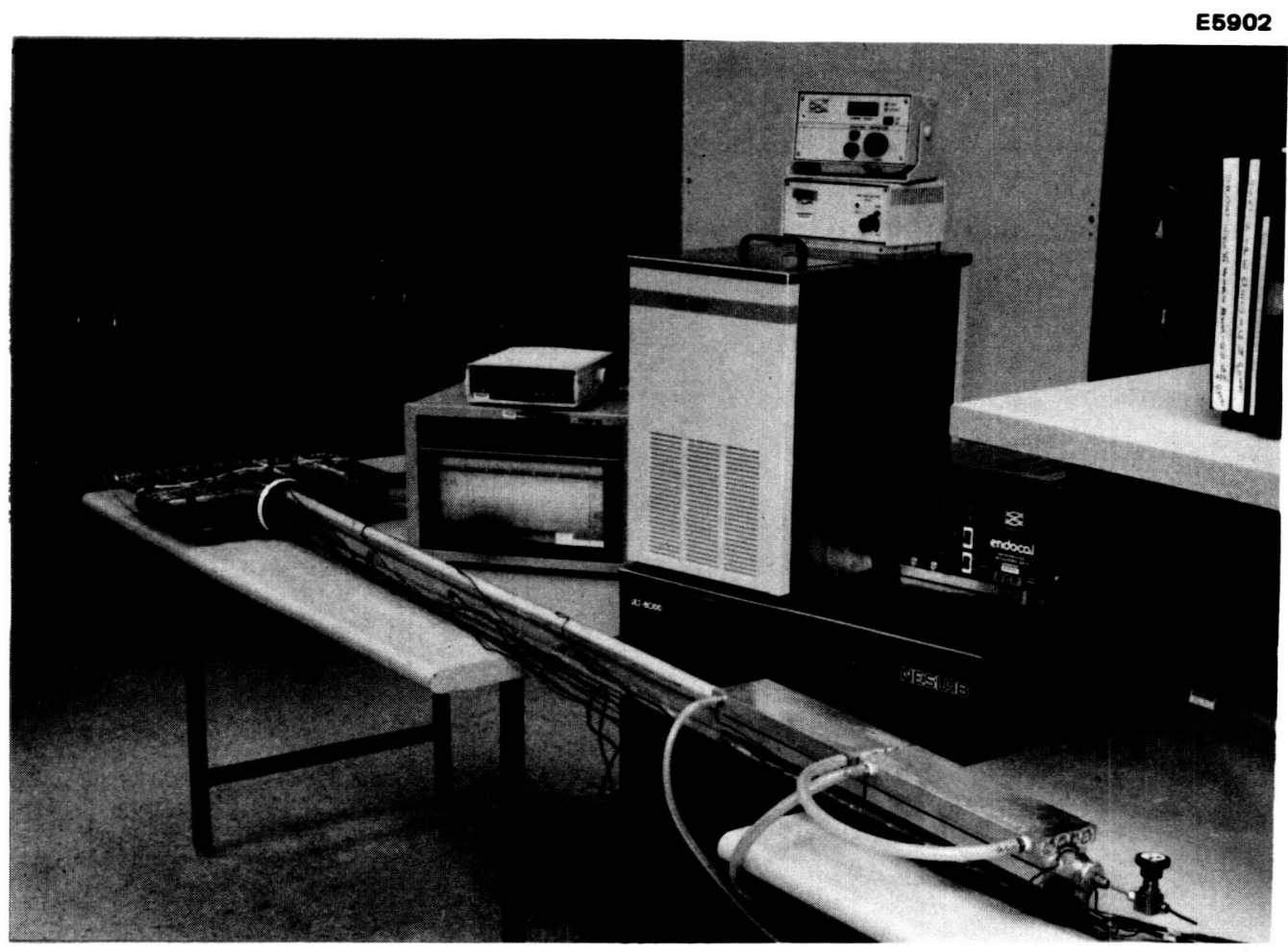

Figure 41 Hybrid test vehicle (244 cm long). 

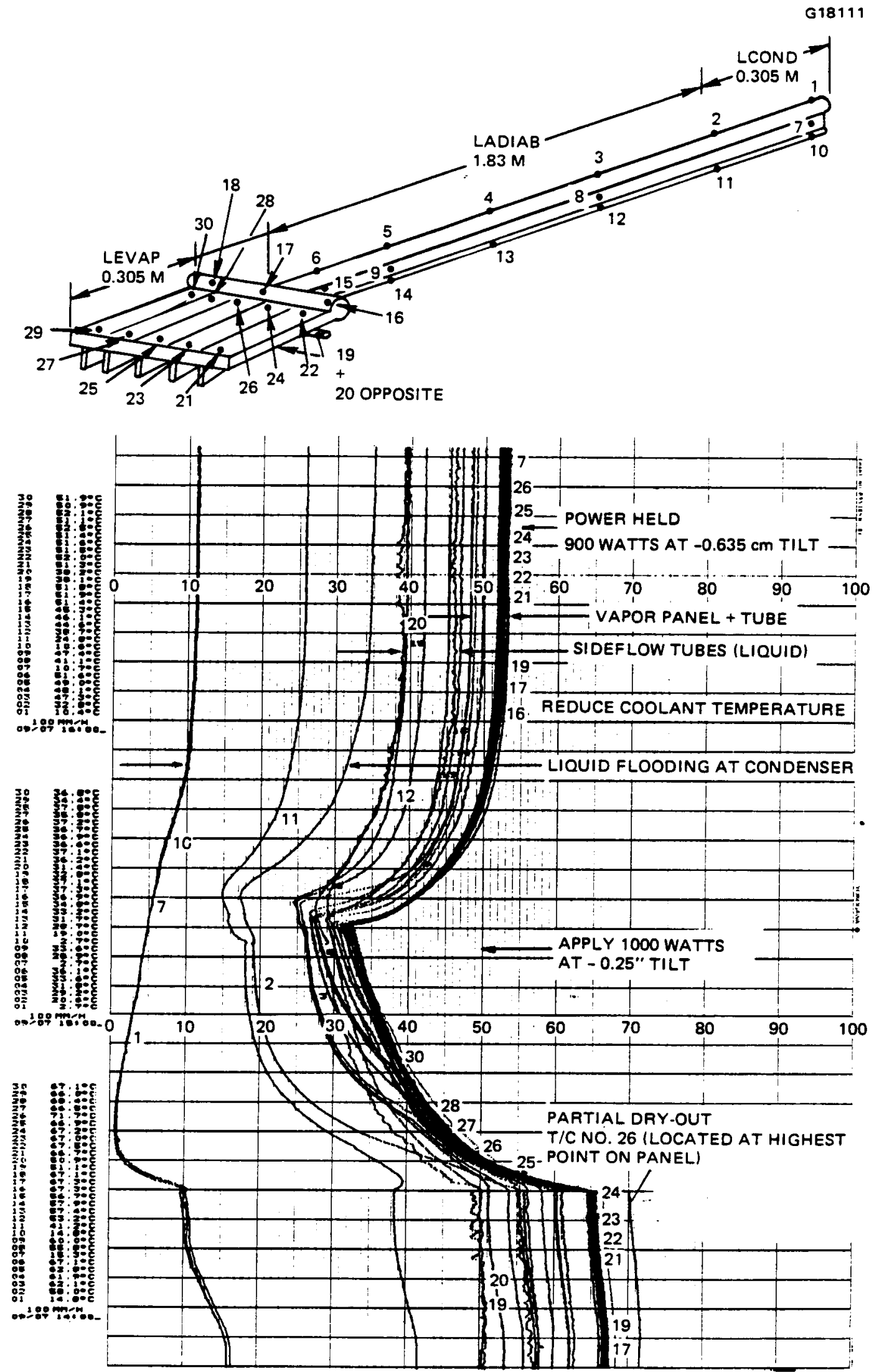

Figure 42 Functional test temperature profile of hybrid test vehicle. 
assumptions and running each prediction code independently of the other. The full 2.44-m length of hybrid radiator was assumed to be either honeycomb panel or round sideflow geometry, and transport power capacities were calculated. The honeycomb panel code can accept only one sideflow branch per panel section, thus since the test vehicle had nine of these sections, a multiplication factor of nine was used. For either code, fluid properties for acetone have not been incorporated. Thus, an approximation method used the ratio of transport factor liquid properties as a multiplication factor (M.F.) applied to prediction results for ammonia fluid. These are determined as follows:

$$
\text { Liquid transport factor }\left(\mathrm{N}_{\ell}\right)=\frac{\lambda \sigma \rho \ell}{\mu_{\ell}}
$$

where

$$
\begin{aligned}
\lambda & =\text { heat of vaporization } \\
\sigma & =\text { surface tension } \\
\rho_{\ell} & =\text { liquid density } \\
\mu_{\ell} & =\text { liquid dynamic viscosity }
\end{aligned}
$$

A spreadsheet summary of the hybrid radiator prediction method is shown in Table 7. Prediction and test data results are shown in Figure 43. Relatively good correlation exists, even considering the approximate predicted method that was used.. 


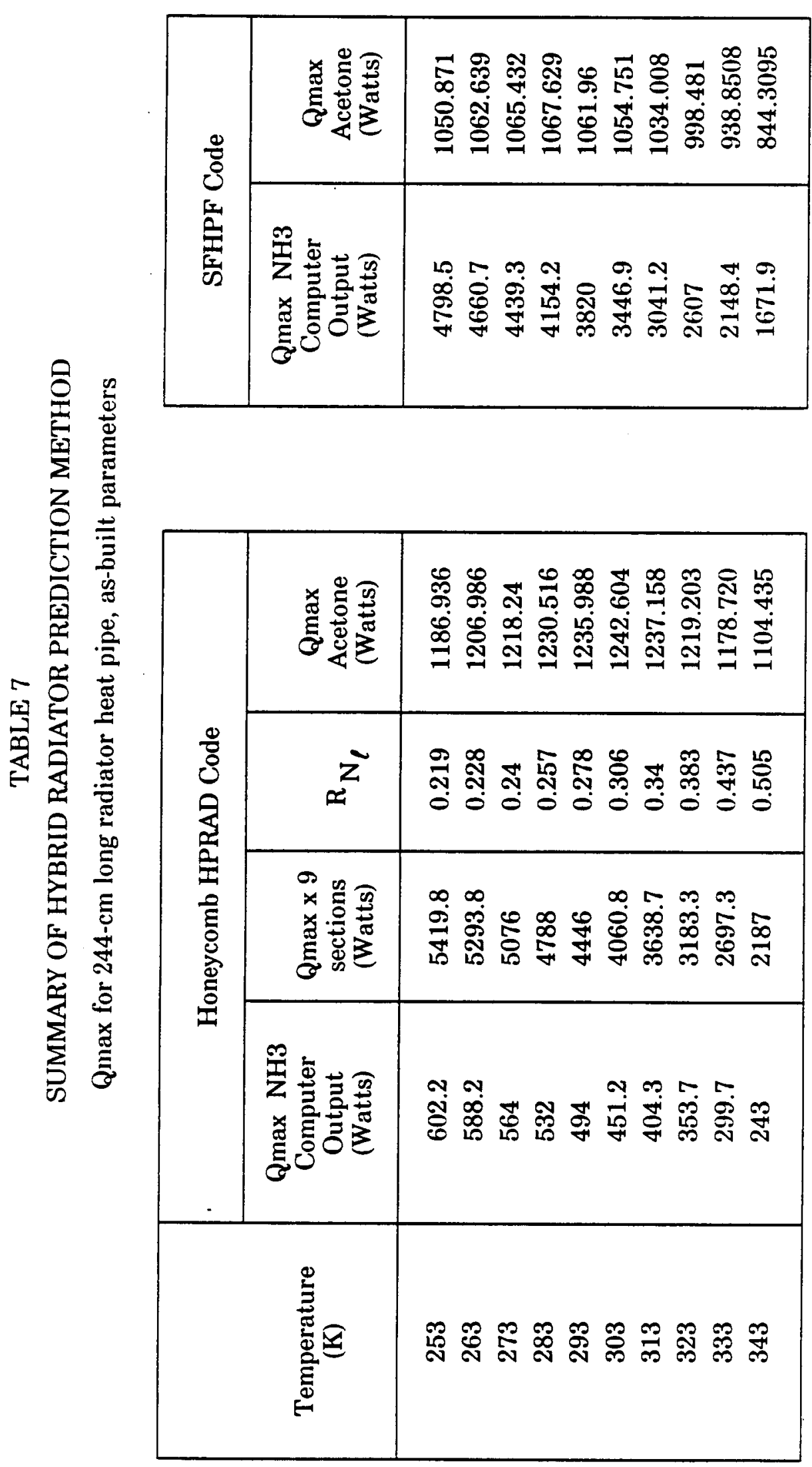




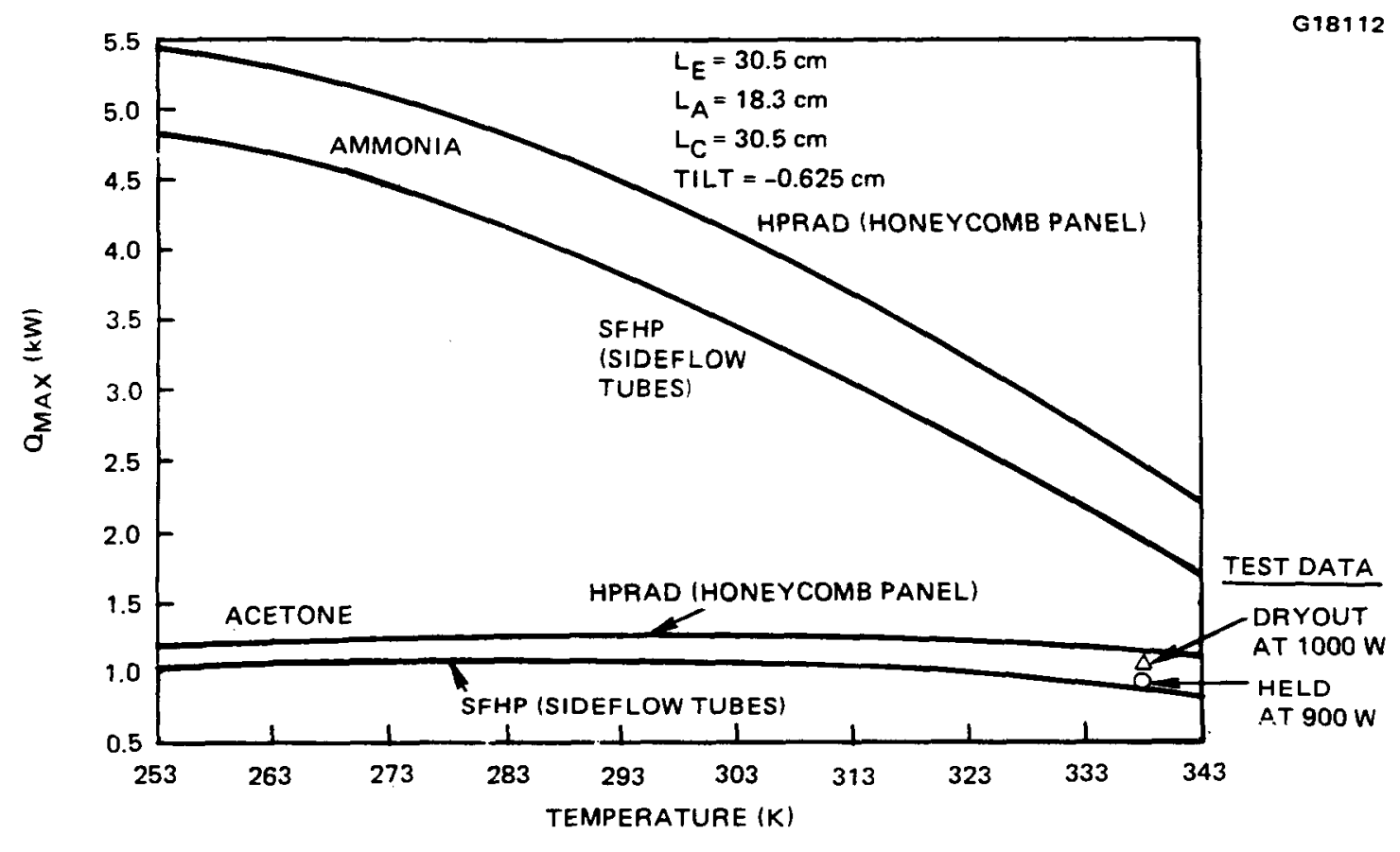

Figure 43 Data correlation: transport capacity computer code coupling. 


\subsection{CONCLUSIONS AND RECOMMENDATIONS}

High thermal capacity and temperature control gas designs of honeycomb heat pipe space radiator panels have been built, ground-tested, and data correlated. The hardware test program involving subscale and prototype radiator panels has resulted in considerable insight into high-performance heat rejection designs. Optimization led to advanced design called the hybrid heat rejection system, which was proof-of-principle tested to a limited extent. The results demonstrate that the thermal performance of honeycomb panel heatpipe radiators, and advanced space radiators in general, can be improved considerably.

Areas of development which require further work before hybrid designs can be finalized are as follows:

\section{Continue Hybrid Radiator Development}

- Perform coupon experiments and develop methods for common wall joining and fabrication.

- Build additional hybrid tests vehicles to test and data correlate (start with new pieceparts and components).

- Ground-test within large thermal-vacuum chambers.

\section{Upgrade Analysis Model}

- Develop a fully integrated prediction model for the hybrid radiator which is scaleable to larger sizes.

- Expand the model to include structural and weight variables, and optimum core configurations.

\section{Continue Hybrid Design Optimization}

- Investigate other materials of construction: aluminum, titanium, composites.

- Redesign the honeycomb panel core to optimize structure, weight, and strength. 


\subsection{REFERENCES}

1. Basiulis, A., and Camarda, C. J., "Design, Fabrication, and Test of Liquid Metal Heat-Pipe Sandwich Panels,” AIAA Paper No. 82-0903, June 1982.

2. Camarda, C.J., and Basiulis, A., "Radiant Heating Tests of Several Liquid Metal Heat-Pipe Sandwich Panels," AIAA Paper No. 83-0319, January 1983.

3. Tanzer, H.J., "Fabrication and Development of Several Heat Pipe Honeycomb Sandwich Panel Concepts,” NASA CR-165962, June 1982.

4. Tanzer, H.J., "High Capacity Honeycomb Panel Heat Pipes for Space Radiators," AIAA Paper No. 83-1430, June 1983.

5. Tanzer, H.J., Fleischman, G.L., and Rankin, J.G., "Honeycomb Panel Heat Pipe Development for Space Radiators," AIAA Paper No. 85-0978, June 1985.

6. Fleischman, G.L., and Tanzer, H.J., "Advanced Radiator Concepts Utilizing Honeycomb Panel Heat Pipes (Stainless Steel)," NASA CR-171977, August 1985.

7. . Peck, S.J., and Fleischman, G.L., "Lightweight Heat Pipe Panels for Space Radiators," Sixth International Heat Pipe Conference, Grenoble, France, May 1987.

8. Fleischman, G.L., Peck, S.J., and Tanzer, H.J., "Advanced Radiator Concepts Utilizing Honeycomb Panel Heat Pipes," Final Technical Report, NASA Contract NAS9-16581, October 1987.

9. Scott, G. W. , and Tanzer, H. J., "Evaluation of Heat Pipes for Conduction Cooled Level II Avionic Packages," Heat Transfer in Electronic Equipment 1986, Vol. 57.

10. Fleischman, G.L., High Power Spacecraft Thermal Management," AFWALTR-87-2057, October 1987.

11. Rankin, J.G., "Space Station Thermal Management System Development Status and Plans," SAE Paper 851350, July 1985. 


\begin{tabular}{|c|c|c|}
\hline \multicolumn{3}{|c|}{ Report Documentation Page } \\
\hline $\begin{array}{l}\text { 1. Report No. } \\
\text { NASA CR-181776 }\end{array}$ & 2. Government Accession No. & 3. Recipient's Catalog No. \\
\hline \multirow{2}{*}{\multicolumn{2}{|c|}{$\begin{array}{l}\text { High Capacity Demonstration of } \\
\text { Honeycomb Panel Heat Pipes }\end{array}$}} & $\begin{array}{l}\text { 5. Report Date } \\
\text { February } 1989\end{array}$ \\
\hline & & 6. Performing Organization Code \\
\hline \multirow{2}{*}{\multicolumn{2}{|c|}{$\begin{array}{l}\text { 7. Author(s) } \\
\text { H. J. Tanzer }\end{array}$}} & 8. Performing Organization Repon No. \\
\hline & & 10. Work Unit No. \\
\hline \multicolumn{3}{|c|}{ 9. Performing Organization Name and Address } \\
\hline \multirow{2}{*}{\multicolumn{2}{|c|}{$\begin{array}{l}\text { Hughes Aircraft Company } \\
\text { Electron Dynamics Division } \\
\text { P.O. Box } 2999 \\
\text { Torrance, CA } 90509-2999\end{array}$}} & $\begin{array}{l}\text { 11. Contract or Grant No. } \\
\text { NAS1-17674 }\end{array}$ \\
\hline & & 13. Type of Report and Period Covered \\
\hline \multirow{2}{*}{\multicolumn{2}{|c|}{$\begin{array}{l}\text { 12. Sponsoring Agency Neme and Address } \\
\text { ivational Aeronautics and Space Administration } \\
\text { Langley Research Center } \\
\text { Hampton, VA } 23655-5225\end{array}$}} & $\begin{array}{l}\text { Contractor Report } \\
\text { March 1984-October } 1988\end{array}$ \\
\hline & & 14. Sponsoring Agency Code \\
\hline
\end{tabular}

\section{Supplementary Notes}

Langley Technical Monitor: Jack B. Hall, Jr.

Final Report

\section{Abstract}

The feasibility of performance enhancing the sandwich panel heat pipe was investigated for moderate temperature range heat rejection radiators on future high-power spacecraft. The hardware development program consisted of performance prediction modeling, fabrication, ground test, and data correlation. Using available sandwich panel materials, a series of subscale test panels were augmented with high-capacity sideflow and temperature control variable conductance features, and test evaluated for correlation with performance prediction codes. Using the correlated prediction model, a 50-kW full size radiator was defined using methanol working fluid and closely spaced sideflows. A new concept called the hybrid radiator individually optimizes heat pipe components. A $2.44-\mathrm{m}$ long hybrid test vehicle demonstrated proof-ofprinciple performance.

17. Key Words (Suggested by Authoris))

Heat pipes, honeycomb panel, space radiators, heat rejection system
18. Distribution Statement

Unclassified - Unlimited
19. Security Classif. (of this report)

Unclassified
20. Security Classif. (of this page)

Unclassified

21. No. of pages
77

22. Price A05 